\title{
PERCEPTION OF TOOLS FOR ASSESSING ON-FARM NUTRIENT LOSSES AND MITIGATION OPTIONS
}

\author{
Maggie Rogers
}

A thesis submitted to Victoria University of Wellington in partial fulfilment of requirements for the degree of

Master of Science

In

Physical Geography

School of Geography, Environment and Earth Sciences

Victoria University of Wellington

2018 


\begin{abstract}
This research focuses on the prominent issue of degraded water quality in New Zealand caused by the intensification of agricultural land use, resulting in increased levels of diffuse pollutants such as sediment, nitrogen and phosphorus in waterways (Duncan, 2017). Degraded water quality is a critical issue that needs to be addressed both socially and scientifically. It needs to be addressed socially as human behaviour is influencing this degradation, and the science is needed to further our understanding and implementation of the best mitigation solutions.
\end{abstract}

The aim of this study was to evaluate how information surrounding potential nutrient mitigation measures provided by decision support tools is understood and interpreted by farmers facing tightening environmental regulations and a changing social outlook on environmental sustainability. To achieve this aim, the following activities were conducted: (i) A review of current theories and tools available to understand and encourage pro-environmental behaviour. (ii) A case study using the Land Utilisation Capability Indicator (LUCI) model to determine stakeholder engagement was carried out through interviews with 6 farmers in the Mangatarere Catchment.

The review showed that while information alone does not drive behaviour change, it is an essential component that when used in collaboration with other methods and incentives, can be very successful (Kennedy, 2010; Mackenzie-Mohr, 2000; Stern, 2000). From this review a method that was identified as having huge potential in terms of managing water quality was the use of land use models alongside targeted on-farm advice (Bouraoui \& Grizzetti, 2014).

To understand the stakeholder perception and uptake of the information this method provides a case study was carried out using the LUCI model with 6 farmers in the Mangatarere Catchment. The results showed that LUCI proved to be a valuable tool for both the case study farmers and the wider farming community. Farmer feedback highlighted the importance of ensuring that information provided by such tools is communicated in a consolidated manner. This thesis shows that land use models such as LUCI have the potential to be a beneficial method of engaging stakeholders in prominent issues such as degrading water quality. 


\section{Acknowledgements}

I would like to firstly thank my friends and family for supporting me throughout this thesis. I would also like to thank my supervisors Bethanna Jackson, Mairead de Roiste and Marcela Palomino-Schalscha along with other staff; particularly Keith Miller, Deborah Maxwell and Martha Trodahl from the University of Victoria for all their help and support. I would like to thank Callaghan Innovation and Ravensdown for funding this project. I also additionally thank Ravensdown for providing guidance, training and advice, specifically Courtney Mitchell, Ants Roberts and Mike White. I would also like to thank Greater Wellington Regional Council for their input, especially Richard Parkes. Lastly, I would like to thank the participants of this study who allowed me into their homes and gave me an insight into their lives. 


\section{Table of Contents}

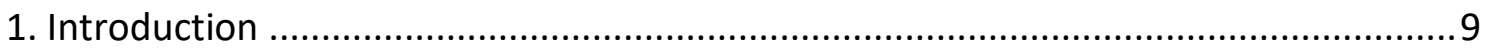

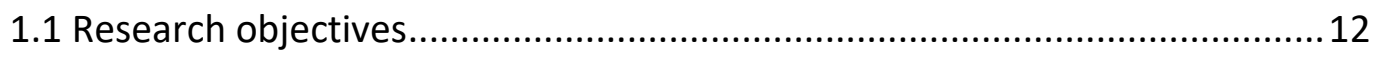

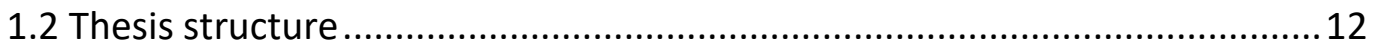

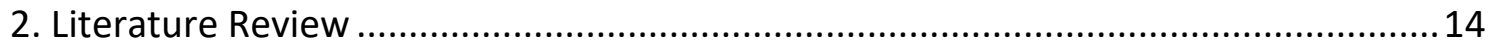

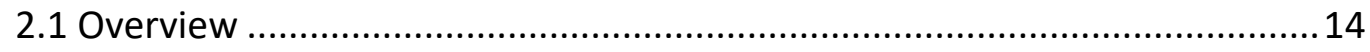

2.2 The state of New Zealand's freshwater systems ...................................... 14

2.3 The Impact of agricultural land use on freshwater systems.......................16

2.4 The social aspect of environmental degradation: How to encourage and motivate pro-environmental behaviour ........................................................22

2.4.1 Understanding the human perspective: ....................................22

2.4.2 Theories and frameworks for assessing, understanding and facilitating pro-environmental behaviour............................................ 23

2.4.3 Conclusions and common themes of the reviewed theoretical proenvironmental models ........................................................................ 29

2.5 New Zealand's methods to encourage pro-environmental behaviour ........ 31

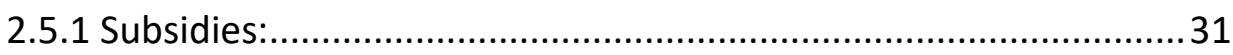

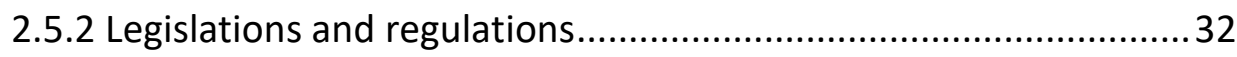

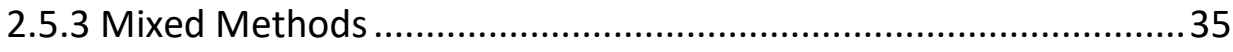

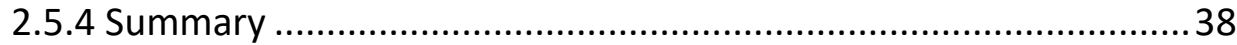

2.6 The role of land-use models to encourage pro-environmental behaviour ..39

2.6.1 Justification of using the LUCI model for this study . .43

2.6.2 Effective communication of land-use models to stakeholders and

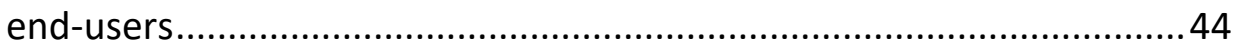

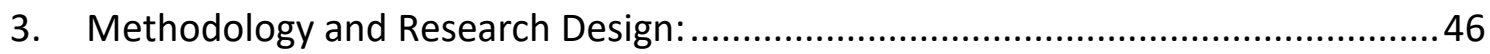

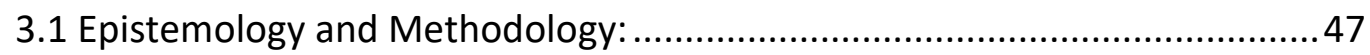

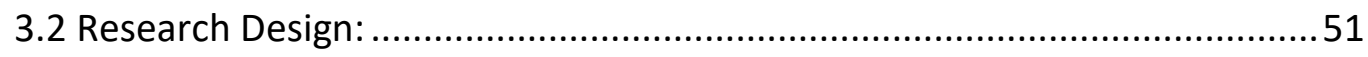

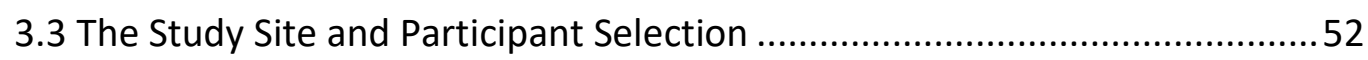

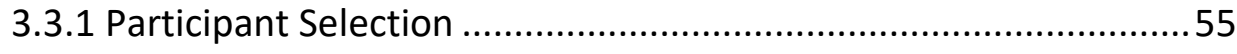

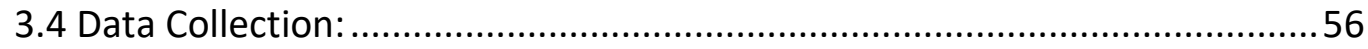

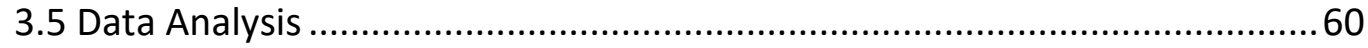

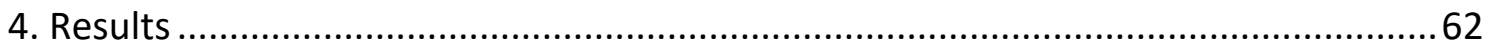

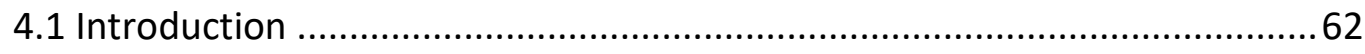

4.2 Participant experience and feedback on $\mathrm{LUCl}$ and the research process ....6.62

4.2.1 User-friendliness, accuracy and credibility 
4.2.2: Perceived value of the $\mathrm{LUCl}$ tool.

4.2.3: Any changing perceptions of the $\mathrm{LUCl}$ tool over the research

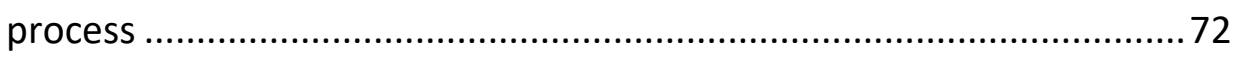

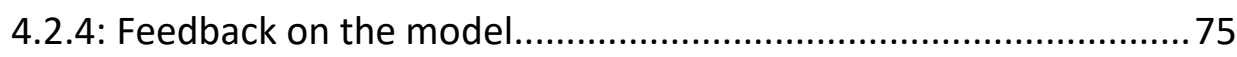

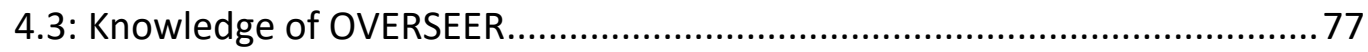

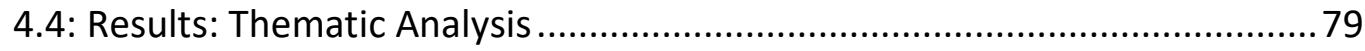

4.4.1: Public perception of farming and the rural/urban divide.............79

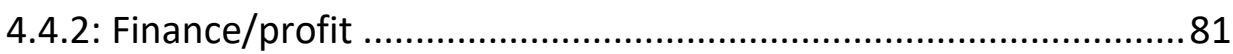

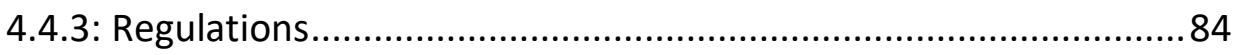

4.4.4_The role of information and models .......................................... 86

4.4.5: Other Findings: ........................................................................ 91

5. Discussion:

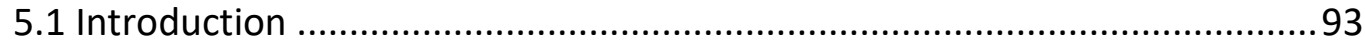

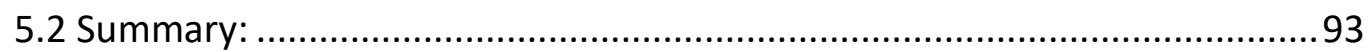

5.3 Participant experience and feedback on $\mathrm{LUCl}$ and the research process ....94 94

5.3.1 Perceived user-friendliness, accuracy, credibility and value .........94

5.3.2 Changing perceptions of $\mathrm{LUCl}$.................................................95

5.3.3 Participant feedback and recommendations..............................96

5.4: Finance and the role of information ...................................................... 97

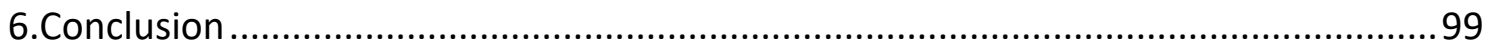

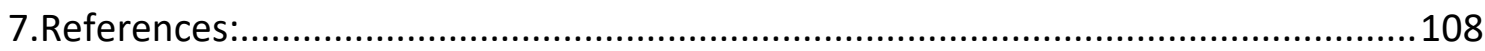

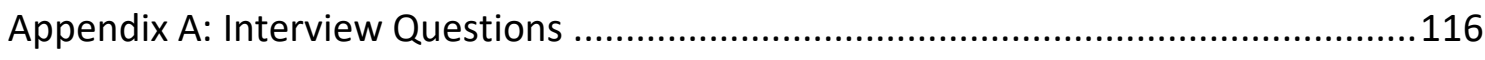

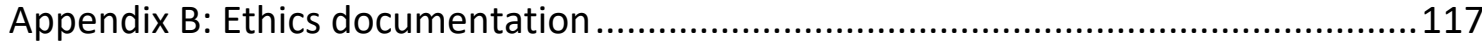

\section{List of Figures}

Figure 1: Trends in total nitrogen at 77 National Rivers Water Quality Network sites (NIWA, 2016).

Figure 2: Estimated and annual nitrogen leached from the soil between 1990 and 2012

(Ministry for the Environment \& New Zealand Statistics, 2015)..................................20

Figure 3: Early models of pro-environmental behaviour..............................................2

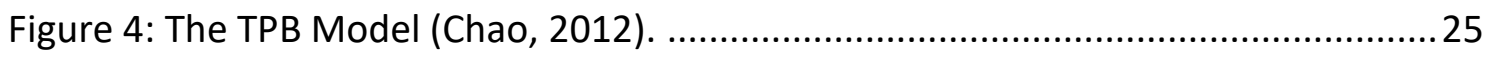

Figure 5: Model of Responsible Environmental Behaviour (Chao, 2012)......................26

Figure 6: Model of pro-environmental behaviour (Kollmuss \& Agyeman, 2002).........2 29

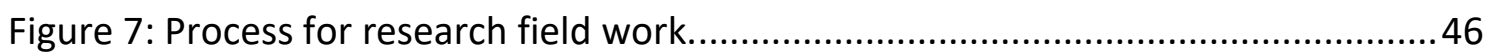


Figure 8: Location of the Mangatarere Catchment.

Figure 9: Nitrogen accumulated load maps (1a.), using national datasets (1b.), with nutrient budget data added.

Figure 10: Phosphorus accumulated load maps (2a.), using national datasets (2b.), with nutrient budget data added.

Figure 11: Phosphorus load with riparian planting (3a.), Phosphorus load without riparian planting (3b.), Nitrogen load with riparian planting (3c.) and nitrogen load without riparian planting ( $3 \mathrm{~d}$.). The black circles are highlighting the areas with and without riparian planting.

Figure 12: Stream entry and exit points and the differences in nitrogen load and concentration with and without riparian planting.

Figure 13: Nitrogen and phosphorus load maps (High (red) and low (green) nutrient levels)

Figure 14: Nitrogen (left) and phosphorus (right) accumulated load maps. 63

Figure 15: The original blocking of participant 5's farm. As can be seen the area 'steep hill ruahine' was all blocked as one area where as this block should have been split within LUCl to include the area of forest and scrub (dashed red line).

Figure 16: The left side shows the original nitrogen load map of the farm and the right side shows the nitrogen loading once the forestry had been added. Note: As the maps were made at various times (the right side at a later date) and the LUCI model was under development during this project the visual nature of the outputs varies slightly.

\section{List of Tables}

Table 1: Summary of flow-adjusted trends in water quality variables at NRWQN sites from 1989 to 2009 (Davis-Colley, 2013).

Table 2: The major land uses within the Mangatarere Catchment (Milne et al., 2010).54

Table 3: Change in participant knowledge of LUCI between interviews.

Table 4: Change in participant perception of the usefulness of models such as LUCI between interviews.

Table 5: Participant knowledge of OVERSEER. 


\section{Introduction}

\section{Research Aim:}

To evaluate how information surrounding potential nutrient mitigation measures provided by decision support tools is understood and interpreted by a group of farmers facing tightening environmental regulations and a changing social outlook on environmental sustainability.

Fresh water is one of New Zealand's most valuable natural resources and our ecology and economy is heavily dependent upon it (Ministry for the Environment, 2014). Fresh water is used to irrigate crops and pastures, produce hydro-electric energy and dispose of or dilute sewage and trade wastes (Ministry for the Environment, 2014). However, the intensification of agricultural land use is increasing levels of diffuse pollutants, such as sediment, nitrogen and phosphorus in New Zealand waterways, degrading the water quality (Duncan, 2017).

The management of diffuse pollutants from agricultural land use is a complex issue, not just a scientific endeavour, but also a social-political problem (Duncan, 2014). The social-political side of the issue comes about as a result of the negative impact humans have had on our water resources and the intricacies that exist in terms of motivating pro-environmental behaviour to prevent and reduce these impacts. Additionally, the complexity of the issue in part comes about as a result of an imperfect understanding of the behaviour of nutrient losses to freshwater. These shortfalls include a lack of extensive and long-term water quality data due to under-funded and underrepresentative environmental monitoring, insufficient ground truthing and poorly understood social-ecological relationships (Duncan, 2014).

Correctly evaluating the efficiency of mitigation measures to combat diffuse pollution of waterways is a challenging task due to the temporal and spatial lags between the action taken and the environmental response (Bouraoui \& Grizzetti, 2014). For example, when using the model EPICgrid in Belgium, Sohier and Degre (2010), observed a 15-year delay in the effects of agricultural mitigation measures in improving groundwater quality due to the aquifer transfer time (Bouraoui \& Grizzetti, 
2014). Cost effective nutrient mitigation requires the correct identification and quantification of sources as well as recognition of critical source areas (areas that contribute the majority of water quality contaminants but account for a minority of the area at the field, farm or catchment scale) (Bouraoui \& Grizzetti, 2014; McDowell et al., 2014).

A beneficial approach of managing water quality is the combined use of quantitative models along with targeted on-farm advice to address water quality concerns and determine appropriate mitigation measures (Bouraoui \& Grizzetti, 2014; McKergrow et al., 2014). Models have been widely used to predict the impacts of mitigation measures on water quality as they have the potential to be very effective tools (Bouraoui \& Grizzetti, 2014; Cartwright et al., 2016; McKergrow et al., 2014). Determining how ecological systems will respond to different management actions is crucial to decide how to manage them appropriately (Cartwright et al., 2016). Currently models can, to a certain extent, target mitigation measures (critical areas and timing), quantify expected impacts and associated costs and take into consideration potential trade-offs in the face of contrasting environmental goals (Bouraoui \& Grizzetti, 2014). Models are also a useful tool to convey information surrounding complex issues, such as water quality, in an accessible manner and involve stakeholders in the development of catchment mitigation plans which increases their acceptability (Bouraoui \& Grizzetti, 2014).

However, in order for models to be used effectively as decision making support tools, there is a need for greater comprehension of the social understanding and impact of the information and data predictive models provide. As models are being used to explain and represent complex systems, it is important that the uncertain information provided is understood, interpreted and used appropriately. Models are often used to inform decision-making and the end users of the model outputs can be policy makers, risk assessors, regulators and resource managers who are frequently non-scientists and/or non-specialists (Cartwright et al., 2016). The implications of failing to communicate successfully to end users has the potential to have profound consequences such as undermining the credibility of the model and reducing stakeholder trust (Cartwright et al., 2016).

Although the need for better science communication is well recognised, there is no 
widely accepted procedure for communicating complex ecological models to stakeholders (Cartwright et al., 2016). This lack of guidance could allow for a knowledge gap to open between modellers and users developers, reduce the societal impact and relevance of the research and limit the effectiveness of complex models in ecological decision making (Cartwright et al., 2016). As the science and knowledge of land use systems improves the complexity and variety of the tools available increases, this means the importance of being able to communicate effectively with end users also increases (Sharps et al., 2017).

To evaluate stakeholder engagement with a complex ecosystem services model, this research will carry out a case study using the Land Utilisation \& Capability Indicator (LUCI). The research will evaluate the use of $\mathrm{LUCl}$ as a tool to communicate information surrounding potential mitigation scenarios that could achieve environmental benefits, such as improved on-farm nutrient management. Particularly this research will evaluate how 6 stakeholders in the Mangatarere Catchment understand and interpret the LUCI process and to what degree perceptions of LUCI change throughout the project. LUCI is a GIS (Geographic Information Systems) based tool that explores solutions to degraded water quality due to its fine spatial scale and focus on the rural environment assisting farmers and land managers in their decision making (Jackson et al, 2016). The aim of the tool is to provide guidance for costeffective nutrient mitigation on farms as well as allowing policy makers to account for the combined impacts of such mitigation at greater scales (Jackson et al., 2016).

The results of this case study will help evaluate how effective the research process was at communicating the LUCI model outputs and mitigation scenarios and determine if the stakeholders benefited from the exchange of information. Additionally, the results will provide important feedback that will be used to enhance $\mathrm{LUCl}$ output presentation style where identified to aid with end user interpretation. This will allow for insight into a beneficial communication approaches to non-scientist end users and better uptake by farm and land managers in the future. 


\subsection{Research objectives}

This research thesis poses the following research aim: To evaluate how information surrounding potential nutrient mitigation measures provided by decision support tools is understood and interpreted by a group of farmers facing tightening environmental regulations, as well as a changing social outlook on environmental sustainability.

This research aim is made up of four objectives which are considered at each stage of this thesis:

1. To understand the role of information in facilitating pro-environmental behaviour and the other additional approaches that are used alongside information to encourage or incentivise behaviour change

2. To carry out a case study evaluating the use of $\mathrm{LUCl}$ as a tool to communicate information surrounding potential mitigation scenarios that could achieve improved on-farm nutrient management for a group of 6 farmers in the Mangatarere catchment.

3. To evaluate the participant's understanding, interpretation and any feedback on the $\mathrm{LUCl}$ tool through analysis of the interview transcripts.

4. To evaluate the effectiveness of using the land use decision support tool $\mathrm{LUCl}$ as a potential approach of displaying and communicating information around complex environmental issues to stakeholders.

\subsection{Thesis structure}

Chapter 2 begins with an exploration of literature surrounding the issue of diffuse pollutants degrading New Zealand water quality. The chapter then moves onto the social aspect of environmental degradation and the different approaches used to encourage and motivate pro-environmental behaviour. This section focuses particularly on the role of information in facilitating pro-environmental behaviour and the other additional approaches such as subsides, legislation and land-use models that 
are used alongside information to encourage or incentivise behaviour change. The aim of this section is to set the broader scene of the pro-environmental research that has informed current environmental education theory and practice.

Chapter 3 outlines the methodological approach of the case study evaluating the land use decision support framework $\mathrm{LUCl}$ as a tool to communicate information surrounding potential nutrient mitigation measures to improve water quality. A description and justification of the qualitative phenomenological approach that was used in this study to structure analysis is provided and the four field visits that were carried out to each farmer to gather their perceptions of the tool are also detailed in this section.

Chapter 4 details the results of the case study and chapter 5 provides the discussion and conclusions of the research findings. 


\section{Literature Review}

\subsection{Overview}

The following literature review explores the state of New Zealand's freshwater systems and the pressures they are currently facing, with a focus on the impacts of agricultural land use. The review then focuses on the human factor and what pro-environmental behavioural theories and tools exist to understand and facilitate pro-environmental behaviour. Discussion will then turn to the impacts of regulatory tools and subsidies as a method to encourage pro-environmental behaviour. Attention will then be paid to the use of models as decision making support tools and the challenges of communicating these complex models to decision makers and other end users.

\subsection{The state of New Zealand's freshwater systems}

New Zealand's freshwater supply is our biggest economic and natural asset and the condition of our lakes, rivers, streams, wetlands and groundwater is important for numerous reasons. Our economy depends on it as it is necessary to sustain tourism, agriculture and hydroelectricity generation (Ministry for the Environment, 2016). Additionally, both New Zealanders and tourists use it for various forms of recreation and thirdly, for Māori freshwater is taonga and is essential for life and identity (Ministry for the Environment, 2016). Our freshwater supply also supports a healthy array of animals, plants and ecosystems.

New Zealand has more than 425,000 kilometres of rivers and streams, around 4,000 lakes and over 200 underground aquifers (rock or sediment is defined as an aquifer when groundwater is able to be extracted from it in sufficient quantities and at sufficient flow rates for human use) (Ministry for the Environment, 2016). Although this provides plenty of water per person, land use and population growth are placing increasing pressure on our waterways. In some areas, we are approaching or exceeding limits to the amount of water we can sustainably use, and in some catchments water quality is declining (Ministry for the Environment, 2016). Declining water quality is illustrated by The National Rivers Water Quality (NRWQN), New Zealand's only national-scale, freshwater quality monitoring network. The NRWQN is 
made up of 77 sites on 35 rivers that are reasonably evenly distributed across the North and South Island and drain around $50 \%$ of the nation's land area (Ballantine \& Davis-Colley, 2014). It is the most comprehensive long-term and consistent water quality dataset and monthly samples have been collected at the 77 sites since 1989 (Ballantine \& Davis-Colley, 2014). Trend analysis of the NRWQN data shows an overall increase in all nutrient concentrations (Table 1), especially nitrogen (total nitrogen and nitrate), from 1989 to 2009 (Ballantine \& Davis-Colley, 2014). Nitrogen concentrations were increasing considerably from 1989 to 2000 and then at a slower rate from 2000 to 2009. Phosphorus levels followed a similar trend and conductivity and visual clarity has also increased from 1989 to 2009 (Ballantine \& Davis-Colley, 2014).

Table 1: Summary of flow-adjusted trends in water quality variables at NRWQN sites from 1989 to 2009 (Davis-Colley, 2013).

\begin{tabular}{llllllllllll}
\hline \multicolumn{10}{l}{ Water quality variable (1989-2009) } \\
\cline { 2 - 12 } & TP & DRP & TN & NOx-N & $\begin{array}{l}\text { Visual } \\
\text { clarity }\end{array}$ & Turbidity CDOM & \%DO & Conductivity & Temperature pH \\
\hline Significant + & 24 & 32 & 45 & 36 & 35 & 12 & 5 & 11 & 45 & 14 & 12 \\
No sig. trend & 42 & 39 & 26 & 25 & 32 & 45 & 55 & 41 & 24 & 56 & 44 \\
Significant - & 11 & 7 & 6 & 16 & 10 & 20 & 17 & 25 & 8 & 7 & 21 \\
Overall trend & Increase & Increase & Increase & Increase & Increase & Decrease & Decrease & Decrease & Increase & Decrease & Decrease \\
\hline
\end{tabular}

An in-depth review of the NRWQN with stakeholders in July 2002 found that the slower increases in nitrogen and phosphorus concentrations, and the increase in visual clarity that occurred from 2000 are consistent with water quality improvements that would be expected from reductions in point source pollution (Scarsbrook and McBride, 2003). Point source pollution defines wastewater discharge or 'end of pipe' sources of water pollution such as city sewage (Scarsbrook and McBride, 2003). These sources require a resource consent and have become increasingly tightly controlled in New Zealand resulting in improved wastewater treatment (Davis-Colley, 2013). Unfortunately, the progress made from point source pollution control have been overshadowed by steadily increasing diffuse pollution from land use. The 'universal' diffuse pollutants are defined as fine sediments, pathogens and nutrients (Bachove et al., 2010). Diffuse pollution is particularly evident through the increased nitrogen and phosphorus concentrations that have been found to occur as a result of pastoral agriculture intensification (Davis-Colley, 2013). 


\subsection{The Impact of agricultural land use on freshwater systems}

Protecting the country's freshwater bodies is a growing challenge and our freshwater quality primarily depends on the dominant land use within the catchment. Land use in New Zealand has drastically changed since the first settlement of humans 700 to 800 years ago (Ministry for the Environment \& Statistics New Zealand, 2015). Today pastoral agriculture is the dominant land use, occupying around $40 \%$ of the nation's total land area (Davis-Colley, 2013). The extent of indigenous forest cover has been reduced from around $85 \%$ to just 23\% of New Zealand's land area between 1989 and 2009 (Davis-Colley, 2013). This results in numerous issues for water quality as in general water quality is very good in areas with intensive vegetation and less intensive land use practices, whereas in comparison freshwater in areas of agricultural or urban land use have reduced water clarity and aquatic insect life and higher levels of nutrients and E. coli bacteria (Davis-Colley, 2013; LAWA). This is illustrated by the study of Ballantine \& Davis-Colley (2014) using national data that found that relationships between median values for nutrients (dissolved reactive phosphorus, total phosphorus, oxidised nitrogen, total nitrogen) and pastoral land cover were mostly positive. This indicated that in catchments with more pastoral land cover, concentrations of water quality variables were higher than catchments with less pastoral land. In this study, visual clarity also declined and turbidity increased with increasing pastoral cover demonstrating increased sediment loads with increased pastoral land. This shows a strong connection between nutrient and sediment concentrations and the percentage of pastoral land cover at the national scale.

The impact of agricultural land use is demonstrated by the fact that since 1990 although the number of dairy farms has decreased, dairy farms have become larger in size and more intensified (Jiang et al., 2009). This trend towards more intensive farming has resulted in a reduction of water quality in lowland rivers and waterways, changes in soil health and increases in some greenhouse gas emissions (Ministry for the Environment, 2016). Agriculture is a core part of New Zealand's economy that is reliant on access to fresh water (New Zealand Statistics, 2016). However, the discharges from agricultural pollutants into waterways and the use of water for irrigation are also some of the largest threats to the long-term health of our water resources (Ministry for the Environment, 2016). Streams that are located in grazed 
pasture are subject to increased runoff as a result of lower interception and evapotranspiration of grasses in comparison to forest (Davis-Colley, 2013). They also have reduced infiltration due to soil compaction by livestock trampling (Davis-Colley, 2013). Increased runoff and reduced infiltration is a major driver of degraded stream water quality (Davis-Colley, 2013). Additionally, livestock are their own source of diffuse contaminants both directly through mobilisation of nitrogen, phosphorus and faecal microbes in their urine and dung and indirectly as a result of fine sediment eroded from livestock damaged soils (Collins et al., 2007).

The association of water quality degradation with intensive pastoral agriculture has clearly been established (Davis-Colley, 2013). The continuing decrease in water quality can be attributed to the intensification of livestock agriculture as a result of the scale and geographical extent of this form of land use (Davis- Colley, 2013). The main diffuse pollutants discharged from pastoral land use into New Zealand waterways include fine sediment, nutrients such as nitrogen and phosphorus and faecal microbial contamination (Quinn \& Stroud, 2002).

\section{The impacts of fine sediment on Freshwater}

Increased sediment loads because of human disturbance of soils are one of the most significant impacts on freshwater globally and in New Zealand (NIWA, 2015). Sediment is a complex contaminant as the impacts are dependent on not just its concentration, but also on a range of other components such as composition, particle shape, grain size and duration of exposure (NIWA, 2015). It can cause water quality degradation, higher costs of water treatment and serious ecological deterioration of aquatic environments (Bilotta \& Brazier, 2008; Quinn \& Stroud, 2002).

Fine suspended sediments change the visual clarity of freshwater and the penetration of sunlight into water needed for aquatic plant photosynthesis (Davis-Colley \& Smith, 2001). Poor visual clarity reduces the aesthetic quality and appeal of water for recreation and damages the visual habitat of animals (NIWA, 2015). This can have follow on impacts for the behaviour of fish and birds such as reduced predation efficiency (NIWA, 2015). Reduced light penetration also inhibits aquatic plant and algae growth (Bilotta \& Brazier, 2008). Fine sediment suspended in the water column can negatively impact animals through effects such as damage to respiratory structures 
through clogging of the gills of fish (NIWA, 2015). It can also reduce the food quality of organic suspended matter for filter feeders as it is consequently diluted with finer mineral sediment (NIWA, 2015). Deposited fine sediment on the beds of lakes, rivers and estuaries can seriously damage benthic habitat and can result in the burial and suffocation of benthic and hyporheic biota due to increased oxygen demand and reduced oxygen exchange (NIWA, 2015). This demonstrates that suspended and deposited fine sediment that can enter waterways because of agricultural land use is a significant stressor of fresh water environments in New Zealand that has numerous impacts on both habitats and species.

\section{Impacts of Nitrogen on Freshwater}

A major consequence of intensified farming is an increase in the level of nitrogen found in New Zealand waterways (Jiang et al., 2009). These increases can be seen through the NRWQN, New Zealand's only national-scale monitoring programme and the best source of water quality data on a national scale (NIWA, 2010). The trends in total nitrogen between 1989 and 2007 over the 77 regularly sampled river sites are shown in Figure one (NIWA, 2010). Most regions have experienced a statistically meaningful increase in nitrogen levels and nitrogen levels were found to increase by around 1.4\% per year over most of the country (NIWA, 2010). The upward trends for nitrogen have strengthened in recent years in comparison with this period which provides cause for concern (NIWA, 2010). There is little doubt that the declining river quality over the past 20 years is related to the intensification of pastoral farming and the conversion of dry stock farmland to dairy farming (NIWA, 2010). This is demonstrated by the fact that between 1992 and 2002 the number of cows in the Waikato increased by $37 \%$, during the same period nitrogen levels in the regions waterways increased by $40 \%$ and phosphorus levels increased by $25 \%$ (NIWA, 2010). 


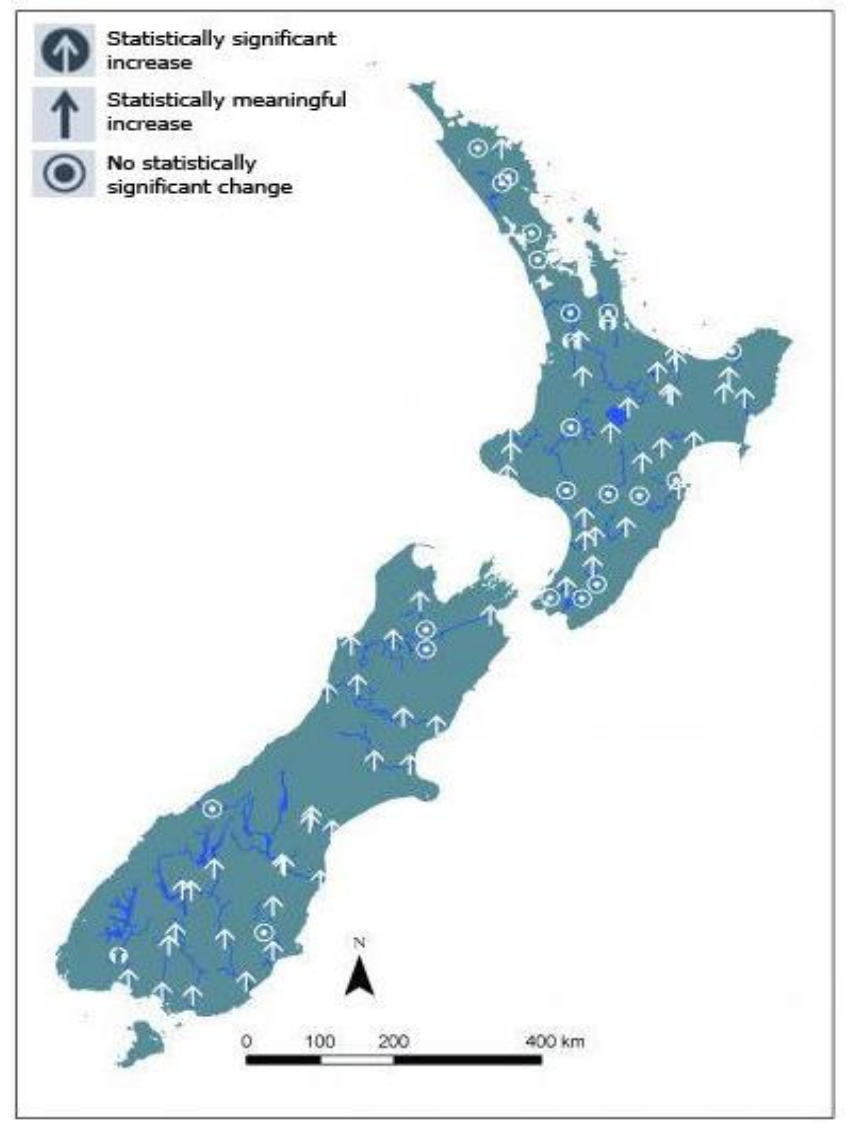

Figure 1: Trends in total nitrogen at 77 National Rivers Water Quality Network sites (NIWA, 2016).

New Zealand's aquatic systems are particularly sensitive to nitrogen and phosphorus so minor increases can result in significant effects (NIWA, 2010). As nitrogen is an essential nutrient for plant growth it is added to the environment through agricultural practices such as fertiliser used to boost production (Jiang et al., 2009; Parfitt et al., 2008). Although most of applied nitrogen is taken up by plants, livestock waste returns a significant amount back into the soil (Statistics New Zealand, 2015). Nitrate formed from this waste easily leaches from the soil before plants can absorb it and can enter waterways (Statistics New Zealand, 2015).

From 1990 to 2012, the estimated amount of nitrogen that leached into the soil from agriculture increased by $29 \%$ which is equivalent to around 1.5 million kilograms per year (Ministry for the Environment \& New Zealand Statistics, 2015). This was primarily because of an increase in dairy cattle (and therefore urine which contains nitrogen) and nitrogen fertiliser use as shown in Figure 2 (Ministry for the Environment \& New Zealand Statistics, 2015). 


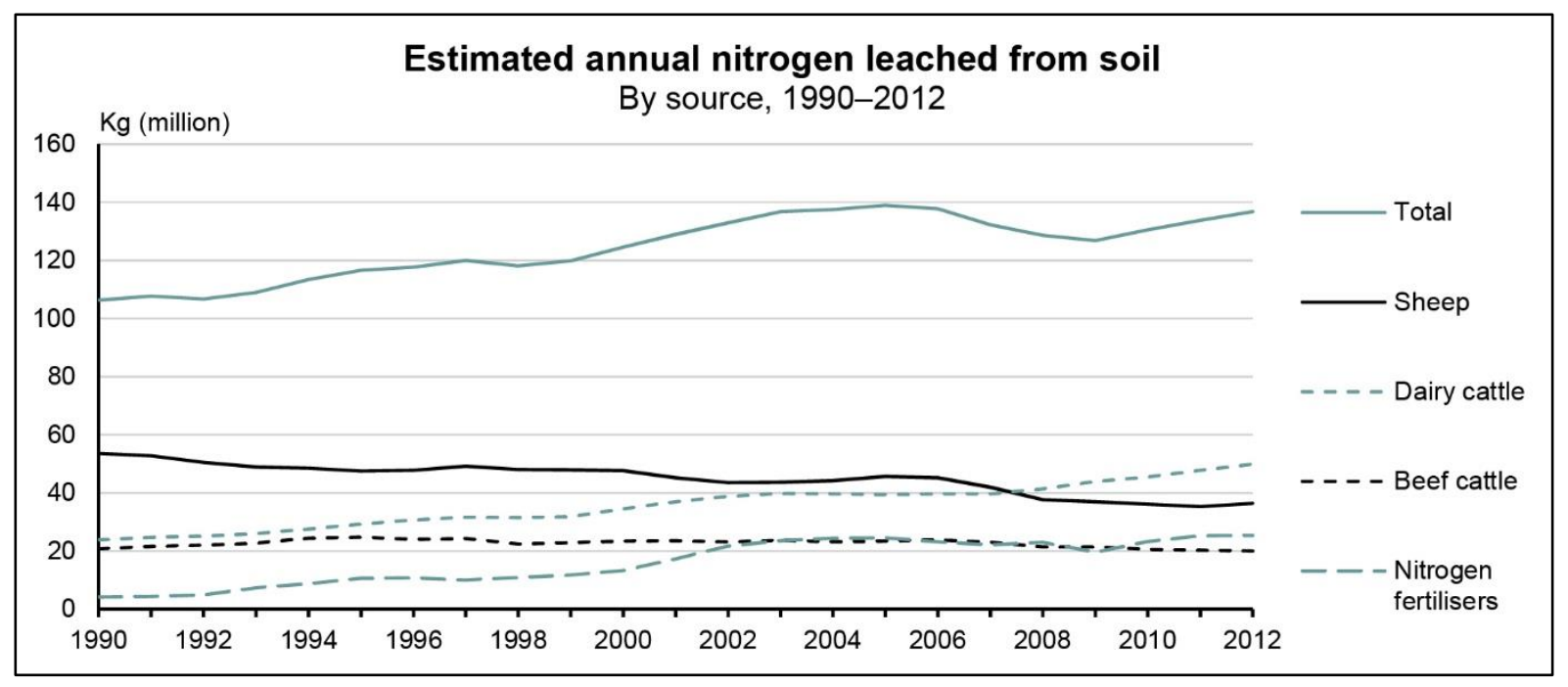

Figure 2: Estimated and annual nitrogen leached from the soil between 1990 and 2012 (Ministry for the Environment \& New Zealand Statistics, 2015).

Once it is in the soil, any excess nitrogen travels through rock and soil layers and ends up in groundwater, rivers and lakes (Ministry for the Environment \& New Zealand Statistics, 2015). Total levels of nitrogen in New Zealand rivers have increased $12 \%$ from 1989 to 2013 (Ministry for the Environment \& New Zealand Statistics, 2015). Excessive nitrogen levels in rivers results in nuisance slime and algae (periphyton) growth (Jiang et al., 2009). This can reduce oxygen levels in the water, inhibit river flows and smother the plant life and riverbed that fish and other aquatic animals are reliant on for food and habitat (Ministry for the Environment \& Statistics New Zealand 2015).

\section{Impacts of Phosphorus on Freshwater}

Like nitrogen, phosphorus resides naturally in the environment and is vital for plants to grow (Parliamentary Commissioner for the Environment, 2012). New Zealand soils are generally low in phosphorus, however increased use of phosphorus-based fertilisers and intensified dairying has led to surplus levels of phosphorus on many farms (Monaghan et al., 2007; Parliamentary Commissioner for the Environment, 2012). These increases can be seen through the NRWQN which shows that from 1989 to 2013 total phosphorus and dissolved reactive phosphorus increased 0.1 and 0.4 percent a year, respectively (Statistics New Zealand, 2015).

The largest sources of excess phosphorus are animal effluent, wastewater from dairy factories, and phosphorus-based fertilisers (Parliamentary Commissioner for the 
Environment, 2012). Phosphate generally clings to soil and organic particles and therefore, unlike nitrogen, only a small amount is leached (DairyNZ, 2013). Instead, phosphorus is predominantly lost from farmland when soil bound with phosphorus particles is eroded, caught up in overland flow and runs off into water bodies (DairyNZ, 2013).

The main impact of surplus phosphorus in the water is the 'over fertilisation' of aquatic plants which leads to excessive plant growth, the depletion of oxygen dissolved in the water and algal blooms (Parliamentary Commissioner for the Environment, 2012). Too many nutrients in the water cause extreme growth of three types of aquatic plants; macrophytes, periphyton and phytoplankton (Parliamentary Commissioner for the Environment, 2012).

The global use of phosphorus has increased from around 873 million tonnes in 1913 to a peak of around 16, 591 million tonnes in the late 1980s (Hart et al., 2004). Although the amounts of phosphorus lost per year in runoff are agronomically inconsequential, only very small concentrations of phosphorus are necessary for a body of water to become eutrophic (Hart et al., 2004).

Concerns about the state of New Zealand's freshwater have prompted significant thought about how our water resources are managed by the government, industry and other stakeholders which is leading to numerous management reforms. This can be seen through the following examples;

First, the National Policy Statement for Freshwater Management (NPS) requires that clear (i.e. unambiguous and measurable) water resource use limits are established for all freshwater bodies in New Zealand. Secondly, reports to the government by the Land and Water Forum (LAWF 2010, 2012a, 2012b) have called for a fundamental change from expert led and often adversarial decision making to more collaborative approaches to setting and living within water resource limits. These reforms will challenge the way water management decisions are currently made and water and land resources are managed (Fraser et al., 2014, p.1).

The push for these changes stems from the recognition that water is affected by a combination of both natural processes and human action such as urbanisation, 
agriculture and river management activities (Fraser et al., 2014). It is additionally recognised that decisions surrounding our land and water resources should consider social and cultural implications as well as economic and environmental drivers. The recognition of these more holistic themes have driven the move toward more integrated management of our natural resources (Fraser et al., 2014).

\subsection{The social aspect of environmental degradation: How to encourage and motivate} pro-environmental behaviour

Pro-environmental behaviour can be defined as a behaviour that harms the environment as little as possible or even benefits the environment (Steg \& Vlek, 2009, p.309).

It is becoming increasingly obvious that environmental challenges such as degrading water quality occur, at least partially, as a result of unsustainable patterns of human behaviour that require social change to reduce environmental impacts (Hargreaves, 2011). Social change is recognised as the "cornerstone of sustainability" (McKenzieMohr, 2011. p.2). Positive changes in behaviour are crucial as they not only directly affect our progress towards sustainability but can also powerfully influence how individuals see themselves (McKenzie-Mohr, 2011). For example, when people engage in activities that reduce carbon emissions, such as taking public transport, they are likely to begin to see themselves as someone who cares about climate change based on their behaviour (McKenzie-Mohr, 2011). Therefore, a central question to this issue is: how can we encourage and motivate individuals to engage in pro-environmental behaviour? And what are the barriers to pro-environmental behaviour?

This section of the thesis will explore a range of theories and frameworks for assessing, understanding and facilitating pro-environmental behaviour, the impacts of regulatory tools, subsidies and mixed methods and the use of GIS based modelling frameworks.

\subsubsection{Understanding the human perspective:}


Throughout human history, environmental impacts have been a side-effect of human aspirations for physical comfort, power, status, financial security and the organisations and technology society has created to meet these aspirations (Stern, 2000). Only recently has environmental sustainability become an important factor in human decision making. Despite recent changes in social consciousness toward the environment, there is a long road ahead to find the balance between meeting human needs and those of the environment. Finding this optimum balance will require a shift away from the current prevailing economic growth paradigm (Scott, 2015). There is growing recognition that the solution lies somewhere in between the social and physical sciences (Scott, 2015; Stern, 2000).

\subsubsection{Theories and frameworks for assessing, understanding and facilitating pro- environmental behaviour}

Numerous theoretical frameworks have been developed to build the understanding needed to effectively change human behaviours that contribute to environmental issues (Hargreaves, 2011; Kollmuss \& Agyeman, 2002; Lokhurst et al., 2011; Lucas et al., 2008; Stern, 2000). However, although hundreds of studies have been carried out, no definitive explanation of how to change human behaviour has been discovered (Kollmuss \& Agyeman, 2002). The available theories and models all have validity in certain circumstances but the question of understanding what shapes proenvironmental behaviour cannot be visualised through one single frame-work or diagram (Kollmuss \& Agyeman, 2002). As yet, the research is not yet tied together in a comprehensive theoretical framework and there are conflicting views on what the most effective strategy for behaviour change is (Hargreaves, 2011).

As we do not have a complete understanding of how to facilitate pro-environmental behaviour, the following section of this thesis will analyse and evaluate a range of theories to determine common and influential themes and factors discussed in these analytical theories. The aim is to set the broader scene of the pro-environmental research that has informed current environmental education theory and practice. This section will focus exploring the research rather than assessing the theories effectiveness as a tool. 
The simplest and oldest models of pro-environmental behaviour are founded on the idea of a linear progression of environmental knowledge leading to environmental awareness and concern and therefore pro-environmental behaviour as shown in Figure 1 (Kollmuss \& Agyeman, 2002). These early models were disproven as research showed that, in most cases, more information did not necessarily lead to an increase in knowledge and awareness which in turn did not always lead to action (Lucas et al., 2008). Information must be backed up by other approaches as a diverse range of barriers to adoption of the desired behaviours often exist (Kennedy, 2010; Lucas et al., 2008). An information-based campaign alone is unlikely to be able overcome these barriers and encourage individuals to take an active role in changing their behaviour (Kennedy, 2010). These other approaches may include means such as regulations and subsidies that will be discussed later in this chapter.

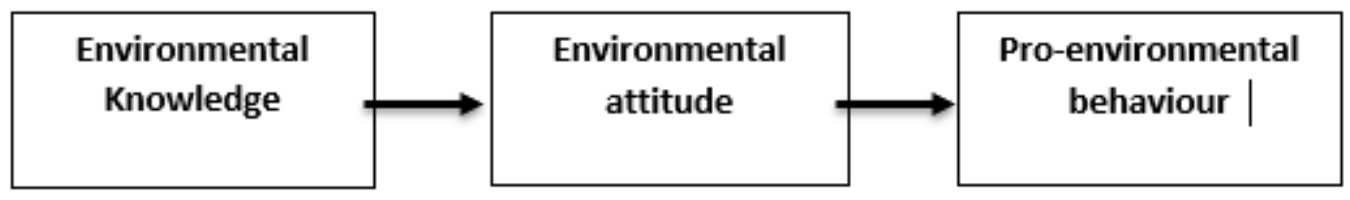

Figure 3: Early models of pro-environmental behaviour.

Regardless of this, many governmental and NGO initiatives still rely on using information to drive change, despite research telling us that changing habits and behaviours is a very challenging task, even if the new behaviour has obvious benefits (Kollmuss \& Agyeman, 2002). Quantitative research has found that there is a discrepancy between attitude and behaviour (Ajzen \& Fishbien, 1980, Kollmuss \& Agyeman, 2002; Rajecki, 1982). This is reflected in the study of Ajzen \& Fishbien (1980) which found that attitudes do not directly determine our behaviours, instead they influence our behavioural intentions which in turn shape our actions. The study determined that intentions are not only influenced by attitudes but also by social ('normative') pressures. Thus "the ultimate determinants of any behaviour are the behavioural beliefs concerning its consequences and normative beliefs concerning the prescriptions of others" (Ajzen \& Fishbein, 1980, p. 239). 
Many additional researchers have attempted to understand the gap between environmental knowledge and awareness and carrying out pro-environmental behaviour (DeSnoo et al., 2013; Kollmuss \& Agyeman, 2002; Lokhorst et al., 2011; Steg \& Vlek, 2009). In this section, key theories which endeavour to explain this gap are reviewed.

\section{The Theory of Planned Behaviour:}

An influential and widely used model is the Theory of Planned Behaviour (TPB). The TPB assumes individuals make deliberate choices and chose to carry out behaviour where the benefits outweigh the costs (in terms of money, effort and/or social approval) (Lokhorst et al., 2011; Steg \& Vlek, 2009). The theory states that the main predictor of any given behaviour is the intention to perform that behaviour (Lokhorst et al., 2011). This intention to perform is affected by the individual's attitude towards the behaviour, the subjective norm and the perceived behavioural control (Chao, 2012; DeSnoo et al., 2013; Lokhurst et al., 2011). Attitude is defined as an individual's evaluation of the specific behaviour: it is a personal evaluation to determine if the behaviour is positive or negative (Lokhurst et al., 2011). The subjective norm is the perceived social pressure to perform a certain behaviour and the perceived behavioural control determines how easy or hard the individual believes it will be to carry out the behaviour (Lokhurst et al., 2011). The TPB is also open to the inclusion of additional constructs which may improve the explanatory power of the model.

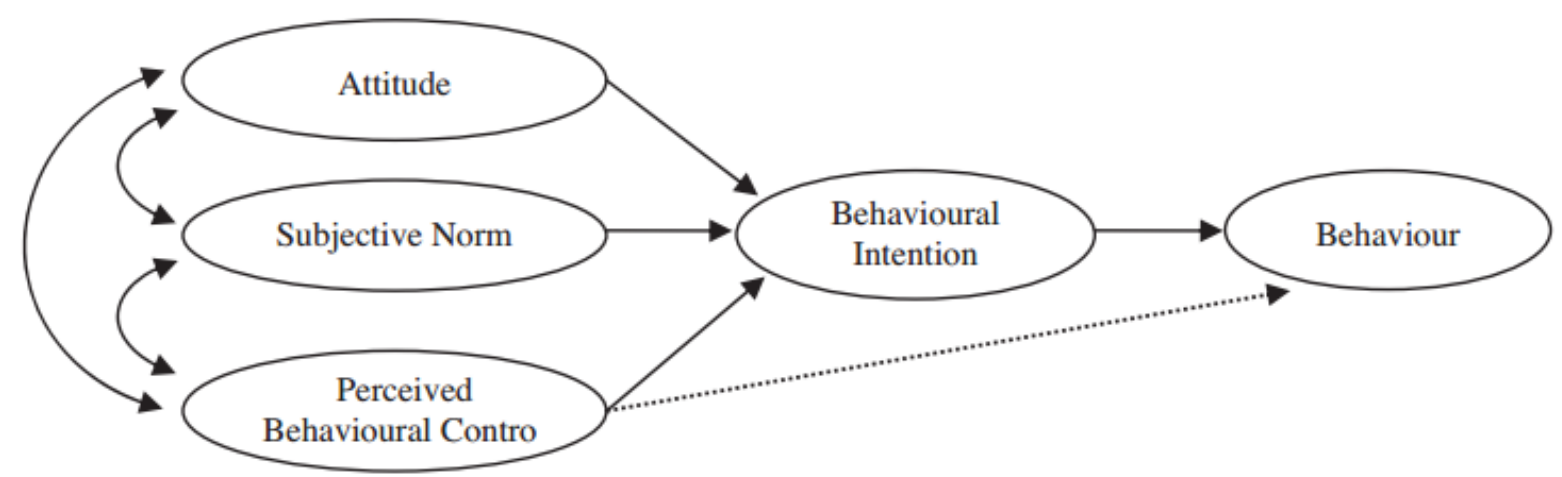

Figure 4: The TPB Model (Chao, 2012). 
Quinn (2008) and Chao (2012) argue that the theory does not include factors such as motive and moral reasoning and it has rarely been used to examine group behaviours. It was also found that the theory has an underlying assumption that people act rationally whereas it has been found that human behaviour is in fact not necessarily rational (Hargreaves, 2011). Despite these limitations, the theory has been found useful due to its clarity and simplicity (Kollmuss \& Agyeman, 2002).

\section{Model of Responsible Environmental Behaviour}

This model, based on the TPB, found a range of variables associated with responsible pro environmental behaviour through a meta-analysis of 128 behaviour research studies. These variables include: knowledge of environmental issues, knowledge of action strategies, locus of control (individual's perception of their ability to bring about change through their own behaviour), attitudes, verbal commitment and individual sense of responsibility (Kollmuss \& Agyeman, 2002). The intention to act will then lead the individual to responsible environmental behaviour if situational factors do not get in the way of the individual carrying out this behaviour (Chao, 2012). This model recognises the complex nature of pro-environmental behaviour as it acknowledges the factors and barriers that arise in the situational context (Scott, 2015).

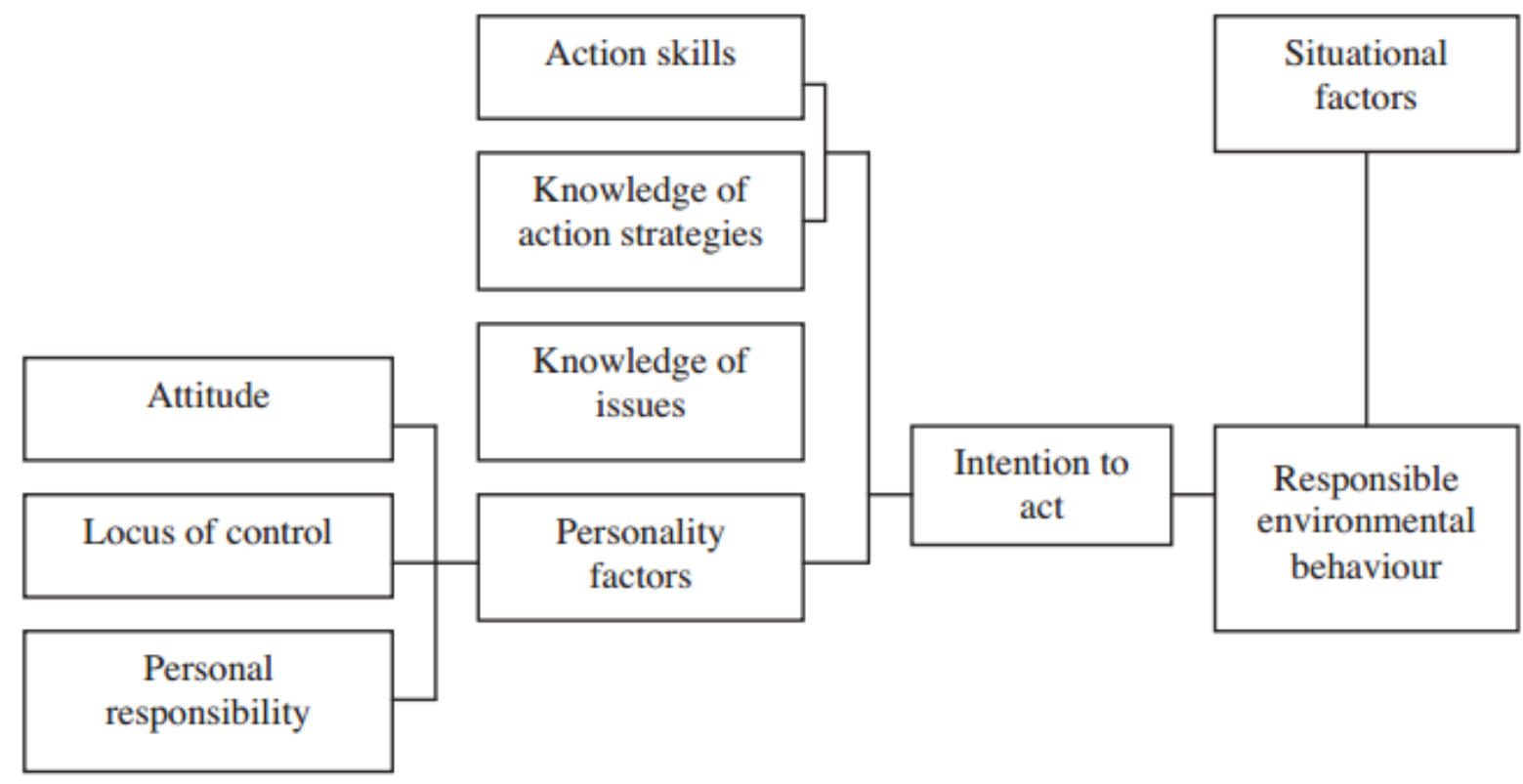

Figure 5: Model of Responsible Environmental Behaviour (Chao, 2012). 
This model is a conceptual framework that does not have adequate empirical tests, although it is cited frequently for its conceptual importance, limited studies have tested this model (Chao, 2012). Additionally, although all the variables of the theory are prerequisites to pro-environmental behaviour, they do not sufficiently explain the behaviour, nor do they necessarily result in environmental behaviour (Kollmuss \& Agyeman, 2002).

\section{An Integrated Framework for Encouraging Pro-environmental behaviour (IFEP):}

The IFEP proposes that three types of goals/motivations drive an individual's environmental behaviour in a given situation, these are; hedonic goals, gain goals and normative goals (Steg et al., 2014). Hedonic goals encourage the individual to find ways to improve their feelings in a situation through means such as avoiding negative thoughts and events. Gain goals encourage the individual to guard and improve one's resources, such as money and status. Normative goals focus on the need to act appropriately and sensitivity to what they think they ought to do such as putting their rubbish in the bin. The focal goal in any situation will be the strongest influence on cognitive processes and decision making (Steg et al., 2014). The other two background goals will increase the strength of the focal goal when they are compatible and decrease the strength when they conflict (Steg et al., 2014).

Individuals may be motivated to participate in pro environmental behaviour as it aligns with their hedonic goals (it is more enjoyable), gain goals (it saves money), or normative goals (they believe protecting the environment is the right thing to do) (Steg et al., 2014). A central issue with many pro environmental actions is that they involve a conflict between normative and hedonic and gain goals (Steg et al., 2014). Acting pro environmentally is generally viewed by society as the right thing to do but it is often less profitable, less efficient and less enjoyable than the alternative (Steg et al., 2014).

Given this conflict between goals, how can people be encouraged to act pro environmentally? The IFEP suggests two strategies to overcome this conflict. Firstly, change the actual or perceived outcomes of environmental behaviour by reducing the perceived costs (time, effort, money, convenience, comfort) and increasing the 
perceived benefits (Steg et al., 2014). For example, this could occur by making the action more convenient by increasing the availability of trash cans, less enjoyable with the addition of speed bumps or financially attractive through subsidies (Steg et al., 2014). This method is found to provide an unstable basis (as it is strengthening hedonic and gain goals, and people who have strong goals in this area act pro environmentally when it feels good or is profitable but avoid it when it is hard or costly), therefore as a method for encouraging pro environmental behaviour as it may result in 'cheap morals' but not in sustained moral actions (Steg et al., 2014).

A second strategy is to strengthen the normative goals which as a result weakens the relative strength of the hedonic and gain goals. This strategy makes people focus on the environmental outcome of choices which can encourage them to act pro environmentally as they want to do the right thing despite the extra inconvenience or cost (Steg et al., 2014). This strategy does not remove the internal conflict between the two goals, but it will reduce the value of hedonic and gain consequences of behaviour (Steg et al., 2014).

\section{$\underline{\text { Kollmuss \& Agyeman Model of pro environmental behaviour }}$}

Through analysis of early rationalist theories, altruism, empathy and prosocial behaviour theory Kollmuss and Agyeman (2002) developed the model of proenvironmental behaviour to show the key attributes of and barriers to proenvironmental behaviour. This model does not attribute a direct relationship to environmental knowledge and pro-environmental behaviour, instead the model places environmental knowledge, values and attitudes, along with emotional involvement into a complex labelled 'pro-environmental consciousness' (Kollmuss \& Agyeman, 2002). This complex is embedded in broader personal values and shaped by personality traits and other internal and external factors. The model recognises that the longer the education is then the more extensive the knowledge about environmental issues is, but this does not necessarily result in pro-environmental behaviour (Kollmuss \& Agyeman, 2002). As shown in figure 5, the biggest positive influence on pro environmental behaviour (as indicated by the larger arrow) is achieved when internal and external factors act co-operatively (Kollmuss \& Agyeman, 
2002). The black boxes represent potential barriers to positive influence on proenvironmental behaviour (Kollmuss \& Agyeman, 2002).

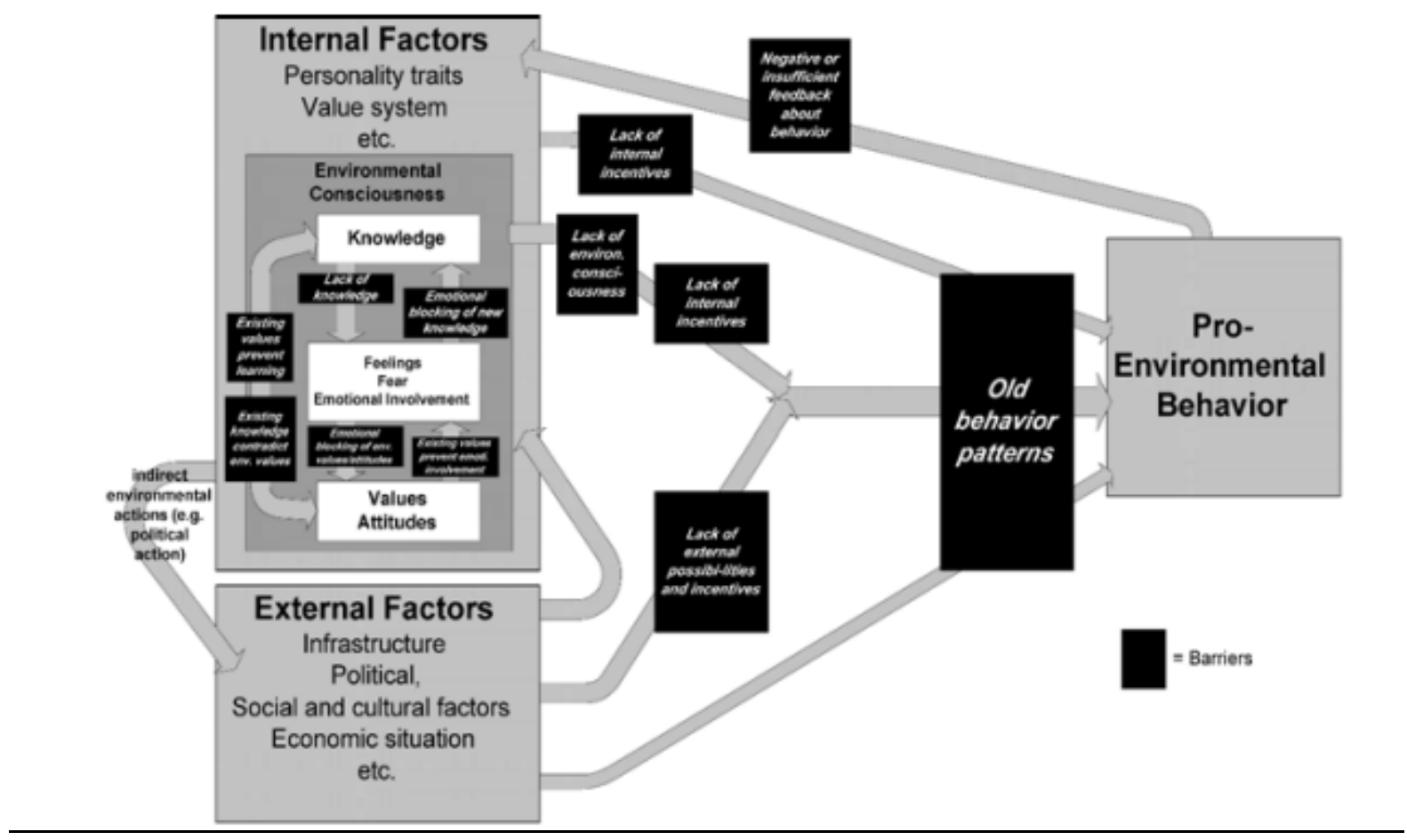

Figure 6: Model of pro-environmental behaviour (Kollmuss \& Agyeman, 2002).

\subsubsection{Conclusions and common themes of the reviewed theoretical pro- environmental models}

Many pro-environmental models are flawed because they fail to take into account the individual, social and institutional constraints, assume that human beings make systematic use of information and that they are rational (Blake, 1999; Kollmuss \& Aygeman, 2002). However, a common theme arising from reviewing these different models is that environmental knowledge does not lead to action, and that as human beings, we are not rational (Kennedy, 2010; Mackenzie-Mohr, 2000; De Snoo et al., 2013; Kollmuss and Agyeman, 2002). It has been found that at least $80 \%$ of the reasons behind pro-environmental or non-environmental behaviour appear to be situational factors and other internal factors (Kollmuss \& Aygeman, 2002). This means that although humans in general have a set of personal values, these values will be trumped or influenced by contextual factors and decisions will occur as a result of the 
balance struck or weighting given to each of these factors at a particular moment in time (DeSnoo et al., 2013; Lokhorst et al., 2011; Steg et al., 2014; Steg \& Vlek, 2009).

Despite this finding, the literature also indicates that although information alone will not drive behavioural change, it more often than not a prerequisite to behavioural change (Mackenzie-Mohr, 2000; Kollmuss and Agyeman, 2002; Stern, 2000). How effective the communication of information is to decision makers and stakeholders can therefore be a crucial factor in facilitating any potential change. For example, when information of a negative nature, such as a potential problem, is communicated without an accompanying achievable solution, the target audience can disengage or discredit the information (Mackenzie-Mohr, 2011). This is a common issue in terms of the climate change debate where people can have symptoms of 'learned helplessness' (Parker \& Shapiro, 2008). To overcome this barrier there is a need for a greater comprehension of the social understanding and impact of the information and data environmental models provide. Although the need for better science communication is well recognised, there is no widely accepted procedure for communicating information to stakeholders (Cartwright et al., 2016).

As a result of this knowledge gap, there continues to be a persistence of linear models of behavioural correction within the literature (Hargreaves, 2011). A potential reason for this is that these models make policy responses relatively straightforward (Hargreaves, 2011). However, if pro-environmental behaviour and sustainable consumption are to be achieved at the necessary rate, conventional narrow models of individual behaviour change likely need to be disregarded (Hargreaves, 2011). In their place, policy and research should be focused on the complex task of generating more sustainable practices (Hargreaves, 2011). Changing public behaviour is a complex matter and innovative policies and practical solutions across a range of different sectors and at every level of society are going to be required (Lucas et al., 2008). Research has found that a holistic approach should be taken when designing policy for pro-environmental behaviour change (Jensen, 2002, Lucas et al., 2008). This comes as a result of policies often focusing too much on short term outputs, meaning the long term 'big picture' goals of the policy are lost (Lucas et al., 2008). Policies and practices must be assessed in terms of their actual environmental impact and behaviours 
upstream and downstream need to be examined to reduce these impacts (Lucas et al., 2008). It has also been found that target audiences are more likely to adapt their behaviour in line with a policy when they have been involved in its formulation (Lucas et al., 2008).

This discussion shows that it is difficult to change individual behaviour with information alone as a diverse range of barriers to adoption of the desired behaviours may exist (Kennedy, 2010). Although information alone does not drive behaviour change, it is an essential component that is often used in collaboration with other methods and incentives. Potential methods and approaches that are non-linear and have been used in to transcend the gap between knowledge to action in New Zealand will be examined in the next section.

\subsection{New Zealand's methods to encourage pro-environmental behaviour}

Environmental problems such as degrading water quality are recognised as both a social and scientific issue. The science is continuously improving in this area but the social understanding of how to communicate that information to decision makers and stakeholders in a way that facilitates optimum understanding and uptake is yet to be found. As concluded in the previous section, although the provision of information is a crucial factor in communication and facilitating change, alone it is insufficient to prompt behaviour change. Information needs to be used in collaboration with other engaging approaches to increase the benefits of desired behaviours or remove the obstacles to them (Kennedy, 2010). Examples of some engaging approaches that are used in New Zealand to encourage in pro-environmental behaviour in regard to water quality are evaluated below.

\subsubsection{Subsidies:}

Subsidies have the potential to improve water quality when they are targeted at the right place and right time. However, subsidies can also constrain enterprises into farming a certain way, limiting flexibility to change land use practices for means such as better profits (McDowell et al., 2015). Subsidies can also stifle innovation and 
should new science affecting the areas where subsidies are in place be published, changing the infrastructure to include this science may take a long time (McDowell et al., 2015). Additionally, subsidised behaviours are driven by financial rewards meaning that as the behaviour is reliant on the continuation of that reward it is often only a temporary change (DeSnoo et al., 2013; Lokhurst et al., 2011). Subsidies can also act to de-incentivise personal motivation and often do not require the farmer to learn about "good" land management practice due to the rule-based framework used for subsidies (Lokhurst et al., 2011). When farmer profit margins are tight it has been found that spending on voluntary initiatives, such as subsidies to improve water quality, is often a low priority (McDowell et al., 2015). The use of subsidies that aim to improve water quality are common in the US and the UK.

The New Zealand Government removed its agricultural subsidies scheme in 1984 and it is often noted that New Zealand's lack of subsidies have resulted in farming operations that are efficient and able to respond quickly to demands of the market (McDowell et al., 2015). Although the removal of farm subsidies resulted in some initial hardship (1\% of farms went bankrupt), since 1986 productivity has continued to increase at a rate of 5.9\% per annum (McDowell et al., 2015). Removing government assistance allowed farmers to produce what people wanted in an efficient way that could make a profit (Siegel, 2016). Despite this, it is also noted that many New Zealand farming enterprises are more vulnerable to spikes in market prices than countries with state support.

Subsidies have the ability to result in positive environmental gains and provide farmers with state support but there is little evidence that they result in either a change in attitude or behaviour toward the environment. There is no simple relationship between a financial reward and behavioural change (DeSnoo et al., 2013).

\subsubsection{Legislation and regulations}

To combat the degradation of New Zealand's freshwater, legislation sets standards for water quality through the National Policy Statement on Freshwater Management (NPS-FM). Before the NPS-FM the management of diffuse pollution from agriculture was largely controlled by non-regulatory methods due to a lack of adequate national 
policy and direction being provided by the Resource Management Act 1991 (Rouse \& Norton, 2017). These methods included pastoral industry self-management such as the 2003 Dairying and Clean Stream Accord, good management practices and promotion of farm environmental plans (McDowell et al., 2015). Methods such as these resulted in some water quality and aquatic habitat improvement and are likely to continue to be important, but the implementation of the NPS-FM and its continuous reforms requires increased use of regulatory methods to manage freshwater (McDowell et al., 2015).

The NPS-FM was introduced in 2011 under the Resource Management Act 1991 leading the drive for improved freshwater management and a consistent national approach (McDowell et al., 2017). The purpose of the NPS-FM is to establish quantitative "enforceable limits" on water quality and quantity to be implemented by local authorities across all regional jurisdictions (Duncan, 2014). Authorities must maintain or improve freshwater quality and they have up to 2030 to set limits (McDowell et al., 2017). Of the 16 authorities, the majority are aiming to implement these limits by 2027, however as of 2015 at least two authorities have already done so (Otago and West Coast) (McDowell et al., 2017). As a result of differences in climate and soil types the implementation of these limits will most likely vary at the farm scale across authorities (McDowell et al., 2017).

The NPS-FM recognises freshwater management as a nationally important issue needing central government direction. In 2014 amendments to the NPS-FM brought in the National Objectives Framework and national bottom lines for water quality (Ministry for the Environment, 2016). This means authorities must set water quality objectives at or above bottom lines except for cases where the existing freshwater quality is as a result of a natural process (McDowell et al., 2015). In 2016 the Government consulted on the 'Next steps for freshwater', the subsequent phase of proposed reforms. The reforms aim to improve the management of freshwater to provide improved environmental and economic outcomes and better outcomes for iwi. They include reforms such as the exclusion of stock from waterways through regulation and good management practice (Ministry for the Environment, 2016). As a result of public feedback on the 2016 reforms the Government is now consulting on 
the 2017 'Clean Water' package. The Clean Water package builds on the NPS-FM and the consultation document is made up of five key components. These components include: details of new national stock exclusion regulations, new maps and information on the current water quality for swimming, changes to the NPS-FM such as water quality requirements for recreation, criteria for allocation of the $\$ 100$ million Freshwater Improvement Fund and a new target that $90 \%$ of rivers and lakes will be swimmable by 2040 (Ministry for the Environment, 2016).

Legislation can take years to implement, but once policy is in place, its normative influence has the potential to be generational (De Snoo et al., 2017). Legislation has been used as a tool to alter behaviour towards the environment with varying levels of success (Kennedy, 2010). Statistics surrounding environmental degradation suggest that regulation is failing to produce sufficient outcomes in many cases (Kennedy, 2010)

The legislative approach for encouraging people to alter their behaviour occurs through the prohibition or enforcement of a certain behaviour by law (De Snoo et al., 2017). This means motivation to comply with legislation comes from fear of punishment or penalty because of non-compliance (Kennedy, 2010). This means regulation targets only some of the drivers of individual compliance even though compliance is motivated by numerous factors such as personal beliefs and values (Kennedy, 2010). To be behaviourally effective regulation needs to be complemented with approaches that engage the intrinsic motivations of individuals and remove barriers to sustainable activities (Kennedy, 2010). Therefore, a sophisticated understanding of human behaviour needs to be integrated into the design and implementation of legislation (Kennedy, 2010).

In the case of New Zealand's freshwater legislation, the NPS-FM represents significant progress for providing a strong national policy direction. Previously (in the 1990's) any water quality and quantity issues and decisions were assessed on a case by case basis of the environmental effects of individual proposed activities (Rouse \& Norton, 2017). The mandatory requirement for councils to set objectives and associated limits for resource use was a fundamental shift in New Zealand's freshwater legislation (Rouse \& Norton, 2017). It appears the NPS-FM and its consistent reforms are improving the policy and placing New Zealand in a strong position to combat the multiple stresses 
our waterways are facing. Going forward, it is important that as each authority implements policy limits clear advice on sources and pathways of nutrient losses as well as cost effective mitigation measures is provided (McDowell et al., 2017). This is necessary to avoid a compliance regime that may not address the cause of the problem or result in overly strict limits (McDowell et al., 2017).

It is important to note that despite significant legislative progress it is obvious from the continual degradation of waterways that we have considerable further progress still to make. As stated above, legislation is not a fool proof tool and often needs to be used in collaboration with other strategies.

\subsubsection{Mixed Methods}

It has been found that the social and economic challenges of meeting water quality policy are often just as large, if not larger than biophysical challenges (McDowell, 2015). The best approach may be a mix of both voluntary and mandatory policy tools in targeted areas (McDowell, 2015). To influence farmers' behaviours towards more sustainable farming, literature suggests tools should not only be trying to influence farmer motivation and behaviour, but the aim should be to place farmland sustainability "in the hands and minds of farmers" (DeSnoo et al., 2013). Some examples of potential mixed methods tools are discussed below.

Social marketing is an approach that uses information-based advertising to increase the awareness of a particular issue. For example, social marketing has been widely used in the field of health for initiatives such as anti-smoking campaigns and AIDS awareness campaigns (Kollmuss \& Agyeman, 2002). These campaigns typically use media advertising and the distribution of printed materials to encourage behaviour change (Mackenzie-Mohr, 2000). These information-intensive campaigns are based on one of two perspectives on behaviour change. This first is the assumption that by increasing knowledge of an issue and encouraging the development of attitudes that are in support of an activity, behaviour will change (Mackenzie-Mohr, 2000). Although good in theory it has been noted by numerous studies that increasing knowledge and creating supportive attitudes typically has little or no impact upon behaviour 
(Mackenzie-Mohr, 2000). The second perspective is that behaviour is influenced by economic motives, this means the economic advantages of engaging in a specific activity will be highlighted following the assumption that society is 'rational' and will behave in their own economic self-interest (Mackenzie-Mohr, 2000). Once again, this method of social marketing has been largely unsuccessful (Mackenzie-Mohr, 2000).

Social marketing has, in general, been unable to breach the gap between raising awareness and actual behaviour change, especially when dealing with complex issues (Kennedy, 2010; Scott, 2015). The range of barriers that exist for any sustainable activity means that the provision of information alone will rarely result in a change of behaviour (Kennedy, 2010; Mackenzie-Mohr, 2000; de Snoo et al., 2013; Kollmuss and Agyeman, 2002, Frisk and Larson, 2011).

Community based social marketing is an attractive variation of social marketing. The concept has emerged based on concerns around the ineffectiveness of environmental campaigns that rely solely on providing information (Kollmuss \& Agyeman, 2002). It has been found that environmental regulation could be improved using community based social marketing techniques (Kennedy, 2010). These techniques have been shown to be very effective at bringing about behaviour change due to its pragmatic approach (McKenzie-Mohr., 2011). They aim to change individual behaviour through direct communication and community level initiatives to remove barriers to change (McKenzie-Mohr., 2011). The method involves, carefully selecting the behaviour to be promoted, identifying the benefits and barriers linked with the behaviour, designing a strategy that uses behaviour-change tools to address these benefits and barrier, piloting the strategy with a small group of community members and then finally evaluating the impact of the program once it has been broadly implemented (McKenzie-Mohr., 2011). Research on community-based social marketing shows that the approach appears to have been successful in bridging the gap between knowledge to action that has characterized many environmental projects to date (Kollmuss \& Agyeman, 2002).

Another potential approach to encourage farmers to carry out pro-environmental behaviour is to attempt to influence social networks within farming communities. 
Farmers are known to be made up of a judgemental peer group who are constantly comparing themselves against one another's performances (Burton, 2004; DeSnoo et al., 2013). Benchmarking instruments may therefore be useful as they make farmers aware of their own environmental provision performances in comparison with their neighbours encouraging them to exchange experiences and learn from each other (DeSnoo et al., 2013). This has the potential to lead to normative pressure for the farmers to want to keep up with others who may be achieving better results (DeSnoo et al., 2013). Numerous studies in social and environmental psychology have demonstrated that providing feedback about their own environmental behaviour can be an effective way of improving this behaviour (DeSnoo et al., 2013).

This method has the potential to be very beneficial when environmental mitigations such as riparian planting are being carried out. For riparian planting to be effective the more of the river that is planted the better. As rivers and creeks typically travel through numerous farms in agricultural areas if farmers are influenced by their neighbours to carry out planting this could be very environmentally beneficial.

An alternative design for the delivery of financial rewards is a 'payment by results' approach. Result oriented schemes create common goals between farmers and conservationists. This is thought to provide environmental benefits that are associated with long lasting social and cultural changes (DeSnoo et al., 2013). As conservation in agricultural areas is partially a social issue, payment by results is aiming to influence farmers' behaviours and motivations rather than solely recognising and rewarding good behaviour though financial premiums as conventional subsidies tend to do (Desnoo et al., 2013).

Farmland conservation can only be successful in the long term with the active support of the farming communities. If knowledge about farming sustainably can be generated within the farming community, rather than just by experts or outsiders, then this knowledge may gain the social legitimacy that it is currently lacking from the farmers perspective (DeSnoo et al., 2013).

Different forms of voluntary subsidies and policies can still be found around the country. An example of such a form is a Farm Environment Plan. A Farm Environment 
plan is

"a non-regulatory tool to help farmers meet regional council requirements without resource consent...[It] is a key environmental risk-management tool which helps farmers recognise on-farm environmental risks, and set out a programme to manage those risks" (Brewer, p.1, p.7)

Variations of farm plans are used by the Northland Regional Council (Farm Water Quality Improvement Plan), Horizons (Sustainable Land Use Initiative), Taranaki Regional Council (Comprehensive Farm Plans and Greater Wellington Regional Council (Farm Environment Plans) (Brewer).

Greater Wellington Regional Council Farm Environment Plans are particularly important to this project as they are offered and implemented in the study site of the Mangatarere Catchment. Farm Environment plans were introduced into the Wellington region in 2012/13 after a pilot programme in 2011/12 that focused on the Mangatarere catchment on the basis of a water quality report on the catchment produced by GWRC in 2010 (Greater Wellington District Council; Milne et al., 2010). The aim of the Farm Environment Plan is to identify options and encourage landowners to mitigate nutrient and sediment discharges from properties in accordance with an overall catchment plan (Greater Wellington District Council). Farm environment plans are $50 \%$ funded by general rates and $50 \%$ by user charges.

\subsubsection{Summary}

In summary, there are numerous approaches such as subsides, legislation and regulation and mixed methods that are used in New Zealand and around the world to encourage pro-environmental behaviour. These are examples of incentives, prohibition or enforcement of a certain behaviour by law and/or voluntary approaches. This shows there are numerous approaches to bringing about behaviour change each with their own strengths and weaknesses. Discussion will now turn to the use of land-use models as a tool to facilitate behaviour change, land-use models are also able to be, and often are, used in collaboration with the approaches mentioned in 
this chapter. For example, they can inform policy or legislation by helping explain complex systems to provide the information needed to make informed decisions. This gives them the potential to be very effective tools.

\subsection{The role of land-use models to encourage pro-environmental behaviour}

As land use change is a globally significant ecological trend, it is critical to understand the interactions between human activities and natural resources (Agarwal et al., 2000). Land use models are necessary to gain insight into this interaction and to make effective and robust policies and management strategies (Agarwal et al., 2002). Models are able to be an informative and useful tool for assisting with environmental issues and pro-environmental behaviour as they allow for the quantification, visualization and spatial mapping of various environments (Vigerstol \& Aukema, 2011). Models are practical tools for advancing our scientific knowledge surrounding water quality and displaying information in an effective, understandable and motivating manner (Sharps et al., 2017). They can provide farmers, land managers and policy makers with the essential information needed to evaluate the impact of potential mitigation management or land use changes (Sharps et al., 2017).

Understanding the role of models in informing decision-making and how they can be used in conjunction with other tools, methods and theories to influence land-use choices will be important in informing how they can best be used in practice (Scott, 2015). In today's world of technology there are a variety of models that can integrate ecology, economics and geography to support our decision making (Bagstad et al., 2013). As the science and knowledge of land use systems increases, so does the complexity and variety of the tools available to model these systems (Sharps et al., 2017). Available tools range from large conceptual frameworks such as the Intergovernmental Platform on Biodiversity and Ecosystem Services to simple spreadsheet models that require limited user time and data inputs to much more complex software packages that require more technical skills and can result in better accuracy and usability as they allow for spatial quantification and mapping of services (Bagstad et al., 2013; Sharps et al., 2017). With the availability of such a wide variability of tools, it can be difficult for decision makers to identify which tools are appropriate 
for their needs and when and if modelling is necessary (Vigerstol \& Aukema, 2011). This means users need to be able to understand the purpose and ability of these tools to make an informed choice of model that will perform to the highest and most accurate standard for their purpose.

The preferential method of being able to make an informed choice is access to thorough reviews of the potential tools that model land use systems. Three in-depth reviews of some of the tools of interest in this space are that of Bagstad et al. (2013), Vigerstol \& Aukema (2011) and Sharp et al. (2017). Bagstad et al. identified, described and reviewed the performance of 17 ecosystem services tools, Vigerstol \& Aukema reviewed two of the most prominent hydrologic tools and newer ecosystem tools and Sharps et al. identified and compared three spatially explicit ecosystem modelling tools. As two of the three papers reviewed LUCI, InVEST and ARIES, with Vigerstol \& Aukema's paper looking at just InVEST and AIRES, this section will mostly focus on these three models.

The aim of the InVEST (Integrated Valuation of Ecosystem Services and Trade-offs) tool is to model and map a range of ecosystem services across the landscape to explain patterns and changes in ecosystem services caused by land cover changes or climate change impacts (Vigerstol \& Aukema, 2011). InVEST has been widely used, is straightforward to operate, freely available and therefore recommended for users who have time constraints (Sharps et al., 2017; Vigerstol \& Aukema, 2011). It is also the only one of the three tools with an advanced economic valuation tool so is recommended for those needing estimates of valuation as an output (Sharps et al., 2017). The main limitation of the tool is its inability to account for seasonal or subseasonal variability, groundwater and water resource infrastructure that redistributes water flow (Vigerstol \& Aukema, 2011). Additionally, INVEST models run the grid cell scale and summarise by watershed whereas LUCI and ARIES can provide information for every point in the landscape.

AIRES is likely to be useful for users who are interested in environmental management and visualizing ecosystem service dynamics, assessing the trade-offs between ecosystem services and the flow characteristics of ecosystem services between 
provisioning and use (Vigerstol \& Aukema, 2011). Similar to InVEST, AIRES is well developed, and field tested in comparison to other ecosystem services tools. As ARIES allows for the customisation of models, the tool requires a high degree of technical skill (Sharps et al., 2017). The tool also possesses a lack of transparency of the model code due to its complexity (Vigerstol \& Aukema, 2011). AIRES is however a useful tool when data is scarce due to its probabilistic approach (Sharps et al., 2017).

LUCI is a spatially explicit land management decision support framework that evaluates current and future land management on a range of ecosystem services (Jackson et al., 2016). It is a GIS toolbox that currently includes models for flood mitigation, water supply, greenhouse gas emissions, biodiversity, erosion, sediment and nutrient delivery to waterways, and agricultural production (Bagstad et al., 2013). $\mathrm{LUCl}$ is public domain tool, but it has not been as widely documented and applied as InVEST and AIRES (Bagstad et al., 2013). Bagstad et al. (2013) found that as a tool LUCI was 'potentially feasible for widespread use given improved guidance on tool use and feasibility of conducting a full stakeholder engagement process' (p.36). $\mathrm{LUCl}$ is the only tool that has a trade-off module which can provide a useful, near real time visual outputs of the potential impacts of land use changes on multiple services (Sharps et al., 2017). It is also the only tool that recognises the fine-scale spatial configurations of landscape features and it is well suited to explore the impacts of rural change (Sharps et al., 2017).

The three reviews found that although these three spatially explicit modelling tools provided comparable outputs and had similar limitations, each model has its own individual strengths and features and the tools varied in the approaches taken and the underlying assumptions made (Bagstad et al., 2013; Vigerstol \& Aukema, 2011; Sharp et al., 2017. The choice of model should ultimately depend on the study question and user requirement. What a model was designed for and how well it fits intended applications should also be considered (Vigerstol \& Aukema, 2011). Other factors to consider include the time required to apply the model, the spatial and temporal scale of analysis, the data availability and data needs of the models, the computational intensity, underlying modelling equations and the level of testing and validation the model has been through (Vigerstol \& Aukema, 2011). 
A tool not mentioned in the above analysis due to its New Zealand specific focus is the mathematical model OVERSEER. OVERSEER is a farm-scale nutrient budgeting tool that was developed by government and industry to determine how much fertiliser to apply on farm (Duncan, 2017). In New Zealand environments OVERSEER nutrient budgets are valuable tools for assessing the sustainability of nutrient flows, greenhouse gas emissions and showcasing any potential negative impacts of nutrient use (Wheeler et al.,2003). The tool has the ability to explore alternate on-farm management scenarios to increase the efficiency of resource use and reduce environmental impacts (Wheeler et al., 2003). It was initially used as a decision support tool but is now being used as a regulatory tool by regional councils across New Zealand. The use of OVERSEER in regulations is controversial due to the model's inaccuracy of between $20-30 \%$ in predicting nutrient losses, variability in how data is interpreted for use in the model, the tendency for regulators to use the numbers in absolute not relative terms and the continual releases of new versions of the model (Duncan, 2017). Despite this, OVERSEER is currently the best tool available for estimating nitrogen leaching losses from the root zone for the diverse range of farming systems in New Zealand (Williams, 2013).

There are many other land use models available and as it is not possible to discuss them all, this section will discuss what appears to be the priority issues for land use change modelling research in the future. As discussed there is a wide variety of approaches and techniques available to model land use change. Comparing these options highlights the areas we lack the understanding to be able to judge which approach will most efficiently improve land use modelling (Verburg et al., 2004). The study of Verburg et al. (2004) has come up with a list of priorities that need attention for future land use models. These priorities include better addressing the multi-scale characteristics of land use systems, development of new techniques to assess and quantify neighbourhood effects, explicit attention on temporal dynamics and the interaction between spatial and temporal dimensions. The large volume of papers and numerous amounts of models available in the land use research community show that there are large investments being made to improve land use change models. This is illustrated by the study of Agarwal et al. (2000) who found that land use cover models 
are improving as they are increasing capability with time and are more user friendly. Additionally, a large variety of concepts approaches, and techniques are already available and by combining their strengths there is the potential for a whole new generation of improved land use models (Verburg et al., 2004). Continuous progress is being in the land use model space to help us both understand natures complex systems and communicate better with the stakeholders (Verburg et al., 2004).

\subsubsection{Justification of using the $\mathrm{LUCl}$ model for this study}

This review of some of the available land use models available showed that there are various models to choose from when carrying out research projects such as this thesis. As mentioned in the above discussion, the choice of model should depend on the study question and the user requirement. There are several reasons why the $\mathrm{LUCl}$ model was selected for this study. Firstly, this study is being carried out with financial support from the farmer co-operative Ravensdown. Ravensdown has recently collaborated with the LUCI developers to enhance LUCl's ability to predict water quality outcomes given a range of farm environments and management practices, and to quickly target where management interventions could improve water quality while minimising productivity loss (Jackson et al., 2016). The overall objective of this collaboration is to provide a decision support tool identifying opportunities for costeffective nutrient mitigation on farms. As this is a recent development, this study is being conducted in part to assess stakeholder perception and uptake of these LUCI enhancements.

Secondly, the LUCI model is well placed to assist farmers and land managers explore solutions to degraded water quality due to its small spatial scale and focus on the rural environment (Jackson et al., 2016). LUCl is able to evaluate the effect of current and future management on a range of ecosystem services (Jackson et al., 2016). LUCI conveys this information through spatial maps and other outputs. As this project is aiming to show a group of farmers potential mitigation measures they could implement to improve their on-farm nutrient management, $\mathrm{LUCl}$ is very appropriate model to use for this study. 


\subsubsection{Effective communication of land-use models to stakeholders and end-users}

This discussion has shown that land use models are critical to gain insight into the workings of natural systems and to predict how ecological systems respond to changing environmental conditions or management actions. A crucial part of the modelling process not yet mentioned, is the challenge of communicating the information these models provide to end-users. The end- users or stakeholders of these model outputs can be decision-or-policy makers, risk assessors, regulators and resource managers who are quite often non-scientists and/or non-specialists (Cartwright et al., 2016). Due to the complexity of the discussed models it can be difficult to communicate the underlying drivers and the accuracy and credibility of the predictions (Cartwright et al., 2016). These elements are important to gain end-user acceptance and correct application of the predictions in a real-world context (Cartwright et al., 2016). Acceptance of models can be reduced by poor communication by modelers throughout the modelling process (Addison et al., 2013). For example, modelers can fail to allow for the various levels of technical knowledge of their audience and/or decision makers can also feel overwhelmed when multiple possible outcomes from model outputs are provided (Addison et al., 2013; Olsson \& Anderson, 2006). This links back to the main idea that information alone cannot drive behavioural change, it must be used in combination with an effective and engaging communication method.

There is currently no widely accepted procedure for communicating complex land use models to end-users, even though the need for improved science communication is generally well recognised (Fischhoff \& Scheufele, 2014). This lack of guidance and structure in carrying out communication has the potential to limit the effectiveness of complex models in ecological decision making and allow a knowledge gap to open between modellers and practitioners (Fischhoff \& Scheufele, 2014). The literature does however conclude that one particularly effective way of communicating and ensuring acceptance and legitimization of land-use models is through the involvement of stakeholders in the modelling and decision-making process (Addison et al., 2013; Olsson \& Anderson, 2006). Stakeholder participation in the modelling process can mean a range of things such as consultation about databases, assessment of whether 
the information the model produced corresponds with local knowledge, if the information is relevant for the problem at hand and which scenarios are going to best achieve the intended environmental goals of the situation (Olsson \& Anderson, 2006). Involvement of stakeholders will encourage an improved collective understanding of an issue and can enhance the knowledge-base and social acceptance of future decisions and facilitate better environmental outcomes (Addison et al., 2013). Other key features of effective model communication include user friendliness of the model, appropriate conveyance of model uncertainty and the use of an effective communication format and timeframe (Fischhoff \& Scheufele, 2014; Olsson \& Anderson, 2006).

Models by themselves are never going to give the solution to an environmental issue, their purpose is to provide information to aid decision making in the form of indications of which sources are important or the potential magnitude of impacts of a suggested measure (Olsson \& Anderson, 2006). Despite this, model-based information has immense potential to facilitate stakeholder dialogues and decision-making processes that are related to complex environmental issues (Olsson \& Anderson, 2006). It is for this reason that effective communication is so crucial. This discussion has shown that effective communication is not simply a one-way transmission of information from the modeller to the intended audience but instead, an iterative, engaging process in which both the science and the stakeholders benefit from exchanges of information (Fischhoff \& Scheufele, 2014). In the future improved measures of the effectiveness of communication between modellers are necessary to help increase the impact of complex land use models (Fischhoff \& Scheufele, 2014). 


\section{Methodology and Research Design:}

A range of different theories, approaches and tools used to encourage proenvironmental behaviour have been discussed providing a broader understanding of the pro-environmental research that has informed current environmental education theory and practice. As a result of this discussion, this thesis turns its focus directly to the use of land use models due to their high potential to be an effective explanatory and communicative tool for encouraging pro-environmental behaviour. Discussion thus far has shown that land use models are critical to gain insight into the workings of natural systems and to predict how ecological systems respond to changing environmental conditions or management actions. A crucial part of the modelling process is the challenge of communicating the information these models provide to stakeholders and end-users in a way that facilitates acceptance of the information provided.

To evaluate the use of land use models in practice, this research carried out a case study based on the land use decision support tool LUCI. LUCI was selected due to a collaboration with Ravensdown to assess stakeholder perception and uptake of recent $\mathrm{LUCl}$ enhancements, and the model is well placed to assist farmers and land managers explore solutions to degraded water quality. The aim of this study was to evaluate the use of the LUCI model as a tool to communicate information surrounding potential nutrient mitigation measures and scenarios to improve water quality. The study involved a group of 6 farmers located in the Mangatarere catchment and was carried out through four field visits to each farmer to introduce and explain LUCI as a modelling tool and gather their perceptions of the outputs of the tool. The structure and progression of these visits is outlined in figure 7 below.

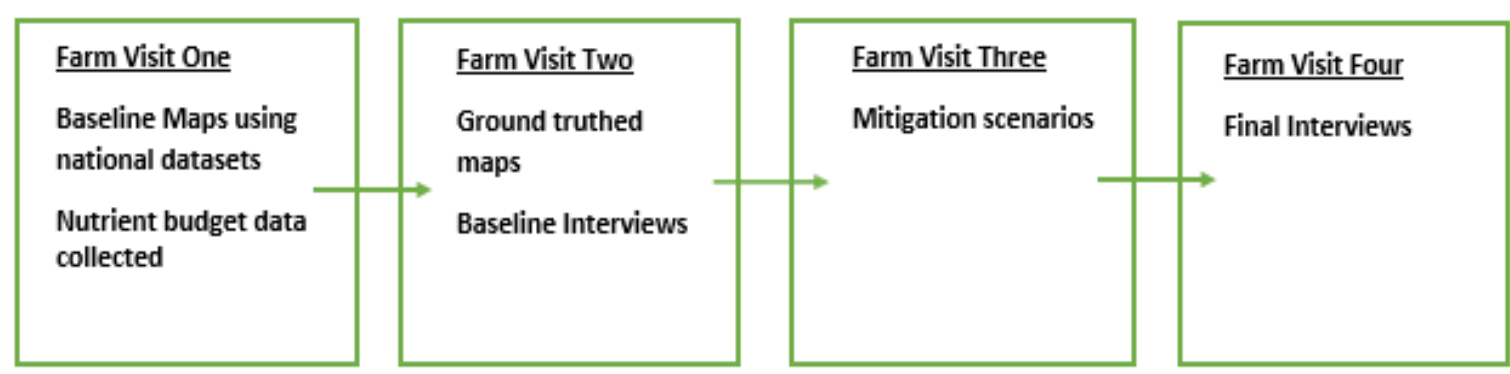

Figure 7: Process for research field work. 
It is important to note that although the literature indicates that information alone is insufficient to motivate behavioural change it is a prerequisite to behavioural change in most cases (Kollmuss and Agyeman 2002, Fisk and Larson, 2011; Kennedy, 2010; Mackenzie-Mohr, 2000; Stern, 2000). Understanding how information is understood and interpreted by stakeholders and end-users through the use of tools such as LUCI will allow practitioners, policy makers and the developers of such tools to manage how information is presented and communicated so that it enables optimum acceptance, uptake and correct application of the information in a real-world context.

Qualitative methods were used to determine how the research participants interpreted the LUCI model and if perceptions about the model changed throughout the project. This chapter outlines the methods used to carry out a case study in the Mangatarere Catchment. The research framework detailed in the first section relies on phenomenology to structure analysis.

\subsection{Epistemology and Methodology:}

The increasing number of GIS based frameworks able to support land use management decisions represent a change in available technology and our ability to map and view the complex systems that impact important resources such as freshwater. This project aims to understand how information is perceived when it is presented through the GIS based $\mathrm{LUCl}$ model. Rather than quantitatively testing $\mathrm{LUCl}$ as a tool this research is aiming to test how the outputs of $\mathrm{LUCl}$ (maps and tables) are interpreted and responded to by a select group of farmers from the Mangatarere catchment. This means a qualitative approach is the more appropriate method to use.

"Qualitative methods are ways of studying people and their social worlds by going there, observing them closely, in their natural setting, and learning how they understand their situations and account for their behaviour...A qualitative method is needed for researchers who are trying to learn something new, rather than test something that is known (Richards, 2015, p.1)."

As this project aims document and analyse how participants interpret the outputs of LUCl, a qualitative research method is applicable. A qualitative method that allowed for open-ended questions and a high level of engagement with the participants was 
necessary to allow the participants to convey information, opinions, attitudes and understandings of the subject in an in-depth manner (Maxwell, 2005). The research framework selected was phenomenology.

\section{The Phenomenological Approach Used in this Study}

Phenomenology is a philosophy and a research approach with two major underlying assumptions. Firstly, the assumption that perceptions give us evidence of the world not as it is thought to be, but as it is lived (Richards, 2007). The second assumption is that "human existence is meaningful and of interest in the sense that we are always conscious of something" (Richards. 2007, p 49.). The goal of phenomenology, as stated by Creswell $(2007$, p. 58), is to "seek to understand the meaning of experience of individuals about a phenomenon that all participants have in common". Phenomenological research involves participants who have a direct 'lived' experience of the phenomenon being studied (O'Rourke, 2011).

Whilst there are many styles and schools of phenomenology, Interpretive Phenomenology Analysis (IPA) most closely aligns with the aim of this research. IPA examines how individuals make meaning of their life experiences and how they perceive and talk about objects and events (Pietkiewicz \& Smith, 2014). These personal accounts are typically paired with the researchers own interpretation (Pietkiewicz \& Smith, 2014). An IPA study is a dynamic process as the researcher is seen to take an active role. The participant tries to make sense of their personal and social world and the researcher tries to make sense of the participant trying to make sense of their personal and social world (Smith, 2004). The researcher's role will therefore influence the extent to which they get access to a participant's experience and how they understand the participant's personal world (Pietkiewicz \& Smith, 2014).

Although IPA is influenced by other forms of phenomenological research such as descriptive and interpretive or hermeneutic, it does provide a specific set of guidelines differentiating it from other types of inquiry (O'Rourke, 2011). IPA data collection is typically carried out in the form of a semi-structured interview where the participant has a vested interest in what is being discussed (O'Rourke, 2011; Richards, 2007). Interview transcripts are analysed case by case through a systematic analysis (O'Rourke, 2011; Richards, 2007). These transcripts are then developed into a 
narrative account which is discussed in depth and supported by direct quotes from participants (O'Rourke, 2011). Due to the detailed analysis associated with IPA, it is only possible to use this method on a small sample, many studies have a sample size of 5-10 (Smith, 2004). As this research uses a sample size of 6 , this approach is appropriate.

\section{Limitations of IPA}

Although the IPA guidelines are attractive, their flexibility also raises some questions about whether the level of interpretation reached using IPA is adequate (Smith, 2004). New IPA researchers can be reluctant to be 'too interpretative' so the finished result is more of a cautious account (Smith, 2004). In order to address this potential issue, Smith (2004), recommends that the researcher keeps two points in mind; 1) an awareness of what is required for an analysis to be up to standard for the specific task at hand; 2) always be mindful of the possibility of pushing the analysis further and accepting that this is often just that, a possibility, rather than a requirement.

Additionally, variability exists within IPA because "researchers direct their attention towards different features of the participants' world, on the one hand, and because different features of that world are made salient by participants, on the other hand" (Smith et al., 2009, p. 46). The implications of this variability are that it is not possible to remove the preconceptions and biases a researcher brings into a study when they are reporting on the experiences of the participants (Larkin et al, 2006). Within IPA there are approaches such as 'bracketing' where the researcher's predispositions are disclosed to ensure data is presented as realistically as possible. This will be discussed later in this section when the role of the researcher in the project is outlined.

IPA aligns with this research as the aim of the project is to determine how 6 different participants interpreted (or did not interpret) the information LUCl outputs and why. This theory acknowledges the fact that subject to similar information, individuals may interpret it in an entirely different way based on what they interpreted and how they interpreted it (Scott, 2015). Additionally, the allowance and recognition of the researcher's active role is very relevant as the $\mathrm{LUCl}$ outputs are novel to the participants, some interpretation from the researcher is necessary. The processes IPA 
uses for data collection (open-ended interviews) and analysis (primarily thematic), also align with the aims of this project (Scott, 2015).

Therefore, this research will use an Interpretative Phenomenological Analysis to determine how the 6 research participants interpreted the information provided by the LUCI outputs.

When using the IPA, it is recognised that the researcher will have an active role in the collection and interpretation of the data (O'Rourke, 2011). It is also recognised that to discover meanings in the data, the researcher needs to have an open mind to allow unexpected meanings to emerge (Chan \& Chien, 2013). In order to do this, the method of "bracketing" is used so that the researcher does not influence the participants own understanding of the experience (Chang \& Chien, 2013). Bracketing requires the intentional putting aside of what the researcher believes or already knows about the research prior to and throughout the research (Chang \& Chien, 2013). This allows the researcher to describe participant's experiences and interpretations as accurately as possible without unconsciously bringing assumptions about the topic into the research process (Chang \& Chien, 2013). It is also a way of illustrating the validity of the data collection and analysis (Chang \& Chien, 2013).

\section{Positionality:}

While acknowledging the difficulties of putting aside any prior knowledge or assumptions, I have sought to present the data as close to actual experiences and events as possible. This has been done by using direct quotes from interviews to demonstrate main themes which places the analysis in the words of the participants. Additionally, I have collected numerous forms of data (nutrient budgets, in-depth interviews) and have involved the participants in data checking by getting them to review their interview transcripts for accuracy. Getting the participants to check over the transcripts is a way of improving the trustworthiness of the data as it ensures that the individual experiences were accurately captured (O'Rourke, 2011). I have also shown transparency by describing in detail how the project participants were recruited, including the interview schedule and explaining how the data was analysed. Whilst I developed the LUCI model outputs for each farm, the outputs themselves were only intended to be used to provide insight into the interpretational process. It is 
also likely that the farmers involved in this research were motivated by the offer of an OVERSEER nutrient budget and specific LUCI modelling of their farm as an outcome.

Additionally, it is important to note I have had prior involvement with $\mathrm{LUCl}$ as I used the model in an honours dissertation to compare the model's accuracy to alternate datasets (Rogers, 2016). This honours thesis and current master's thesis is supervised by the lead developer of LUCI. This was beneficial for this research as it meant I had additional skills and experience to use the model and explain it to the research participants. Any influence of supervision from the lead developer of $\mathrm{LUCl}$ was addressed through a collaborative and well-planned out structure of the project and two additional supervisors who did not have a vested interest in $\mathrm{LUCl}$. This project was also funded by Ravensdown and I have recently started full time work with Ravensdown. This position commenced in February 2018 after all the interviews were completed. The farmers were aware that Ravensdown was involved in the project from its commencement as it was outlined the initial letter. It is likely that this added to the credibility of the project in the eyes of the farmer as all participants were Ravensdown customers.

\subsection{Research Design:}

This research used the LUCI framework to present 6 farmers within a catchment a range of visually explicit maps to show the benefits of potential low-cost mitigation measures. Current state and future scenarios (such as nitrogen and phosphorus load and concentrations) were generated and presented for each farm. Current state maps of their farms were presented to check that the information portrayed was credible (farm boundaries, streams etc). Once current state baseline maps were agreed upon, potential future mitigation scenarios (riparian planting, reducing fertiliser use etc.) were shown to demonstrate the benefits and implications of such land use changes. The aim of the mitigation scenario maps was to show the farmers the areas that provided opportunity for low cost mitigation measures to be implemented.

The purpose of this study was to determine how participants interpreted the phenomenon of the LUCI maps and resultant mitigation scenarios. In line with a phenomenological approach it was determined that the best way to collect this data was through semi-structured, one-on-one interviews. These interviews took place at 
the participants' home and a digital voice recorder was used. Researchers using the IPA approach typically develop an interview schedule to prepare, I adopted this approach and a copy of the schedule can be found in Appendix A. This schedule was revised many times between July and September 2017. The same open-ended question and discussion format was used by the researcher during all interviews and a standardized list of prompts was used to capture information for specific questions deemed important. The interview began with questions about the present to engage the participant (i.e. how long have you been farming?), as participants became more comfortable with the process, questions about software tools and farming practices were included to encourage more descriptive answers (O'Rourke, 2011). From prior research it was concluded that interviews of this nature allow for rapport to be easily developed between participant and researcher encouraging the participants to tell their personal accounts freely and in their own way (O'Rourke, 2011).

A qualitative research interview is described by Smith et al. (2009) as an interview with purpose, the purpose of the first interview was to determine the participants knowledge and perceptions of $\mathrm{LUCl}$ and software tools as pro-environmental decisionmaking tools before they had seen the mitigation scenarios. The second and final interview occurred once the mitigation scenarios had been presented to and discussed with each participant. The main purpose of the second interview was to determine any changing perceptions about how user-friendly, accurate and credible they found LUCI tool once they had seen it the outputs. Additionally, this interview aimed to determine if the participants found the information models such as LUCI provide encouraged proenvironmental behaviour.

These interviews were transcribed, and analysis of the resultant data was carried out using a thematic approach focusing on addressing the research questions.

Ethics approval was granted on the 6th of September 2017 (Application ID: 0000025202) by Victoria University's Human Ethics Committee.

\subsection{The Study Site and Participant Selection}

\section{Site Selection}


The Mangatarere catchment was selected for this research due to:

- Data availability

- Access to Greater Wellington Regional Council and Ravensdown information and landowner networks

- Diverse land use

- Proximity to Wellington where the research and researcher were based

The Mangatarere catchment is located in the central Wairarapa Valley as shown in Figure 8 . The catchment is made up of an area of approximately 15,670 ha and nearly half of this is covered in indigenous and exotic forest (Milne et al., 2010).

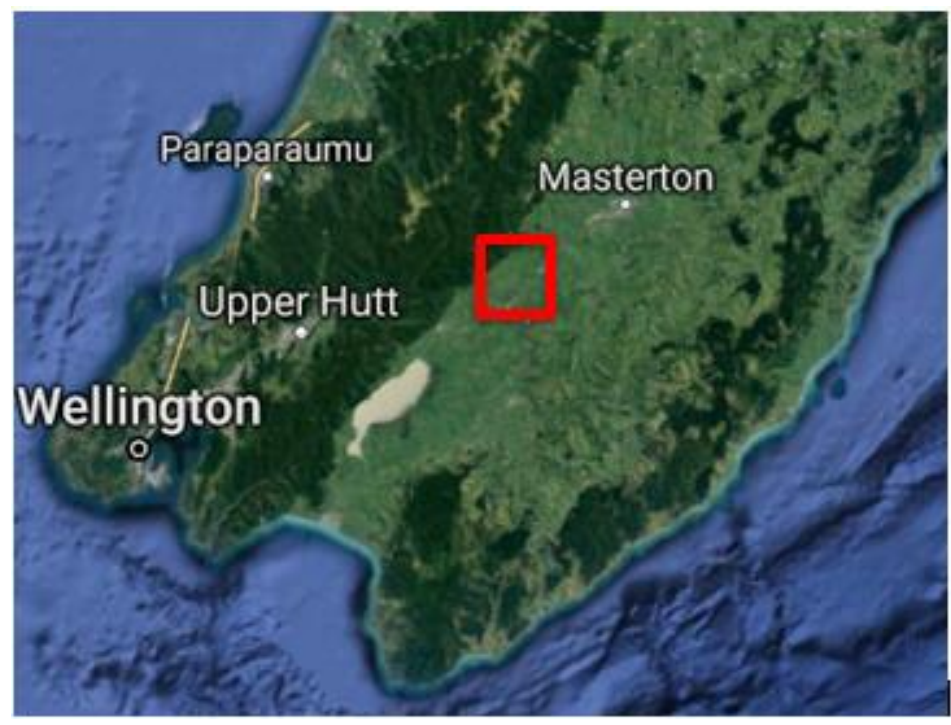

Figure 8: Location of the Mangatarere Catchment.

There has been substantial land use change within the catchment since 1850 including the removal of native vegetation and the modification of water bodies that have shaped the current water quality (Stewart, 2014). The catchment is subject to multiple stressors such as intensive land use, water abstraction and the discharge of treated wastewater from the Carterton Township (Milne et al., 2010). The majority of the alluvial river terraces have been established as pasture and are used extensively for agriculture, especially dairy and dry stock farming (Milne et al., 2010). The Mangatarere catchment encompasses a number of creek and stream systems, the largest of which is the Mangatarere stream. This stream is the main tributary of the Waiohine River and it drains a catchment of $157 \mathrm{~km}^{2}$ (Milne et al., 2010). The stream 
has elevated soluble nutrient concentrations and is recognised in the Greater Wellington Regional Council's Regional Freshwater Plan as needing improvement for aquatic system purposes. The stream provides a habitat for trout spawning as well as four species of threatened native fish.

Table 2: The major land uses within the Mangatarere Catchment (Milne et al., 2010).

\begin{tabular}{|lcc|}
\hline Land use & Area (ha) & $\begin{array}{c}\text { Percentage of catchment } \\
\text { area (\%) }\end{array}$ \\
\hline Indigenous Forest \& Scrub & 6,051 & 39 \\
Forestry & 842 & 5 \\
Drystock & 4,224 & 27 \\
Dairy' & 4,290 & 27 \\
Urban & 263 & 2 \\
Total & $\mathbf{1 5 , 6 7 0}$ & \\
\hline${ }^{1}$ A small portion of dainging land is used for piggery effuent appication. \\
\hline
\end{tabular}

Precipitation levels in the catchment are influenced by the Tararua Ranges which act as a topographic barrier from the predominant westerly winds (Guggenmos, 2010). The mean annual precipitation levels vary from around $900 \mathrm{~mm}$ on the Wairarapa plains near Masterton to up to $3,000 \mathrm{~mm}$ at the top of the catchment located at the foothills of the Taraua Range (Guggenmos, 2010, Milne et al., 2010). The majority of this precipitation falls in the Winter months of June, July, August and October and the driest months tend to be January to April, however summer precipitation is more variable (Guggenmos, 2010, Milne et al., 2010).

The soils in the upper reaches of the catchment are characterised by well drained brown soils throughout the hills, terraces and alluvial plains (Milne et al., 2010). Brown soils transpire in areas where summer dryness is uncommon and areas that are not waterlogged in winter (Hewitt, 1998). The soil types present include Tauherenikau stony silt loam, Opaki brown stony loam and Kohinui loam all of which have a drainage class of 5 signifying well-drained soils (Milne et al., 2010). The surrounding area of the middle reaches of the Mangatarere stream are made up of some poorly drained recent soils such as Ahikouka silt loam and Otukura silt loam, a gley soil (Milne et al., 2010). The lower reaches of the Mangatarere Stream are made up of Greytown silt loam and sandy loam which are classified as well drained recent soils. 


\subsubsection{Participant Selection}

In consultation with Greater Wellington Regional Council and Ravensdown, a group of 26 farmers were identified in the Mangatarere catchment as potential willing and engaging participants in this research. A letter outlining the objectives and logistics of the project was then sent to the 26 farmers with the researchers e-mail and phone number to contact if they were interested in being involved. As a result of this letter, four farmers made contact with the researcher and were confirmed as participants. After this initial response, no further farmers contacted the researcher. A follow up email was then sent to all farmers with only one further participant recruited after an exchange of emails and phone calls. The last farmer was recruited via phone calls using advice from the Greater Wellington Regional Council and Ravensdown as to which specific farmers that remained out of the 26 may be most appropriate candidates for the project.

This selection process targets early adopters. An early adopter is an individual who is often viewed as an opinion leader in the local social system and who is influential in influencing adoption by other members of the system (Batte, 2003). An early adopter is also defined based on the timing of adoption of new ideas (Batte, 2003). Rogers (1983), defines innovators as the earliest $2.5 \%$ of adopting producers and early adopters as the next $13.5 \%$ of adopters (Batte, 2003). As the farmers in this research project are among the earliest adopters of the LUCI model they can be classified as early adopters.

The six participants are not a random sample of the Mangatarere catchment nor are they assumed to be representative, but the information gathered from these participants will be indicative for the larger catchment community (Batte, 2003). This research approach remains valid as should early adopters from within the Mangatarere farming community not find the LUCI tool valuable or credible, it is unlikely that wider members of the farming community will. 


\subsection{Data Collection:}

The data collection for this project was carried out through four field visits to each farm.

Field visit 1: Data collection and presentation of baseline national data set maps

Baseline maps of each farmer's property were presented. These maps were generated using $\mathrm{LUCl}$ and regionally available national data sets of soils, stream network, rainfall, landcover and topography. The maps portrayed total nitrogen and total phosphorus loads and concentrations both in stream and on land. These maps were presented to check that they were an accurate farm representation by looking at the farm boundaries, productivity and waterways.

A Ravensdown environmental consultant accompanied the researcher during this visit to complete an OVERSEER nutrient budget. A nutrient budget accounts for all the nutrients coming onto the farm, calculates where all the nutrients are going and then completes a balance to determine if the inputs are equal to the outputs. It includes information about stock movement, effluent, fertiliser application etc. This step was important as the information gathered from the nutrient budget can be integrated into $\mathrm{LUCl}$, making the tool more accurate and specific at the farm level.

\section{Field visit 2: Baseline interview and presentation of maps including nutrient budget} information

An interview was undertaken at the beginning of this visit to provide a baseline to determine how, or if, participant perceptions of LUCI change throughout the project. This interview included a series of semi-structured, open ended questions about current farming practices and mitigations and knowledge and expectations of software modelling tools.

After the baseline interview, the participants were presented with the same series of maps as the first visit but with the nutrient budget data included. The maps were explained in detail with an indication of where nutrient loads were accumulating and therefore locations where low-cost mitigation measures would be most beneficial. Once again during these visits the accuracy of the boundaries and watersheds was 
checked in preparation for the computation of land use scenarios to present during the next visit.

An example of the contrast between the maps generated for nitrogen and phosphorus accumulated loads using national data sets and then with the addition of nutrient budget data is shown in figure 9 and 10 which show an organic dairy farm on a flat landscape. The maps are coloured according to nutrient levels, high loads and concentrations are shown in red and low loads and concentrations are shown in green. The addition of the farm specific nutrient budget data to the LUCI maps resulted in more spatially targeted nutrient accumulated loads than the national datasets used for the baseline maps. This in turn allowed for more targeted, practical and effective mitigation measures to be explored in the next visit.

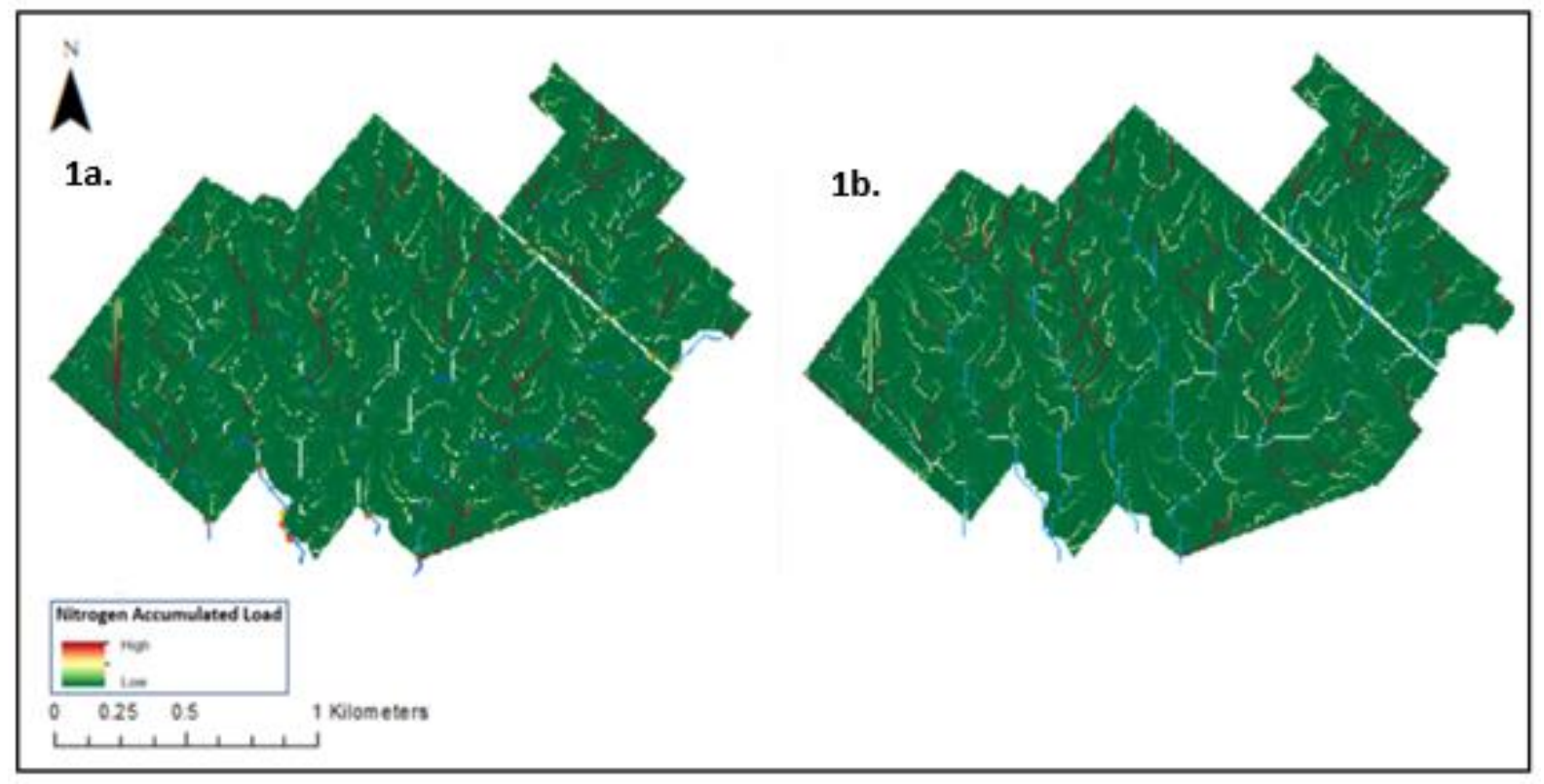

Figure 9: Nitrogen accumulated load maps (1a.), using national datasets (1b.), with nutrient budget data added. 


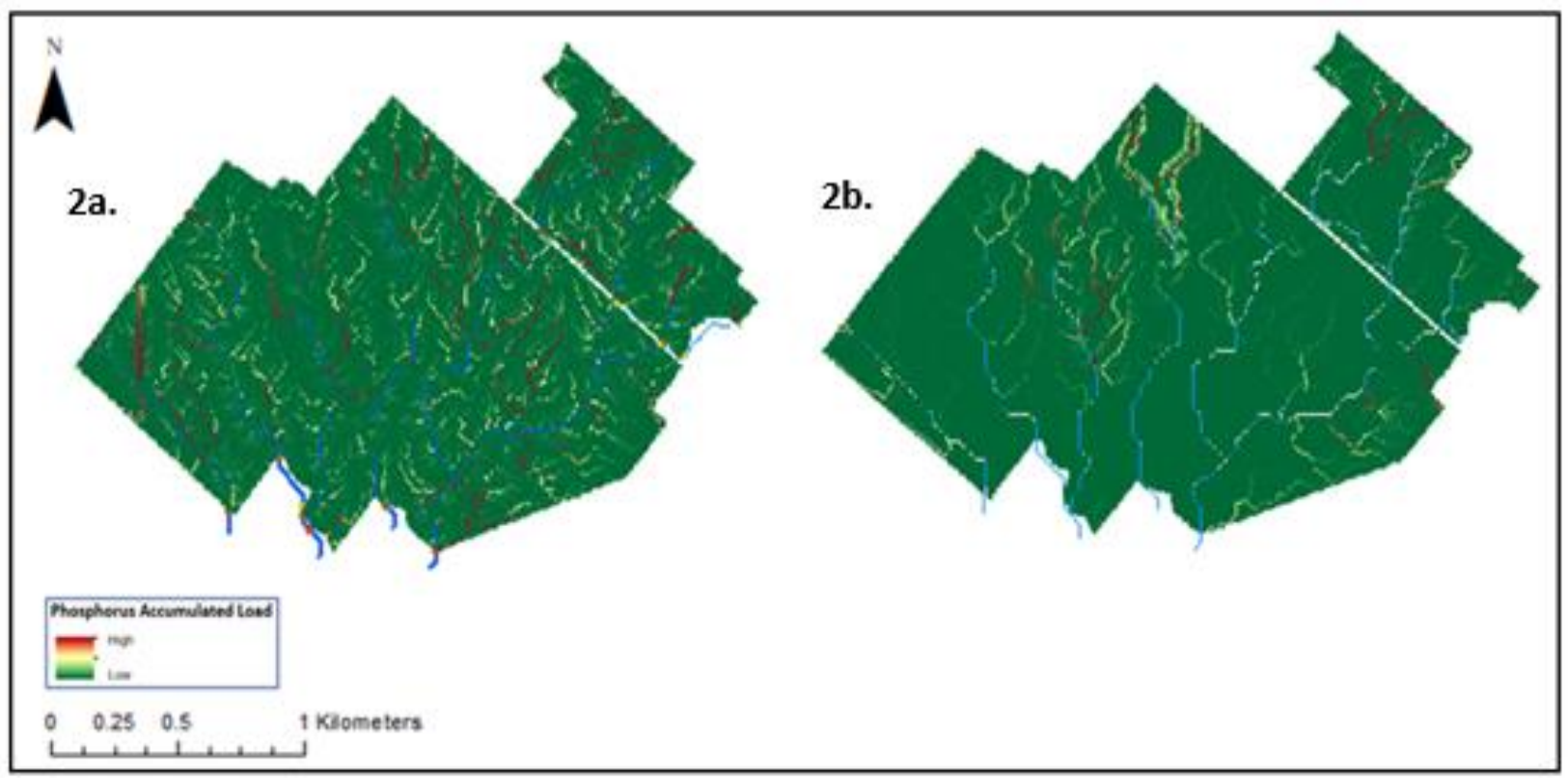

Figure 10: Phosphorus accumulated load maps (2a.), using national datasets (2b.), with nutrient budget data added.

\section{Field visit 3: Presentation of Scenarios}

A range of appropriate on-farm specific mitigation scenarios were presented to demonstrate the benefits and implications of such land use changes. The aim was to show the areas that provided opportunity for low cost mitigation measures that could be explored using LUCl's mitigation scenarios tools. Cost effective nutrient mitigation requires the correct identification and quantification of sources as well as recognition of critical source areas (areas that contribute the majority of water quality contaminants but account for a minority of the area at the field, farm or catchment scale) (McDowell et al., 2016). Therefore the mitigation strategies used target either nutrient sources or hydrological pathways that carry nutrients to water bodies and included riparian planting, reduced and strategic fertiliser application and examples of reduced Olsen $\mathrm{P}$ levels.

As all of the farmers had already invested in some form of mitigations, such as stream fencing and riparian planting, this visit was also used to show the farmer the benefit of any work already done to optimise land use and protect water quality. For example, for farmers that already had riparian planting, LUCI was used to remove the planting to show what their on-farm nutrient loading would look like if they had not carried out the work. Figure 11 illustrates the removal of riparian planting for the phosphorus and nitrogen load for a sheep and beef farm. Figure 12 shows the nitrogen loads (kg/ha/ $/ \mathrm{rr}$ ) and concentrations $(\mathrm{mg} / \mathrm{l} / \mathrm{yr})$ at the two stream exit points on the farm which the 
riparian planting related to. As can be seen in the table in figure 12 the loads and concentrations of nitrogen were lower when riparian planting was present by around $22 \%$. This is because riparian planting intercepts nutrients that are washed down slopes toward stream (NIWA, 2010). When there is no riparian planting in the area around a waterway it becomes prone to stock trampling, erosion, excess nutrients, chemical contaminants and microbial contaminants (NIWA, 2010). The reduction of the loads and concentrations of nitrogen by $22 \%$ with the addition of riparian planting for this farm shows the significant positive impact riparian planting has for nutrient management. The fact that values could be attributed to the benefits of riparian planting for each farmer was very beneficial as it showed the farmer that the work that had completed has made a difference to the on-farm nutrient loads.

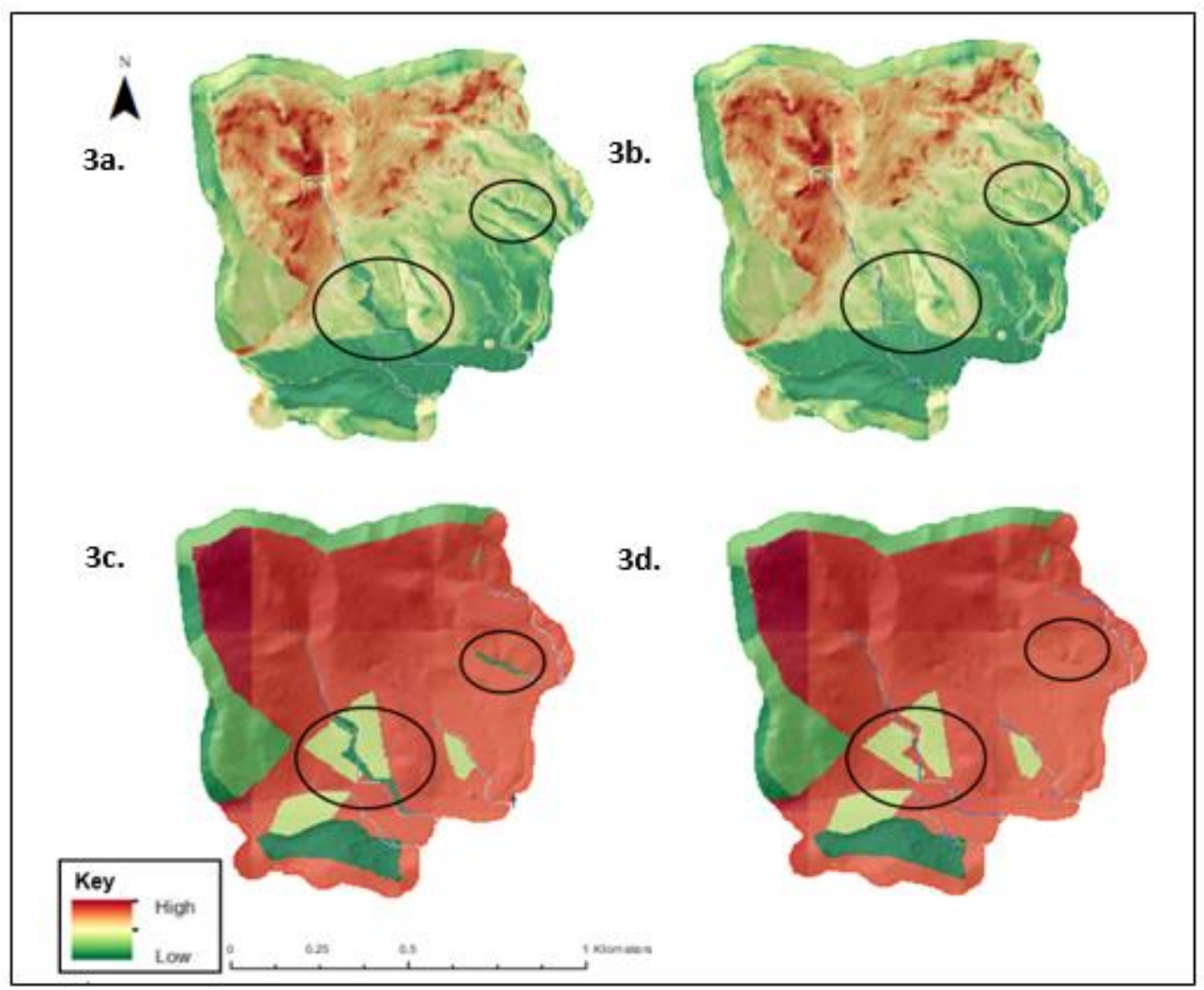

Figure 11: Phosphorus load with riparian planting (3a.), Phosphorus load without riparian planting (3b.), Nitrogen load with riparian planting ( $3 \mathrm{c}$.) and nitrogen load without riparian planting (3d.). The black circles are highlighting the areas with and without riparian planting. 


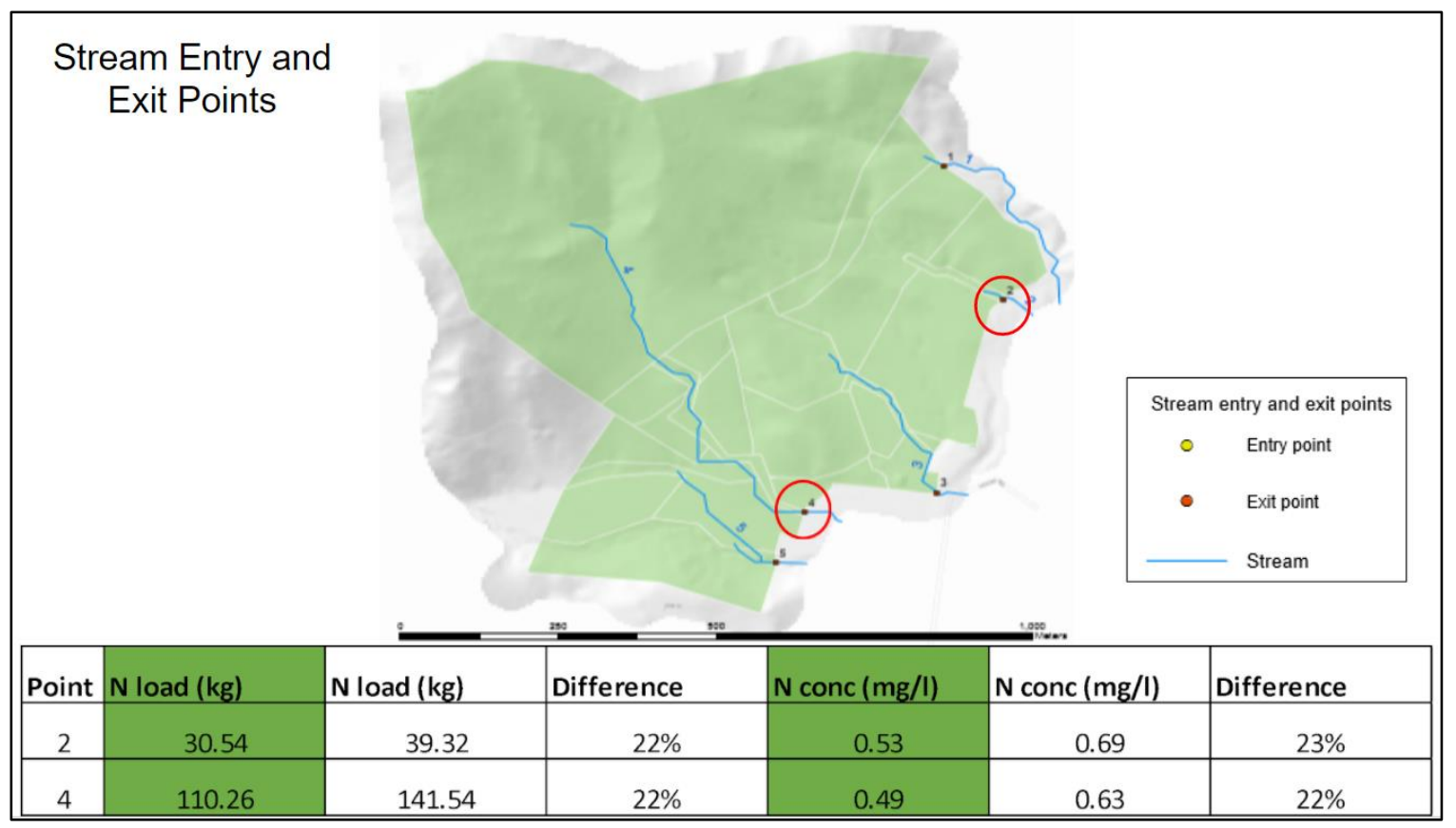

Figure 12: Stream entry and exit points and the differences in nitrogen load and concentration with and without riparian planting.

\section{Field visit 4: Final interview}

In this visit, final interviews were carried out with the research participants to determine how they interpreted the information LUCI provided and if and how any perceptions about the LUCI model had changed from the first interview.

\subsection{Data Analysis}

Data analysis was carried out in several steps and was based on IPA. First all the interviews were transcribed by the researcher, second the transcripts were printed and manually coded. This exercise involved highlighting any points of interest and writing important themes in the margins, this meant the researcher had a good knowledge of the transcripts for the third step of coding the transcripts using NVivo 11. This occurred by coding each participants transcript individually and then analysing them both individually and collectively. The interview transcripts were coded to understand themes, sub-themes and patterns emerging across the research. These packages of text were initially analysed against the interview questions, to ascertain what the participants thought. A deeper analysis was then undertaken to understand why participants responded as they did and what other factors influenced participant interpretation of the LUCl outputs. Examples of what themes were focused on include 
finance, the role of information as a tool, mitigation measures and opinions on software tools.

All transcripts were also provided to participants and they were given four weeks to advise of any changes or inaccuracies within the material. 


\section{Results \\ 4.1 Introduction}

This chapter provides the results of the baseline and final interview carried out for this research project. The transcripts were coded against the interview questions to understand the participant responses to the questions and any emerging patterns, similarities, and contradictions. A deeper analysis was then carried out by identifying and coding any prevalent themes and sub-themes to determine any other important topics that arose in the transcripts. Although 5 participants were male and 1 was female, to retain anonymity the pronoun he/his will be used throughout. Additionally, all 6 participants participated in the first interview but due to time restrictions only 5 completed the final interview.

\subsection{Participant experience and feedback on $\mathrm{LUCl}$ and the research process}

This section will address participant experience of the LUCI modelling process through the following four different sections through analysis of responses to interviews questions.

1) Their understanding/interpretation of the LUCI model including how userfriendly accurate and credible they found the tool

2) What value (if any) the modelling exercise had for the participant and the wider farming community

3) Any changing perceptions of the $\mathrm{LUCl}$ tool over the research process

4) Any feedback and recommendations for future development of the LUCI model and the research process

\subsubsection{User-friendliness, accuracy and credibility}

In the final interview, all the participants were asked:

'What did you think of the maps and scenarios? And how well do you think they portrayed on farm information?' 
The following type of maps were provided to the participants. While these are indicative examples, they provide context for the participant responses.

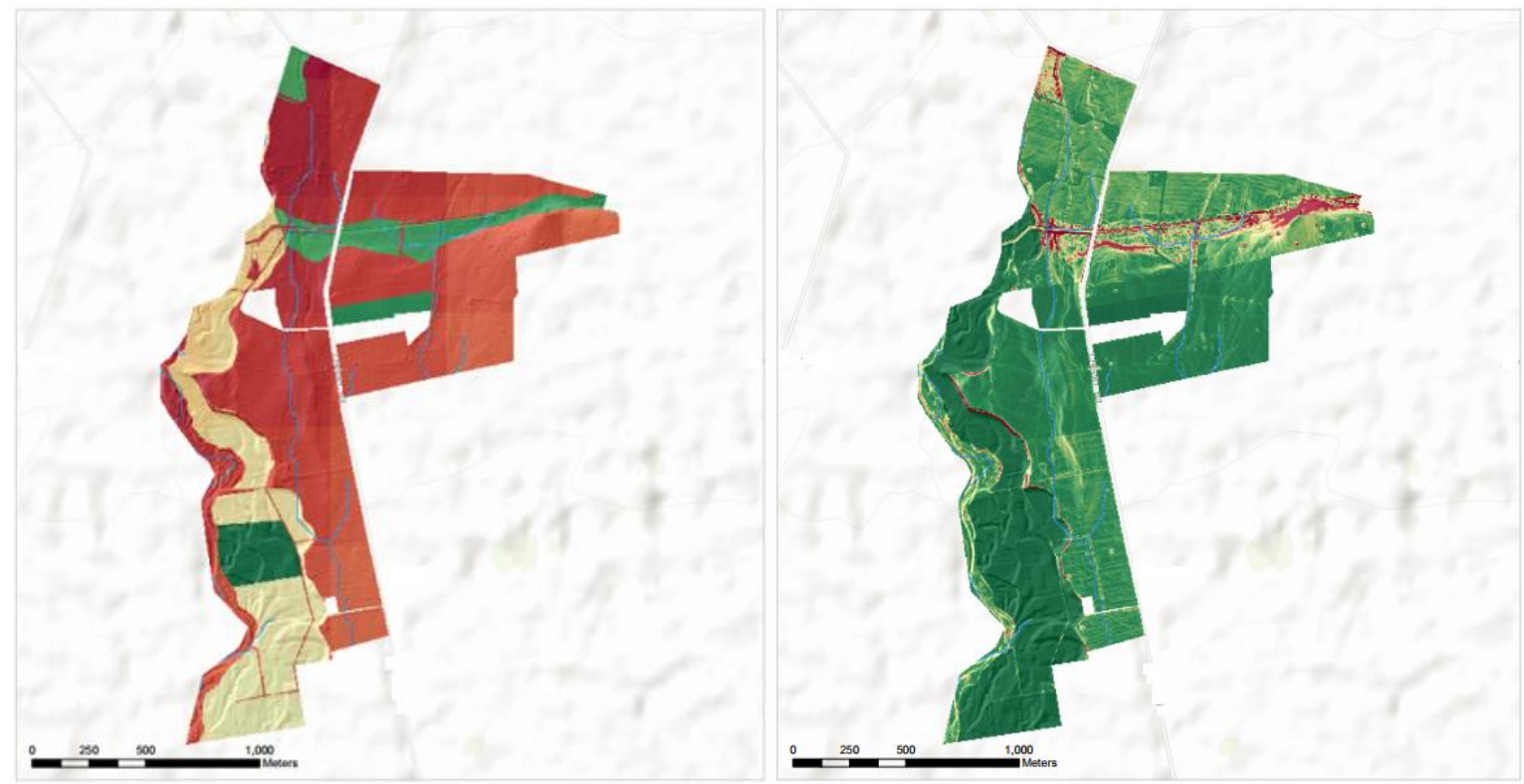

Figure 13: Nitrogen and phosphorus load maps (High (red) and low (green) nutrient levels).
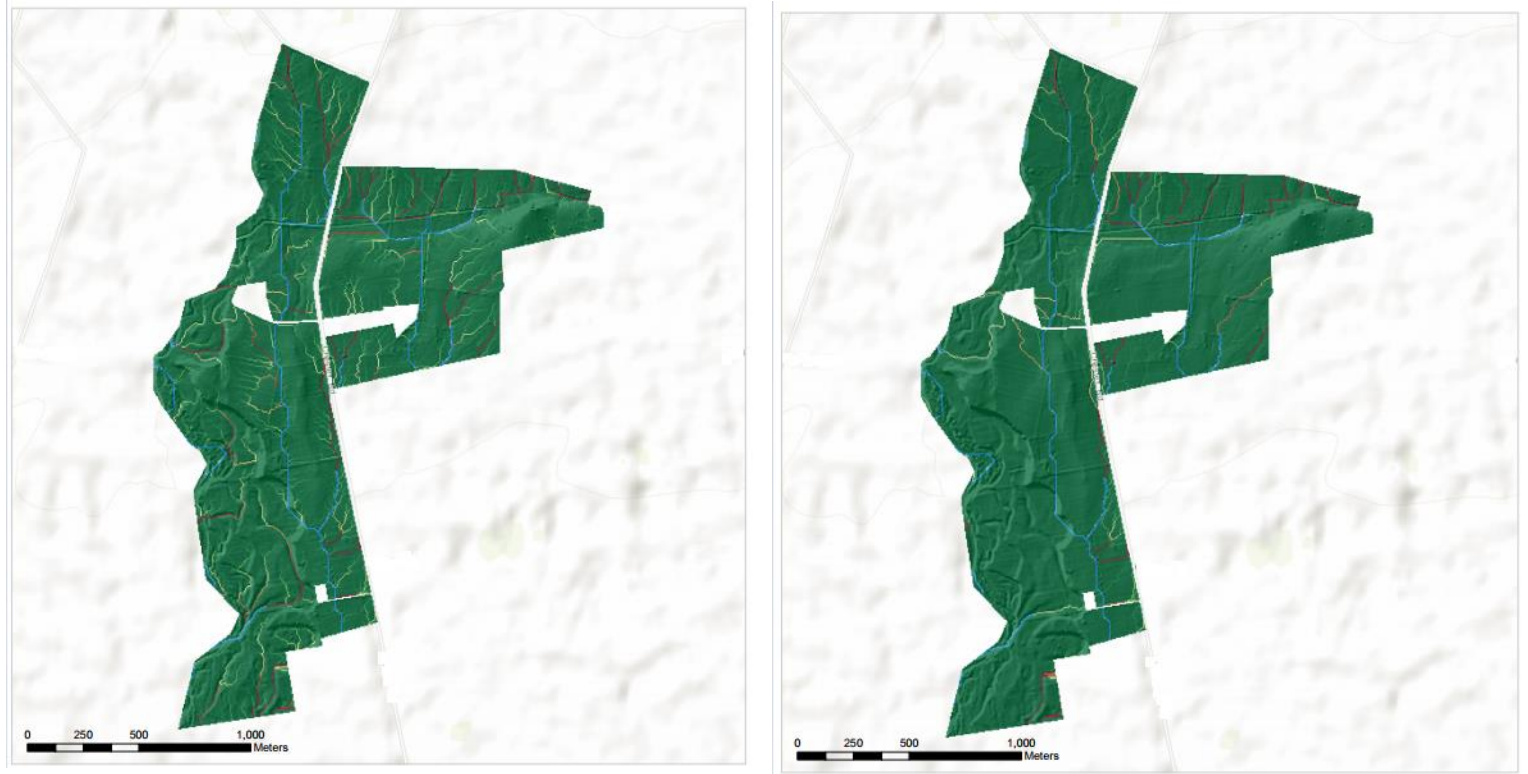

Figure 14: Nitrogen (left) and phosphorus (right) accumulated load maps.

The images of nitrogen and phosphorus load show LUCl's predictions of the total amount of $\mathrm{N}$ and $\mathrm{P}$ exiting from any point in the landscape through surface or subsurface processes. The green areas show a low nutrient load and the red areas show where particularly high loads can be found and are therefore priority target 
areas for potential mitigation. Not all the nutrients lost from individual points in the landscape exit the farm. LUCI tracks their progress through the landscape via dissolved and particulate pathways, and accounts for interception, retention and loss processes that may prevent the nutrients ending up in waterways

The images of accumulated $\mathrm{N}$ and $\mathrm{P}$ load show where water and nutrients converge in the landscape, the red areas show where high loads can be intercepted and are therefore targets for mitigation.

Four out of the 5 participants responded to this question positively saying that $\mathrm{LUCI}$ appeared to have portrayed on farm information well and with plenty of detail.

Participant 4 stated that:

I think they were good. I think they were nice and clear, yup...happy with them. Participant 6 supported this statement with his response that:

They're pretty good actually, because I do know quite a fair bit about where the flow [of water] was and that, and that did seem to follow the same as what I've already been advised from elsewhere.

As the participants had a good knowledge of their own farm systems, they related to the information LUCl portrayed as it was in the form of a map of their farm. Each farm was different due to changes in aspects, such as slope, soil and location so this was a positive outcome. It showed that the maps and scenarios were perceived as portraying on-farm information well for a range of farms. Additionally, the outputs were viewed by an assortment of participants showing that the information made sense to a range of people.

In contrast to the other 4 positive responses to this question, participant 5 found it a challenge to understand the information immediately or in detail, in part to being overwhelmed by the large volume of information portrayed and the number of maps shown.

I found them a wee bit challenging at first to understand but I think the more I got to look at them, like throughout the process it became a bit easier. There was a lot of mapping that can kind of confuse you a wee bit so I think like if there was probably less mapping just showing the important parts that might 
have been a bit easier to, yeah, take it all on board.

This shows that the portrayal of information was not as user-friendly as it could be due to the challenge for participant 5 to understand it. However, due to the complex nature and volume of the information provided to the participants, some difficulties may be expected. Although this farmer was the only one to highlight this challenge in response to this question, other participants also mentioned the issue of comprehending all the information presented. This is an important finding of this research that will be explored further later in this section along with potential solutions, such as reducing the amount of information presented or highlighting important points.

To gauge the perceived accuracy and credibility of the LUCI outputs the participants were asked:

Did the maps and scenarios LUCl created appear to be accurate and credible? If so/not, in what way?

Participants 1,3 and 6 found the maps to be accurate and credible immediately, whereas for participant 2, 4 and 5 there was a process of ground truthing and refinement to ensure the $\mathrm{LUCl}$ maps portrayed the farm accurately by the final farm visit when potential mitigation scenarios were presented.

The positive perception of accuracy and credibility of the LUCI outputs can be seen through the following comment made by participant 3 :

Pretty precise and that, and they certainly picked up where there is dips and hollows and you know, it was pretty obvious. It's down to the specific paddocks and that so it was pretty good, pretty accurate.

Additionally, participant 1 commented:

There were bits, like last time we were looking at where those drains were...the drain goes across the corner and there is all this long rank grass there because the cows don't go over it, so why don't we just fence that corner off and plant it. Yeah, we will just throw a few willows or something along the stream.

During this discussion, participant 1 pointed out an area where water flow (and therefore nutrients) were accumulating as shown by $\mathrm{LUCl}$, this was an area identified 
by the farmer as a 'wasteland'. As the participant had identified this area before the project, LUCI identified something he was already aware of. This result adds to the accuracy and credibility of the model as it lined up with the farmers knowledge of his farm that he gained from practical on-farm experience. Because of what LUCI showed, this participant decided that it would be worth fencing off the area, as LUCI identified it as where nutrients accumulate and due to the farmers practical experience the area is of no use to him as productive land.

In contrast to these responses, participant 5 responded to this question saying:

I think so. Yeah, they did. I think as I said before it takes a wee bit to understand them, but when you do look at them and look at them in probably a bit more detail it makes sense. And once we took out that forestry bit, you know, it kind of made sense. So, I guess it's just understanding, making sure you understand your property. 


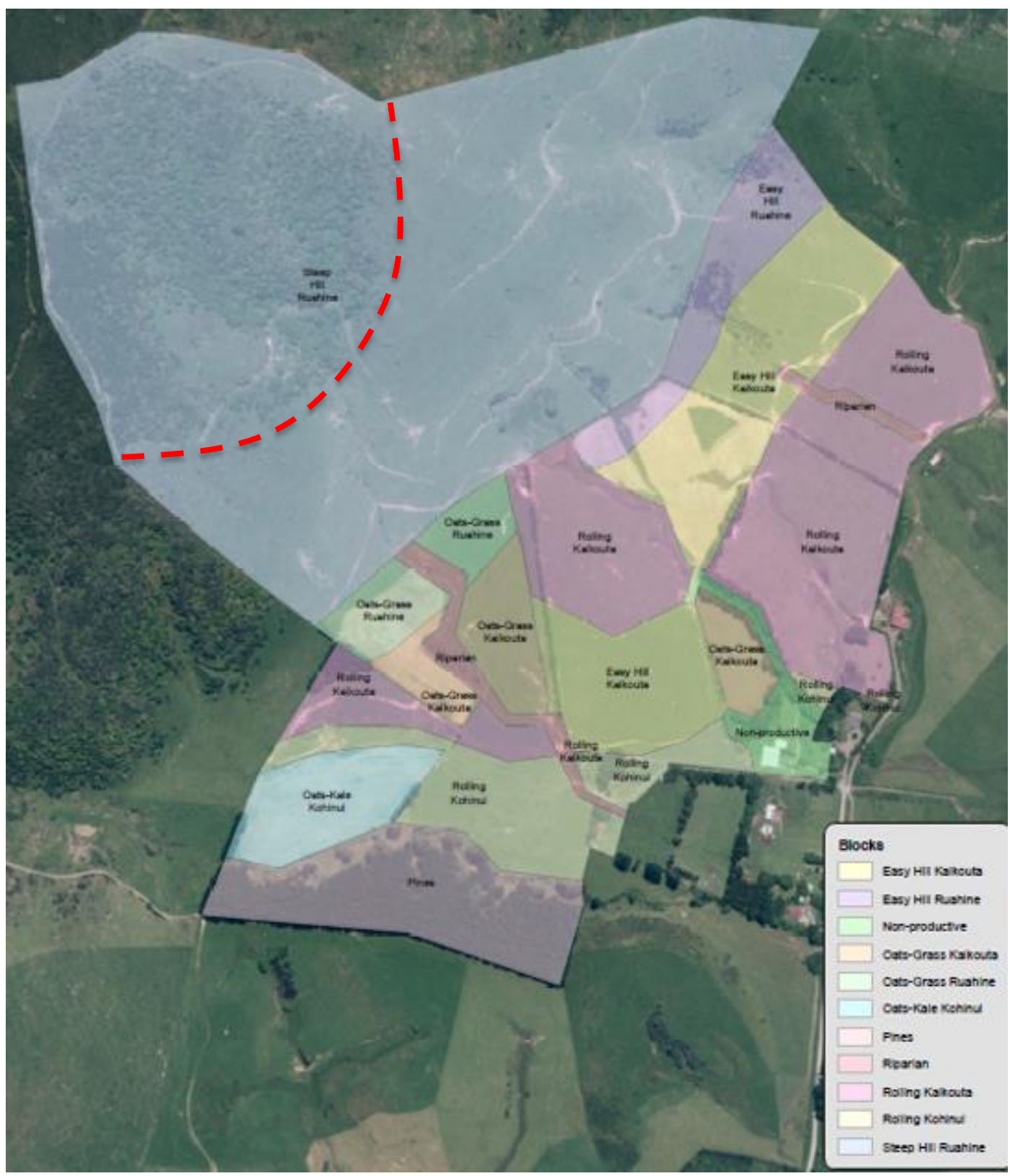

Figure 15: The original blocking of participant 5's farm. As can be seen the area 'steep hill ruahine' was all blocked as one area where as this block should have been split within LUCI to include the area of forest and scrub (dashed red line). 


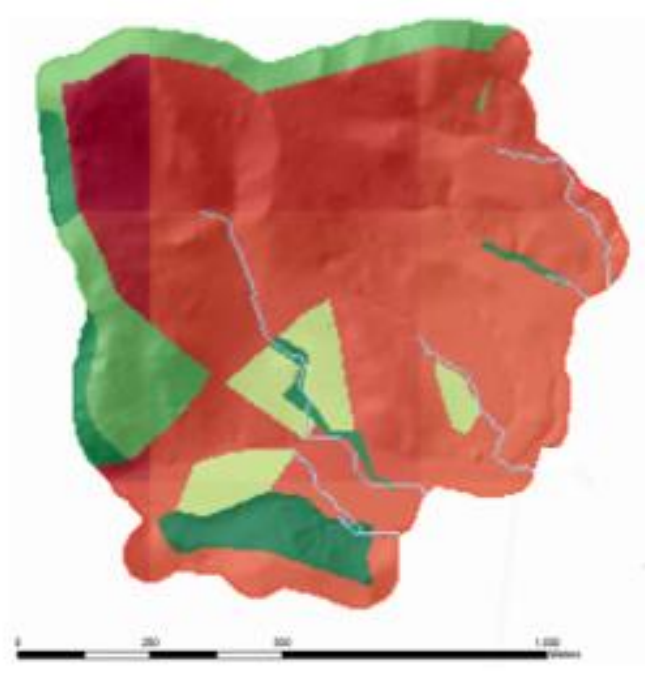

Nitrogen load

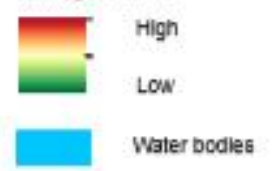

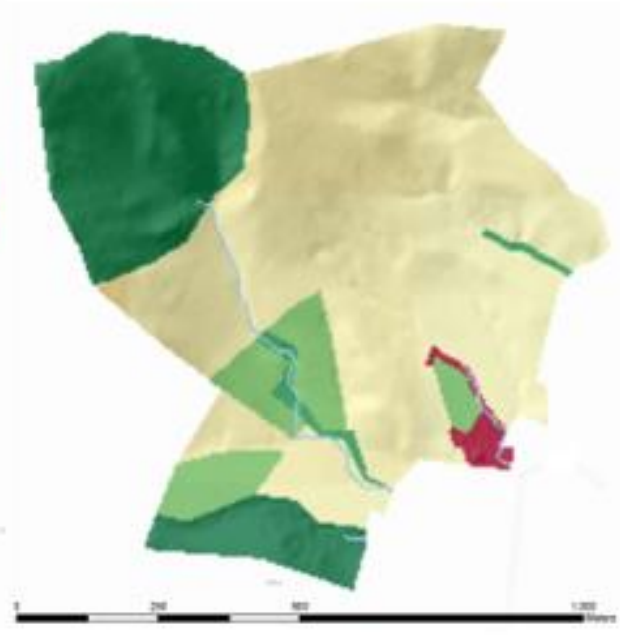

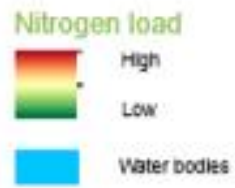

Figure 16: The left side shows the original nitrogen load map of the farm and the right side shows the nitrogen loading once the forestry had been added. Note: As the maps were made at various times (the right side at a later date) and the LUCI model was under development during this project the visual nature of the outputs varies slightly.

This comment reiterates participant 5's view that the maps were challenging to understand at first. This specific comment refers to the LUCI maps of his property where there was an area originally mapped as a pastoral area, but it should have been trees and scrub. This result meant that the area, outlined in figure 15 by the red dotted line, was treated the same by LUCI making it an area of high nutrient loading. This treatment did not make sense to participant 5 as it was steep land covered in trees that was not grazed. Once the area was re-blocked to include the area of trees the loading changed as seen in figure 16. This example shows the importance of ground truthing the maps with participants. This discrepancy was identified as participant 5 had a good knowledge of his own farm allowing for more accurate and credible LUCI outputs. Participant 5's answer also shows that the repetitive nature of the modelling process was beneficial to his understanding of the maps and scenarios. Therefore, despite the initial challenge, and with the appropriate changes, he eventually found that the maps and scenarios appeared to be accurate and credible.

Participant 2's maps contained an error in the farm outline as the DEM did not extend 
to the whole farm. This mapping error (rather than a LUCl error) was easily resolved.

Participant 4 had initial questions about the nutrient loading maps LUCI produced:

The thing that I mostly remembered was wondering whether, so we've got that peat seam that goes through, and whether that was low in phosphorus or whether it wasn't, it was something like that.

This participant thought that the result of the level of nutrient loading shown in the peat seam was unexpected. It was explained the loading of nutrients is also dependent on the inputs (fertilizer, effluent etc.) so for this situation these factors that were influencing the comparative loads. The areas showing high phosphorus loads in this case were the areas that were receiving a high quantity of phosphorus in the piggery effluent that was being spread to these areas. Additionally, the area highlighted was a poorly drained soil with an ASC of $38 \%$. Poorly drained soils are more subjective to overland flow and therefore phosphate and sediment loss. The ASC measures the ability of the soil to store phosphate and sulphate, the ASC of this soil was classed as medium which means the soil has a medium sorption capacity (Hill Laboratories). Going through this explanation process was beneficial to both the participant and the lead researcher as it led to a deeper understanding of the LUCI outputs for both the researcher and the participant.

Overall, the participants found the found the LUCI outputs to be accurate and credible although for 3 of the participants some adjustments and further explanation were required before this stage was reached.

\subsection{2: Perceived value of the $\mathrm{LUCl}$ tool}

The following question was asked to gauge the participants perceived value of the LUCI modelling exercise:

What value, if any, will this modelling exercise add to your farm in the future?

The responses to this question were varied. Participant 1,4 and 5 could see immediate value whereas participant 3 didn't think it would have a lot of value as he had already carried out numerous mitigation measures and participant 6 did not think it would have value for his farm as it had no waterways. This can be seen by the response of 
participant 6 who owns three farms and had one of these farms modelled:

Probably not much to this one, but certainly to the other two.

This participant had no streams running through his property so did not see a huge value in the model for this particular farm, however as he has streams and irrigates at his other two properties he was interested in seeing the LUCl outputs for these farms. Although he did not see a huge value for that specific property included in this study, he could see how the information could be used for alternative situations.

Participant 3 did not see much personal value in applying $\mathrm{LUCl}$ as he felt they were already doing everything they could think of to run their farm sustainably.

We're pretty set up in our system. We're not adverse to change or if it's a good idea and it's going to be beneficial for the whole system... but I don't think I really saw anything that jumped out at me, because we're changing over to organics I think we're probably ahead of doing anything anyway, and you know, we're changing our pasture species and we're not using urea and it's a bit lower stocking rate, and we're doing once a day milking so we're already doing a lot if the stuff that would be in the list of things to do if we were starting from scratch, we've fenced all drains and waterways and that off and planted them.

The model did not provide suitable options that would encourage him to change his farm system. As this project was voluntary the participants were unlikely to be unaware of environmental issues and more likely to be employing more sustainable practices. All the farmers involved in this project had considered their environmental impact and carried out at least some mitigation measures. For example, all waterways were fenced on each farm.

This participant mentioned the value of the model in showing the impacts of existing mitigation measures.

You can show the value of what we have done which is quite good and you know if you're trying to go catchment wide or get more buy in from landowners, you can put up quite a good [argument] with good numbers behind it, rather than saying you should be able to achieve this, and achieve that and that...and you can put costs around it too. 
It is important to quantitatively show the value of an action and farmers are much more likely to take information on board or carry out an action if they can see a tangible result. $\mathrm{LUCl}$ is a beneficial as it is able to quantify loads, concentrations and values of nutrients entering and exiting farms which can help farm and catchment managers to explore and quantify spatially explicit solutions to improve water quality (Trodahl et al., 2017).

In contrast, participant 5 identified LUCl outputs as of immediate value for his farm.

I think [LUCI] will make it an environmentally safe and attractive property. You know for us it makes us sustainable. And when we do go to, you know if we sell it in the future it's set up for someone else, they don't have to spend time and money making it environmentally friendly, so I think it will be an attractive property down the track. And so that's the advantage we see out of it.

As the purpose of using $\mathrm{LUCl}$ is to show mitigation measures that would improve environmental sustainability, this is positive feedback.

The participants were also asked "Do you think the information LUCI has provided will be useful to other in your catchment/the farming community?".

All participants thought that LUCI would have value for the wider farming community. Participants 1 and 3 both thought that the tool would be beneficial in identifying hotspots to be targeted to make the biggest difference.

Yeah, because everyone is going to have to do it eventually. Maybe if they could do that and see the worst areas and do that first and keep, you know because it's so expensive to do a whole farm, maybe they could think, right, well we'll do that worst area and that keeps people happy for a while and then they can do the next bit and the next bit from there... Rather than you know l'll do that bit but it's actually not the worst bit. So, make the big difference first maybe.

Participant 1 highlighted the potential of the model to help make financial decisions. Participant 4 identified the need to use the information in a way that avoids conflict.

I think that entry and exit points could be really good to help people to avoid conflict because that just seems to happen, boundaries can be quite a challenge when we're working with people of whose is what and where things have come 
from. And that has definitely been a conversation in the farming community of understanding the water comes from somewhere and then it goes to somewhere and the difference that we make in the middle doesn't stay with us. Hopefully it can be used well to avoid conflict and strife.

As LUCI can calculate the loads and concentrations of nutrients that enter and exit at the farm scale, it is easily imaginable that if farms upstream of their counterparts are discharging large concentrations of nutrients conflict could arise. It is typical for farms to border each other and with waterways, what happens upstream influences downstream locations. As farming may be more regulated in the future, monitoring nutrient discharges will be important. To ensure that blame is not passed or that conflict does not arise, this information needs to be presented in a way that is able to bring about change that is beneficial for the environment as meaningful impacts are likely to only be possible at the catchment scale.

\subsection{3: Any changing perceptions of the $\mathrm{LUCl}$ tool over the research process}

In order to determine if participant knowledge changed between interview 1 and 2, all participants were asked about their knowledge of $\mathrm{LUCl}$ during the first baseline interview before they had seen the $\mathrm{LUCl}$ scenario maps and then "how much do you now know about LUCI" in the second interview once all the maps and scenarios had been shown and explained. Participants were asked to rate their knowledge from 1-5, a response of 1 represented knowing very little and 5 meant knowing a lot. The responses of are outlined in table 3 below. This table shows that during the first interview all participants felt they knew very little about LUCI apart from participant 1 who gave a 3 which would indicate he felt as though he had a reasonable knowledge of the model.

\begin{tabular}{|l|l|l|}
\hline Participant & Interview 1 & Interview 2 \\
\hline 1 & 3 & 3 \\
\hline 2 & $1-2$ & N/A \\
\hline 3 & 2 & 4 \\
\hline 4 & 1 & 4 \\
\hline 5 & 1 & 5 \\
\hline
\end{tabular}


Table 3: Change in participant knowledge of LUCI between interviews.

As can be seen from this table all the participants (excluding participant 1) believed their knowledge of LUCl increased between the first and second interview. This was to be expected due to the structure of the research process. However, if the information was not portrayed or explained appropriately then this knowledge may not have increased, so this showed the strength of the project structure. Additionally, these participants responded with either a 4 or 5 in the second interview which indicates that they felt their knowledge had increased to a level where they knew a lot about the LUCI model. Participant 1 is an outlier in this scenario as he felt that he had a reasonable knowledge of $\mathrm{LUCl}$ during the first interview and this number did not change for the second interview, the explanation behind this is unknown as it was not questioned. It is possible he did not feel his knowledge increased or that he was not aware of his original answer.

The participants were also asked to rank from 1-5 how useful they thought models such as $\mathrm{LUCl}$ are. Table 4 shows a range of perceptions between the participants. Participants 2, 3, 4 and 5 all thought that models such as LUCl are highly useful, as shown by their response of 4 or 5 , and this view did not change over the period of the project (as participant 2 was unable to participate in the second interview due to time restrictions it cannot be determined if his perception changed). Two participants provided lower numbers.

\begin{tabular}{|l|l|l|}
\hline Participant & Interview 1 & Interview 2 \\
\hline 1 & 3 & 4 \\
\hline 3 & 4 & 4 \\
\hline 2 & 5 & N/A \\
\hline 4 & 4 & 4 \\
\hline
\end{tabular}




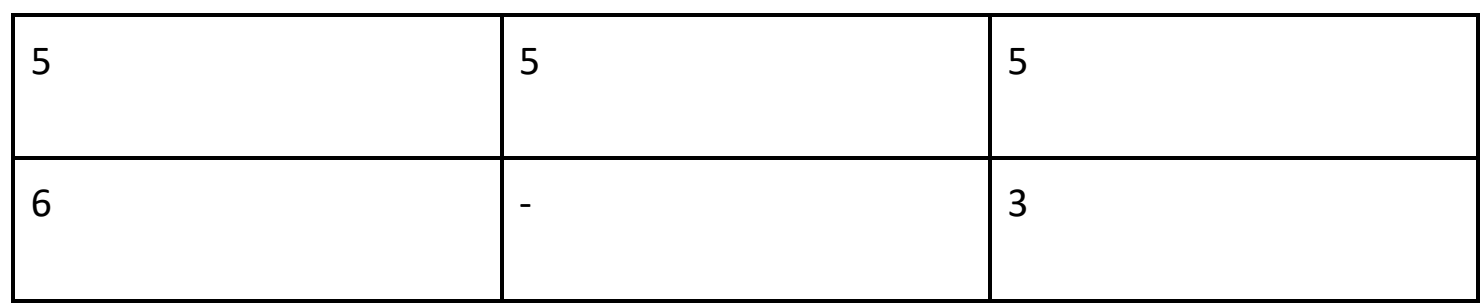

Table 4: Change in participant perception of the usefulness of models such as $\mathrm{LUCl}$ between interviews.

Participant 6 did not give a number answer for interview 1 and justified his response of 3 to the second question by saying

Probably a 3, or just that probably means still more work I think. And how many models do we need?

Later in the interview the participant also said:

So, I think it's a good model...it's a gap Overseer doesn't fill. The only thing that worries me is that there's too many different things, and it's a bit of information overload for a lot of people... I think it [LUCI] definitely has a place, because the more information we have, in general, the better. But, on the other hand, I'm probably not the dumbest one, but are we going to swamp people with too much information where they do nothing?

This comment shows the danger of saturating this space with numerous models that do similar things that are either slightly different or presented in a different way. Water quality is a topic that is currently of high public importance and increased science knowledge is needed to help further our understanding of this topic. However, if farmers and stakeholders are constantly being exposed to various sources of information that are all slightly different, it is likely to be overwhelming and counterproductive for its purposes. This highlights the importance of prioritising and displaying critical information in an easy to understand form. Additionally, even though models are based on real systems they are representations of real life scenarios, this means that the information they present isn't always comparable and interchangeable due to different assumptions underlying models. This is a factor that should be considered when carrying out research. As this project found that these participants had not seen a models or information presented in the same manner as $\mathrm{LUCl}$, these participants were not overwhelmed in the sense that they had already received similar 
information from other sources. Where these participants source their information from and what tools and models are used will be discussed further later in this section. Overall this discussion shows that all participants thought that models such as $L U C I$ had the potential to be very useful apart from participant 6 who thought it needed more work and that there were already enough models available in a similar space. He did not justify why he believed LUCI needed more work however, he did still think LUCI was reasonably useful.

\subsection{4: Feedback on the model}

To gain feedback on the LUCI model and the process of the research process the following questions were asked:

Do you have any feedback on how to improve the modelling process?

Participants 1, 3, 5 and 6 all thought that the information could be summarized so that the amount of information presented is reduced to prevent overwhelming the participant, this can be seen by the response of participant 5 who said:

No, probably as I mentioned earlier on just the mapping trying to make, maybe that a lot clearer to the customer. Yeah, easy, because I guess you know there's a lot of farmers that maybe don't read maps much, so I guess there needs to be pretty...pretty clear as to what's happening and probably only a couple maps not 5 or 6 or 7 otherwise they will get very flustered.

Participant 1 also commented that the number of maps presented could be reduced.

Say there was one map with different colours, so you're looking at one map thinking right there's the potassium, nitrogen...

This resonated with the lead researcher as it was difficult to explain each map in depth in a clear and concise manner whilst making all of the information relevant and relatable. For this project, there were 11 maps for both nitrogen and phosphorus which showed load, accumulated load, accumulated load (classified), accumulated concentration, Ln accumulated concentration, accumulated concentration (classified), concentration in water, location of stream entry and exit points, stream watersheds, stream entry and exit point values (load, concentration and flow) and values of stream 
averages (load, concentration and flow). These maps in conjunction with the different potential mitigation scenario maps made for a lot of information to present and for the farmer to take on board. Reducing or summarizing this information would be beneficial for future projects, additional information could still be provided if the farmers were interested. It is recommended that the maps that are presented show load, accumulated load, the stream entry and exit points and their values.

Another point raised by participants $1,3,5$ and 6 was an appreciation for the visual nature of the maps.

But like the visual thing is really good rather than reading your potassium levels are blah blah blah, actually just looking and thinking right! It's much better.

- Participant 1.

And as participant 5 also said:

People you know like pictures and like to see their farm.

How information is presented is important and it was encouraging to find that the visual nature of the maps was beneficial and relatable in comparison to an explanation using just words. It was also pleasing that as the farmers had a good knowledge of their own farm systems and their layout, they reasonably easily related it Colour blindness is an important aspect that should be considered when presenting visual information and one participant mentioned he was colourblind. LUCI uses a traffic light system where green areas show a low nutrient load and the red areas show where particularly high loads can be found. A 2013 paper by Jackson et al. that introduces the LUCI model in its early stages, points out the necessity of accounting for colour blindness. This paper notes that the colour scheme of $\mathrm{LUCl}$ can be altered if required and that the output is restricted to a range of 5 colours to facilitate visualization and negotiation (Jackson et al., 2013). This shows that the LUCI modelers have considered this aspect. To be mindful of colour blindness when carrying out research such as this project the issue of colour should be covered during initial meetings. It was not known that this participant was colour blind until the final meeting, so attention could have been paid to the differences in colours during explanation of the maps if this was originally known to the lead researcher. 
Participants 3 and 4 also mentioned that having numerical values on the loads and concentrations of nutrients was good. Figures were also given to show what differences certain mitigations could make to loads and concentrations which participant 4 specifically highlighted as being helpful. However, participant 3 pointed out a relevance needs to be associated with these values. For example, showing the nitrogen load of a farm does not tell a farmer much if it is unknown the relativity of this number. This was also brought up in other conversations with farmers but as mentioned earlier, the Greater Wellington region does not have set limits and controls on nutrients yet, so it was difficult to provide a guide of what is "high" or "low" as this is currently unknown.

\section{3: Knowledge of OVERSEER}

It was found that the knowledge and/or use of OVERSEER was a lot lower than the lead researcher initially expected, with most farmers saying they never use it and have a limited understanding of the tool.

Table 5 shows the response of all participants to the question: "On a scale on 1-5 how much do you know about OVERSEER?". One represents knowing very little, and 5 a lot. Participant responses show that at least 4 out of the 6 farmers felt that they knew very little or close to very little by giving a response of 1 or 2 . Only 2 of the farmers felt that they knew a reasonable amount.

Table 5: Participant knowledge of OVERSEER.

\begin{tabular}{|l|l|}
\hline Participant & Knowledge of OVERSEER (1-5) \\
\hline 1 & 1 \\
\hline 2 & 2 \\
\hline 3 & 3 or 4 \\
\hline 4 & 2 \\
\hline
\end{tabular}




\begin{tabular}{|l|l|}
\hline 5 & 1 \\
\hline 6 & 3 \\
\hline
\end{tabular}

This is further shown by participant 4's response to the question:

So, you wouldn't use OVERSEER or anything like that?

No, we did fiddle around with it a long time ago

\section{What did you think of it?}

We thought we could, same as numbers, same as doing financial, like same as doing a budget, you can make it say anything you want.

This is also shown by participant 6 's response to the question:

\section{So, I'm getting the idea that OVERSEER isn't used that widely?}

No, not by the farmers, it's used a lot by the advisors but not the farmers themselves. I had a bit of a tinker with it. I put it on the computer but it's one of those things that takes time to use and that sort of thing. And it is yeah unless you're using it quite frequently it is quite a complicated bit of software. Yeah you can end up with the wrong result if you play with it incorrectly. So, I can see why its advisors that are using it most.

This is potentially a region-specific outcome due to the nature of the implementation of the National Policy Statement for Freshwater (NPS-FM). Regional councils are required to implement the NPS-FM as promptly as is reasonable, and no later than 2030 (McDowell et al., 2017). Greater Wellington Regional Council's progressive implementation programme is to be completed by 2025 through Whaitua Committees which are advisory bodies established by the Regional Council (Greater Wellington Regional Council., 2017). This means that although consultation is well underway, no specific statutory regulations have been set for the region. Consequently, for the Greater Wellington region, farmers do not need to be as aware of OVERSEER. The lead researcher expects this result to differ in other regions such as Canterbury where a nitrogen baseline is modelled using OVERSEER which is necessary for resource 
consenting purposes (DairyNZ).

Additionally, the participants stated a mistrust of the use of OVERSEER as shown by participant 6's comment:

[Overseer] has become this big, big monster, and I'm not totally negative about it, but I think it's being utilized for the wrong things. It should be just a modelling tool, they're now trying to make it a restricting tool, and actually, I don't think it works very well from that point of view.

This reflects the fact that in general, use of OVERSEER in regulations is controversial due to the model's inaccuracy of between $20-30 \%$ in predicting nutrient losses, variability in how data is interpreted for use in the model, the tendency for regulators to use the numbers in absolute not relative terms and the continual releases of new versions of the model (Duncan, 2017). Despite this, OVERSEER is currently the best tool available for estimating nitrogen leaching losses from the root zone for the diverse range of farming systems in New Zealand (Williams, 2013).

\section{4: Results: Thematic Analysis}

The following section provides a thematic analysis of the participants transcripts, this means these themes were arose from general analysis of the transcripts rather than in response to specific questions. The themes that arose include: public perception of farming and the rural/urban divide, financial barriers, regulations and the role of information and models.

\subsection{1: Public perception of farming and the rural/urban divide}

The rural/urban divide and the need for better representation in the media as a rural sector was a common theme during analysis of the interview transcripts. Four of the farmers believed that they were being portrayed as the villains and much of the hardwork and progress they have made environmentally was not being communicated to the wider public.

This is shown by participant 6 who stated: 
Obviously, we need to do more and be seen to be doing more and marketing ourselves better from the water quality side of things than what we are doing. Taranaki is getting rave reviews, they've turned their water quality around and yet you know if you talk to all of the environmentalists, it can't be because they've got some of the densest dairy area of the country, one of the most dense areas... they are achieving good results and that doesn't really get put out in the media to the same extent. It gets put in the rural magazine but that doesn't really get out, New Zealand herald is where it needs to be because all of the bad stuff ends up in there.

This participant believes that although farmers are putting in the work and making an environmental difference, their efforts are not being recognized by urban communities or the media. From his point of view, there is evidence of positive environmental change in Taranaki as they have "turned their water quality around", but there is such a widely held perception that dairy farming is bad for the environment this is disregarded as not possible and is therefore not publicized to urban communities.

The participant's resultant conclusion of the need for the farming sector to market themselves better to change public perception of farming was also mentioned by participant 1:

I like what those farmers who have just recently opened up their farms to show the public that actually it's not all bad and just you know to show the good side of farming and to get across that you know, most farmers are doing their very best to be sustainable even though the very odd one sort of, someone sneaks in to film or something.

This comment shows some of the progress farmers are starting to make in reducing the negative perception of farming by having open farm field days to demonstrate to the public what they are doing to protect the environment (Woodward, 2017). However, this participant also reinforces the idea that even though farmers are in general 'doing their very best to be sustainable', negative stories still get out about the farmers who are in fact the 'very odd one', rather than your typical farmer. This quote also shows the mistrust the farmer has of the media/urban community as by saying that someone might sneak into film he is implying that outsiders are trying to catch 
farmers out as doing the wrong thing.

These ideas and comments on the theme of the public perception of farming also relate to the idea of the social license of farming. A social license is the level of acceptance or approval by local communities and stakeholders of organizations and their operations (Woodward, 2017). As a result of the perceived negative public perception of farming analysis of the interview transcripts show there is also a fear that farming will lose its social license. This is shown by the response of participant 2 to the question:

\section{What is important to you for the wider farming community?}

Hopefully that we keep going. Because lately there's been talk about maybe farming in general shouldn't be happening. So, I don't know, that we do well...and hopefully New Zealand doesn't lose the view that...at the moment it gets a bit murky as to whether they see farming as being...so I think you know probably hopefully New Zealand keeps the agriculture legacy it's always had and doesn't lose its way when it comes to thinking which is the main stream of driving the country.

This response shows that this farmer is aware that to a certain extent farming is reliant on the support of the New Zealand public, to remain not only a core part of our economy but to be allowed to continue to farm in the future. It is likely that these responses and themes were heightened as the majority of these interviews were taking place in the lead up to the 2017 elections where water quality and a potential water tax was a hotly debated topic (NZ Herald, 2017). A survey commissioned by DairyNZ found that water quality is the number one thing that is driving negative perceptions of dairy farming as the public don't hear, see or believe farmers are doing enough to protect our waterways (Piddock, 2018). Despite this there appears to be growing recognition that other sectors such as industry and business, have a role to play in water pollution (Piddock, 2018).

\subsection{2: Finance/profit}

Finance (or money, profit, economic, financial, cost, spend etc.) was referenced 49 
times throughout the interviews. Finance (or a synonym) was mentioned in every interview except for a single second interview. This theme arose from analysis of the transcripts and was usually brought up by the farmers on their own accord rather than in response to questions about financial matters.

This focus on finance was generally in the context of needing to run a profitable business and therefore the significant role finance has in terms of on-farm decision making. The importance of weighing up management decisions against financial cost was mentioned by all participants at some point during the interview process.

This can be seen by the response of participant 4 to the question:

How do you make decisions arounds these issues?

How do we make them? Probably a fine line in between gut feel of what we'd like to do and necessity of what we seem to need to do to have an income so it stays above what we're actually spending.

For participant 4, finance is a significant driver for on-farm decision making that often dictates what decisions will be made in order to be able to make a profit. Participant 1 , 3 and 6 also mentioned finance as a decision driver in response to this question, although participant 5 and 2 did not, finance was mentioned as a decision-making factor at a different time. A further example of the influence of finance for participant 4 can be seen by their response to the following question about $\mathrm{LUCl}$ mitigation options:

\section{Are these mitigations realistic?}

I've got no idea. It's something, that one, we've thought about for a length of time. I don't...but I haven't delved into what actually, financially, what big challenge there might be. So, if everything was ideal and you could just do what you wanted and you didn't have to think about survival then I would say yes.

For this participant, the biggest challenge in terms of deciding to implement this mitigation measure (a wetland) is the financial cost. For this farmer the future potential benefits for the farm are more uncertain than the costs of implementing this mitigation measure. Additionally, this participant has assumed the wetland will be too expensive which meant that the option was not fully investigated. This is an example 
of financial cost acting as a barrier to pro-environmental behaviour.

However, when the same participant was asked:

What value (if any) will this modelling exercise add to your farm in the future?

They responded with:

Maybe, partly as a communication tool. So, the water scientist that we'd already talked to about that one area, having something firm to look instead of it just being ideas might be handy and I think that will probably put that idea back up on the table instead of it just being a... instead of it having disappeared because we weren't 100\% sure about whether it was a sensible idea or if how much difference it would make. And we'll have to balance that difference against what the cost is and being able to see that would be quite handy.

The participant is referring to the mitigation of the wetland in this response. Although originally the potential financial cost of putting a wetland in place meant it wasn't considered it as a viable option, now that $\mathrm{LUCl}$ has provided additional information that appears to back up what the water scientist said, the option is 'back on the table'. This implies that he will now look further into the option of constructing a wetland which he was not actively planning on doing without the information from LUCl. This not only shows the importance of information but also solidifies the previously discussed idea that information alone is not sufficient to make change (Kennedy, 2010). The farmer already had access to this information, it took hearing it again from a different source to get him to consider this mitigation in more depth. Unfortunately, it is outside the scope of this research of this study to determine if any future action is taken because of this response.

In relation to the theme of finance the importance of dairy milk payout also mentioned by participant 3 who referred to the payout 3 times in the first interview. No other participants mentioned the payout despite 3 of the other participants also being dairy farmers. The other 2 are sheep and beef so this was less surprising.

This can be seen in this participants' response to the question:

What is important to you for the wider farming community? 
things you know it can sort of like decimate rural communities...there used to be a school and everything just everything just everywhere, and now they are like a ghost town...So yeah, it's got to be vibrant and that really cause otherwise there's not money in it, less workers, less staff so less people in the area so less schooling and less services so it becomes a downward spiral.

This shows the importance and influence the payout can have on rural communities.

\subsection{3: Regulations}

Regulations were a prominent topic the lead researcher was interested in getting farmer opinions on due to the relevance of the National Policy Statement for Freshwater Management. As Regional councils are required to implement the NPS-FM as promptly as is reasonable, and no later than 2030 , new regulations will be set for the Greater Wellington region in the near future. At the time of this research, what these regulations and their implications will be was unknown. To gauge farmer knowledge/opinions of the potential impacts of these regulations, analysis of responses to the following questions that were asked in the first interview will be considered:

Are you aware of changing regulations around water quality?

Four out of the 6 participants said they were aware of changing regulations surrounding water quality. However, despite answering no participant 1 went on to say "no, but l've heard a lot about the One Plan and Horizons and everybody's thinking oh my goodness". Here, the participant referred to the One Plan which the Horizons regional council has implemented partly in response to obligations to the NPS-FM. This shows that although this participant said they were not aware of region specific regulations they were aware of what was occurring in other regions in this space. This shows that in fact, 5 out of the 6 farmers are aware of potential incoming regulations.

Do you think that changing regulations around water quality will affect you and the decisions that you make?

Only 1 farmer appeared to believe that changing regulations would have a significant impact on their personal farm. It appeared this response may have come from the fact 
that the participants either felt they had a good understanding of changing regulations or that they were already making the best environmental decisions so there was little they would have to change.

This can be seen by participant 4 response which was:

I think the correct answer is yes because that's the theory that they should, but probably the truth is that they don't make a difference because we were already thinking.

The only farmer who felt that the changing regulations would have an effect is participant 6 who had "to put in an effluent pond, that's part of the process these days". However, he saw this as a positive that gives them more flexibility.

Despite a consensus that regulations wouldn't have a significant impact for these farmers when they were asked the question "Do you think that incoming water policy will change farming in the future?" all participants answered yes. It appeared from responses to this question that although all participants thought it would result in change, not all participants were exactly sure how. The consensus was that it would result in more regulated farming but there were differing opinions on the impacts this may have on the farming community.

For example, participant 2 response to this question was:

Definitely will change it. Farmers are quite resilient, so I think probably they'll tend to work stuff out and as long as some of these changes have reasons behind them and ways to kind of be ideas of how to do it better, not just 'destock that land', more around timings and stuff, then it will probably be alright.

In contrast participant 3 said:

Yup, it will dictate stocking rates, fertilizer use, mitigations, it will just everything, you will have to have a license to farm, like in some catchments already they are pretty well like that and it's just going to be the whole country. It's a timing thing and it's going to be the whole country. So that's going to change it.

Participant 2 thought that as long as the regulations were implemented with specific purpose they should not have a significant impact, whereas participant 3 thought that the inevitable will be very regulated farming in the future. Both participants displayed 
underlying concern of how future regulations will be implemented. This concern is very understandable as times of change can be unnerving and this sphere is currently facing a lot of public attention and change.

\subsubsection{The role of information and models}

LUCl is a tool used to communicate information. Although information alone does not drive behavioural change, it remains an integral part of any decision-making process (Mackenzie- Mohr, 2011). In order to determine what impact LUCI had or may have on influencing decisions, this section will discuss the role information had for each participant in terms of decision making. The viewpoints of the participants on the use of models will also be discussed, as opinions on models will preempt the likely uptake of information from models such as LUCl.

Data was collected for this section from a combination of analysis of answers to specific questions concerning the role of information as well as through sections of text that were coded to this theme and a text search for all references made to information or stemmed words/synonyms of information (e.g. data, evidence, knowledge).

When the participants were asked what they base their decision making on, participants 1,2, 6 and 3 mention that they source, at least in part, the information they use for decision making from talking to other people such as other farmers, consultants, advisors or the regional council.

This can be seen by the following comment made by participant 2 :

Well there's a guy...I guess my decisions are made just through talking to other people in similar boats. Got quite a few friends in the dairy industry so they sort of, they talk about it, so I can't help but take it in. And then kind of just try and read as much information as possible, especially when it's localised to my area, like this. That's about everything.

This response shows the importance of social networks within farming communities. DeSnoo et al. (2013) found that farmers are often made up of a judgmental peer group who are constantly comparing themselves to others. Farmers are likely to influenced 
by the performance and experience of other farmers in their area. For example participant 2 makes decisions based on his friends who are also farmers. This factor may be beneficial when trying to encourage environmental change. It is likely that even if a small group of farmers can be encouraged to make a change and positive results are seen, it can influence the rest of the farming community to also make change. It is also likely to lead to a degree of normative pressure for the farmers to want to keep up with others who may be achieving better results (DeSnoo et al., 2013).

The pressure and social influence of farming communities was also mentioned by participant 6:

I think if enough of us are, like you said, with the planting the streams and that, if there's enough of us who've done it ... The streams are starting to look pretty good... if you're the last one left standing, it just about gets forced upon you without the counsel doing anything about it.

During this exchange, riparian planting was discussed, for mitigations, such as riparian planting to be effective, the more of the river that is planted the better. As rivers and creeks typically travel through numerous farms in agricultural areas if neighbouring farms upstream and downstream had carried out this planting there would be pressure on the other farmers to also carry out the planting. Participant 6 recognised this as he says that 'it just about gets forced upon you', this implies that action is forced upon you as a result of pressure from the farming community rather than the counsel. If these social networks are used advantageously their influence has the potential to be very environmentally beneficial.

All of the participants were also asked:

Are there areas you are lacking the information needed to make informed decisions? Why?

Participants identified a range of factors. Participants 1 and 3 felt that all of the necessary information needed to make decisions was readily available. This can be seen by participant 3's response:

I don't think so, we're pretty set. Like as farmers it's as much or as little as you 
really want to use, just on everything. You've got your accountants, your fert reps, your vets, and just everything is kind of available.

Participants 6, 5 and 4 had specific areas they lacked information but this differed for each participant. Participant 6 felt there wasn't enough information available about the use of legumes with long taproots, participant 4 found it difficult to get absolute figures in terms of the impacts of changes to farm systems made over time and participant 5 felt they were lacking information in terms of nutrient management in terms of both LUCI and OVERSEER and feed budgeting. This shows the huge range of issues and topics farmers need to have knowledge on.

Participant 2 on the other hand was unsure if he had any areas he lacked information as shown by the following response:

I don't know. I don't know if up until recently I've even needed the information, so I suppose it's hard to know whether I am or not. I probably am, maybe, on the water quality thing, because there's constantly testing downstream and if there's an issue that would soon turn up I suppose...I haven't needed the information, so I don't suppose I have really.

The reason behind this response could be attributed to numerous factors, first this participant is a sheep and beef farmer meaning his farm is less intensive in comparison to the majority of the other participants who have dairy farms. Second, as he alluded to when he mentioned 'the water quality thing', there is a potential that increasing awareness of the issues surrounding water quality as a result of things such as media coverage is making him more attuned to the issue. This is a potential reason to explain why this farmer had not felt as though he needed the information up until recently.

Despite the varying answers to a lack of information, when the participants were asked "what do you expect the model to do/achieve out of this practical exercise?" participant 1, 2, 5 and 6 all had high expectations from the project. This can be seen from the following response of participant 5:

I guess I'm hoping the model will tell us if we are sustainable or not. And from that information I guess either - if we're sustainable I guess we need to look at our system and change it so that we are sustainable going forward cause obviously it's pretty critical for us. So, I guess as mentioned earlier that's 
probably a limiting factor for us is probably understanding that what we're putting on and what we're leeching so yeah, we're hoping LUCI will tell us you know what we're doing if we're doing this well or not well and areas for improvement

Participant 5 is expects the research project to give him an indication if they are farming sustainably or not and if not, he is willing to make changes to their system. This firstly shows that he is unsure if their system is sustainable reflecting a lack of information and benchmarking or measuring tools such as LUCI, that would be able to provide an indication of their progress. Additionally, this response shows that if information provided indicates that a change is needed, he is willing to carry out the action in order to make his farm more environmentally sustainable. As participants 1, 2 and 6 all had similar responses it shows that there is a potential lack of information available that measures on-farm progress in terms of nutrient management and water quality. This is a gap that models such as LUCI would be able to fill. Additionally, these responses may reflect a general openness to new information and feedback. This is likely an additional factor as the 6 farmers voluntarily came forward for the project making them open to new information by nature.

In order to determine how receptive/open minded the participants were to the use of models such as $\mathrm{LUCl}$, a set of questions regarding the use of software tools were asked in the first interview.

\section{What (if any) tools do you use to make these decisions?}

The responses to this question showed that in general the participants did not use any tools similar to $\mathrm{LUCl}$ to make on-farm decisions. The most common software tools that were mentioned were for financial budgeting, weather tools and GPS based mapping tools that guide fertilizer spreaders to the correct paddocks.

Participant 1 was not overly receptive of using technology:

We don't really use the computer much except for emails. Two things in me head - eyes. Yeah, we're not computer wizzes at all. If we need things like that our daughter will do it for us.

Being uncomfortable with technology is a factor that could influence the uptake of the 
information LUCI provides as $\mathrm{LUCl}$ is a technical software that is heavily reliant on the use of computers, although this information can be provided as printed maps. Despite this response the same participant thought that if $\mathrm{LUCl}$ provided the appropriate information he would change his farm systems accordingly. This shows that despite being uncomfortable with using technology himself, he does not disregard the importance and value of such tools and is open to using the information to make changes.

Although none of the participants used tools similar to LUCI when they were asked "what is your opinion of using/or not using software tools?" to gauge how open they would be to the use of software tools such as $\mathrm{LUCl}$, all participants felt positive about using software tools. For example, participant 5 felt it was essential to use software tools as this is where the future is heading as shown by the following response:

I think it's a must given where technology is going, and if you don't use them your kind of gonna get left behind. There are some great tools out there and I guess if you can get the right ones for your farm business you can probably generate a lot more profit and again look after your environment a lot better. So, I think it's probably very important.

This shows that participant 5 felt that tools such as LUCI were essential and were able to benefit the user in terms of both profitability and environmental sustainability. Participant 2 also thought that software tools were useful, but he had some doubts about how they would be used as shown by the following response:

I suppose if it makes it easier, if what you say is right about LUCl and it works, then I suppose that will be helpful long term, because we'll know where we're better or worse when it comes to ... Yeah, it's all helpful. As long as it doesn't make us worse, you know, as far as like other people with their opinions. Because it's easy access, when things are online, anyone can get on there and then they start poking their nose in when they really have no practical knowledge of what's going on and how it's applicable to the specific ... because every farm's a bit different, eh?

This raises an important point that information needs to be understood in context. It is very easy to cherry pick information and make conclusions that are not representative 
of the whole situation. As the future of farming appears to be becoming more regulated it is important that if the information LUCI provides is used for its appropriate purpose.

Participant 3 had an interesting response to this question as he had, through use of an industry consultant, had his farm modelled with the tool Udder. Udder is a computer software that is used to help dairy farmers make decisions to make their farm more profitable (Agrion, 2018).

When he was asked "did you end up changing anything in your farm system from it [the Udder model]? He responded saying:

[The\} last consultant guy we used, he did a scenario for us when the payout was quite high, and he would have us sort of spend quite a bit of money on extra feed and maybe a feed pad and stuff like that, and I sort of wasn't really that comfortable with that idea and as it turned out with the payout dropping, yeah really good we didn't do it. It's still just a tool you have to have your eyes open with the whole effect, it would have been more work, physical work and that too, and capital so we weren't really that keen on it.

This shows that although participant 3 was open to the use of the Udder model, but he did not implement the model suggestions. For this participant it was a financial barrier as well as physical labor that prevented him from carrying out the recommendations. As can be seen from his response he believed that the benefits of the changes the tool suggested did not outweigh the costs to implement these changes. This reflects the findings that there are many barriers in place that prevent behaviour change for any given individual (Kennedy, 2010; Lucas et al., 2008).

\subsection{5: Other Findings:}

On a wider level, the interviews also found that 4 out of the 6 participants were interested in the use of deeper rooted plants for pasture as a mitigation strategy. This was a useful outcome for future development of the LUCI model as it had not initially been considered as a priority mitigation measure for the model to include. The interest however is logical for the Mangatarere catchment due to the susceptibility of the area to flood and drought. There is also an increased level of research in progress by 
organizations such as DairyNZ to determine the effectiveness of using deeper rooted plants such as plantain in pasture to reduce nitrogen leaching while maintaining or increasing milk solids production (DairyNZ). 


\section{Discussion:}

\subsection{Introduction}

Analysis of the interview transcripts provided important results that allowed for an insight into the perceptions of a group of farmers on the LUCI model, how the research project allowed them to process information and a general understanding of their views on some prominent topics in the agricultural sector. Comments on any limitations of this project as well as potential research opportunities that arose will also be provided.

\subsection{Summary:}

This research aimed to evaluate how information surrounding potential nutrient mitigation measures provided by decision support tools is understood and interpreted by a group of farmers facing tightening environmental regulations and a changing social outlook on environmental sustainability. To achieve this aim the research first explored the literature and a range of available theories that intend to determine how to motivate pro-environmental behaviour. Changing human behaviour is a very complex and challenging task that comes with various intricacies that are difficult to portray in one idea or theory. Although information alone does not drive behaviour change, it is an essential component that when used in collaboration with other methods and incentives can be very successful (Kollmuss and Agyeman 2002, Fisk and Larson, 2011; Kennedy, 2010; Mackenzie-Mohr, 2000; Stern, 2000).

A particular method identified as having potential in terms of managing water quality was the use of land use models alongside targeted on-farm advice (Bouraoui \& Grizzetti, 2014; McKergrow et al., 2014). To understand stakeholder perception and uptake of the information this method provides, a case study was carried out using the LUCI model with 6 farmers in the Mangatarere Catchment. The results of this study allow an insight into the potential role and impact of the information and data predictive models provide to facilitate behavioural change. The results will allow for future refinement of the process to allow for beneficial communication approaches to non-scientist end users and, hopefully, better uptake by farm and land managers in the 
future.

\subsection{Participant experience and feedback on $\mathrm{LUCl}$ and the research process}

\subsubsection{Perceived user-friendliness, accuracy, credibility and value}

The interviews highlighted a number of important points that provided insight into the positives and negatives of the communication process of land-use models and the level of uptake of information by the participants. The first important point that was explored was participant perception of the user-friendliness, accuracy and credibility of the model. In order for a model to be accepted and the information it provides used correctly in a real-world context, it must be usable and perceived as accurate and credible (Cartwright et al., 2016). Transcript analysis found that although all participants found the model to be accurate and credible, ground truthing was necessary for 3 out of the 6 participants. Although the information was not portrayed in a manner that was immediately understandable to each participant, the research process was structured so that each participant was visited 4 times. The first visit was to gather data, the second to carry out the first interview and present baseline maps, the third to present mitigation scenarios and the fourth and final visit was to carry out the last interview. This was a valuable process for the researcher and the participant and they were able to work through the issues together and come up with a result both parties understood and were happy with. Including the participants in this process gave them increased ownership of the final LUCI outputs which likely had a positive influence on perceived accuracy and credibility. This is reflected in the literature which states that social learning that occurs through joint problem solving and reflection is more efficient and more likely to be accepted (Berkes, 2009). Additionally, this process of frequent personal contact through telephone calls, emails and face to face meetings was beneficial as there was a level of trust able to be built between the researcher and participants (Addison et al., 2013).

An important result was how the different participants ranked the value of the information that LUCI provided. Initially the purpose of this question was to determine any specific value LUCI had for each farmer for their personal farm, however the results were a lot more variable than expected as they showed the participants saw the value of the model for numerous reasons. For example, 2 out of the 5 participants 
felt that the information provided had little value for their specific situation. It can therefore be assumed that these participants are unlikely to do anything further with this information for their personal farm. However, the reason these participants could see little personal value was because they believed they were already running their farm as sustainably as possible. Despite this, both participants could see what value the model would have for other situations such as the wider farming community, catchment level projects or other farmers who are not as sustainably advanced.

Additionally, seeing the quantitative difference past work has made was perceived as being of value for 3 participants. $\mathrm{LUCl}$ could provide information that showed a measurable difference in nutrient levels by showing the change between nutrient loads and accumulation before and after riparian planting. For 4 out of 5 participants with riparian planting, this exercise showed a reduction in nutrient loading as a result of this planting. As noted by the participants, attributing number values to this information is of great value as an informative and persuasive tool. Although the overall purpose of this research was to understand how participants perceive information with the end goal of encouraging pro-environmental behaviour, the power of showing the value of past work is also of great importance. The validation of what can be seen physically gives the farmers confidence that their actions are beneficial and effective.

Another value of the LUCI model picked up by the participants was the ability to identify and therefore target the worst areas first. A staged plan can then be made rather than an overall blanket plan and consequently the costs are more spread. Overall, all participants were able to see the value of the model in one way or another.

\subsubsection{Changing perceptions of $\mathrm{LUCl}$}

This research also investigated changing perceptions of the LUCI model throughout the research process. Firstly, the success of the research project was illustrated as all participants felt that their knowledge of the LUCI model had increased. As the purpose of this project was to use $\mathrm{LUCl}$ as a tool to communicate information, it is very beneficial to see that the model has potential to be used to increase stakeholder knowledge. 
However, an important point raised about the usefulness of $\mathrm{LUCl}$, was the potential issue of the uncertainty of models which could reduce stakeholder engagement with the outputs. Decision making for the implementation of mitigations often involves evaluating risks when ecological knowledge is incomplete and the outcomes are uncertain (Addison et al., 2013). Models provide a way of dealing of uncertainty by representing complex systems in an understandable manner to aid decision making. Despite this, the uncertainty involved in modelling can affect participant's view of the role of models and their acceptance of the final model outputs (Addison et al., 2013). Research shows that there are certain factors that need to be given consideration to ensure the success of research projects using models to inform decision making and implement change. Practical recommendations of solutions to this issue include; active engagement of stakeholders in the modelling and decision-making process, improve communication and build trust (Addison et al., 2013). Although these recommendations were considered in this project, decision making under uncertainty is often difficult especially when there are numerous external pressures such as the social and economic factors that were influencing the participants. Deeper consideration of these recommendations has the potential to improve the participants trust of the model and its outputs in the future. Good modelling practice is an important feature of facilitating optimum information uptake.

\subsubsection{Participant feedback and recommendations}

The most important feedback on the research process was to reduce or summarize the amount of information presented. A common issue in the use of models is that decision makers can feel overwhelmed when presented with a lot of information or multiple possible outcomes from model outputs (Addison et al., 2013).

It was found this was also the case for this research project as participants 1, 3, 5 and 6 thought that the information could be condensed so that the amount of information presented is reduced to prevent overwhelming the participant. They found too many maps made the model presentation confusing. Reducing and summarizing this information would be beneficial for future projects, additional information could still be provided if the farmers were interested. It is recommended that the maps that are presented show load, accumulated load, stream entry and exit points and their values 
for nitrogen and phosphorus. This means 4 maps would be presented rather than the 11 that were shown for this project. These maps are the most beneficial to present to stakeholders as they show areas of high and low nutrient loads, where nutrients and water converge in the landscape and provide a metric value of the nutrients entering and exiting the farm.

Other than this constructive feedback all participants appreciated the visual nature of the maps and the numerous farm visits that occurred during the research process. It was found the multiple farm visits allowed for trust to be built between the researcher and the participants as well as an increased level of information uptake by the participants.

\section{4: Finance and the role of information}

A variety of constraints often act as barriers to action which influence and shape individual behaviour (Mackenzie-Mohr., 2011, Stern., 1999). Although this research has not investigated all the complex factors and barriers that influence the participants decision making, the results highlighted the significant role finance plays for these farmers. The importance of weighing up management decisions against financial cost was mentioned by all participants at some point during the interview process. Finance is likely to be one of the biggest barriers for these participants to implement mitigation measures in the future. With careful design and deliverance information alone has been found to be able to change environmentally significant behaviours, however little to no effect has been achieved when there are important external barriers such as financial cost (Stern., 1999). This shows that when presenting information, such as that provided by $\mathrm{LUCl}$, it is likely other additional mechanisms would need to be used to facilitate a change in behaviour. These additional means may include endorsement by respected peers (Mackenzie-Mohr, 2011; Rogers, 2003), practical examples of applying the information or other mechanisms of behaviour change such as incentives, or regulation (Scott, 2015).

The impact of regulations was a prominent theme highlighted in the results and is likely that the external factors influenced this finding. During the progression of the research project, the 2017 elections occurred. Water quality and the impact of 
agriculture was a very prominent topic in the media during the lead up to this election and new regulations for the Greater Wellington Region were and remain to be impending as a result of the NPS-FM. Mackenzie-Mohr (2011) found that during times of change, the opportunity to introduce new behaviour is elevated as habitual behaviour is often no longer possible or appropriate.

As the majority of the participants were aware of this imminent and uncertain change, it is likely to have increased participant engagement with this project. This is because the participants were aware they are likely to have to understand the impact of potential new limitations and may have to explore options to reduce nutrient discharges. As these regulations have yet to be imposed the impact they will have on the region and these specific participants is undefined. However, once the implications become clear there may be an opportunity for increased engagement with new tools if and when farmers need to change management practices.

Additionally, through this research the researcher was able to observe an example of a successful implementation of a pro-environmental behaviour incentive occurring in the Catchment. All participants in this study had carried out a Farm Environment Plan (FEP) with the Greater Wellington Regional Council. FEP's were discussed in the literature review as a potential method to encourage pro-environmental behaviour and this research found that as a result of having an FEP all farmers in this study had already completed, to varying degrees, some mitigation measures (e.g. stream fencing, riparian planting and steeping poles to prevent hillside erosion). As these FEP's are $50 \%$ funded by general rates and $50 \%$ by user charges, this method was able to overcome some of the financial barrier for these farmers. The study of Stern (1999) found that once an incentive is large enough for a consumer to believe there is a personal benefit to be gained from taking advantage of them, it can be more beneficial to invest in improved information rather than to increase the incentive.

As the participants perceived the LUCI model as accurate, credible and of value it could be an effective and beneficial tool to use alongside incentives such FEP's. The effectiveness of the incentive often depends on how it is explained to people (Stern., 1999), LUCI has the potential to be used not only as an informative tool but additionally to show the benefits of past work as was done with riparian planting for the participants of this research. Currently there are no specific measurements in place 
to determine the impacts and benefits of the implementation of the FEP's at the farm scale, LUCI has the potential to fill this gap.

Additionally, carrying out a FEP in the greater Wellington region at this stage is a voluntary measure, as was this research project, meaning the participants in this study are early-adopters and therefore open to new information by nature. Therefore, there will be others in the catchment, and across New Zealand, who are not as advanced in terms of mitigating water quality degradation, the results of this study show that LUCI has the potential to be a beneficial source of information in this area.

This research has shown that $\mathrm{LUCl}$ is seen as a credible, accurate and valuable tool to convey information, but the literature review has shown that information alone is unlikely to result in behaviour change. Information presented on potential mitigation scenarios should be presented in collaboration with additional practical information about the // implementation and financials of the change. This aligns with the finding of Mackenzie-Mohr's (2011) study that to be effective information needs to include what needs to be done and the steps needed to carry out that action in an explicit manner (Scott, 2015). In order for processes such as this to facilitate optimum uptake of information research such as this study is needed to understand the best way to portray and explain information when using models such as LUCI.

\section{Conclusion}

This research focused on the social as well as physical science dimensions affecting our ability to manage the prominent issue of degraded water quality in New Zealand caused by the intensification of agricultural land use. This intensification has led to increased levels of diffuse pollutants such as sediment, nitrogen and phosphorus in waterways (Duncan, 2017). This thesis explored appropriate methodologies to effectively use models as a communication tool to encourage pro-environmental behaviour. The research carried out a case study using the LUCI model with 6 farmers in the Mangatarere Catchment and found that the participants in general, perceived the model to be credible, useful and valuable. The study also found that the manner of communication, especially the volume of information presented, is critical to allow for optimum uptake of information. For this specific case study, it is likely the volume of 
information presented was more than was necessary for optimum stakeholder engagement. It is therefore recommended that in the future the amount of information is condensed, and important points clearly highlighted. Despite this finding the participants still found the model to be informative and useful. LUCI therefore has the potential to be a beneficial method of engaging stakeholders in prominent issues such as degrading water quality. It is through models such as LUCI that we will be able to advance our scientific knowledge surrounding water quality and display information in an effective, understandable and motivating manner (Sharps et al., 2017). This will allow for more informed decision making around the use of freshwater to make it a long term sustainable resource for future generations.

\section{Research objectives and Findings:}

This research thesis poses the following research aim: To evaluate how information surrounding potential nutrient mitigation measures provided by decision support tools is understood and interpreted by a group of farmers facing tightening environmental regulations, as well as a changing social outlook on environmental sustainability.

This research aim was made up of four objectives, how these objectives were achieved is outlined below:

Objective 1: To understand the role of information in facilitating pro-environmental behaviour and the other additional approaches that are used alongside information to encourage or incentivise behaviour change.

As a change in human behaviour is needed to reduce the negative impact we are having on water quality, the purpose of this objective was to explore the intricacies that exist in terms of encouraging pro-environmental behaviour to prevent and reduce these impacts. To achieve this objective the research explored the literature and a range of available theories that examine how to motivate pro-environmental behaviour. Changing human behaviour is a very challenging task as humans are complex beings that are influenced at any one time by an infinite number of factors and barriers. Although the various theories differentiated in their ideas of how to influence human behaviour, a common finding was that information alone does not drive behaviour change (Mackenzie-Mohr, 2000; Kollmuss and Agyeman, 2002; Stern, 
2000). Despite this, information is often a prerequisite to behaviour change. When used in collaboration with other methods and incentives it can be very successful (Mackenzie-Mohr, 2000; Kennedy, 2010; Kollmuss and Agyeman, 2002; Stern, 2000). A number of methods that can be used in collaboration with information were then explored such as subsidies, legislation and regulation and mixed methods (social marketing, community-based marketing, influencing social networks). A method identified as having huge potential in terms of managing water quality was the use of land-use models alongside targeted on-farm advice (Bouraoui \& Grizzetti, 2014; McKergrow et al., 2014). Land-use models are practical tools for advancing scientific knowledge surrounding water quality and displaying information in an understandable and motivating manner (Sharps et al., 2017). A crucial factor in the success of the method is considered to be the effectiveness of communication to decision makers. Therefore, the LUCI model was selected for use in a case study as it is well placed to assist farmers and land managers explore solutions to degraded water quality. The case study used the model in the Mangatarere Catchment with a group of 6 farmers to determine participant uptake of the information provided.

\section{Objective 2: To carry out a case study evaluating the use of $\mathrm{LUCl}$ as a tool to} communicate information surrounding potential mitigation scenarios that could achieve improved on-farm nutrient management for a group of 6 farmers in the Mangatarere catchment.

As discussed, land use models have a high potential to be effective explanatory and communicative tools for encouraging pro-environmental behaviour. Therefore, the purpose of this objective was to carry out a case study using the LUCI model to understand the stakeholder perception and uptake of the information models such as LUCI provide. The study was carried out through four field visits to each of the 6 farmers to initially introduce and explain $\mathrm{LUCl}$ as a modelling tool, and later to gather their perceptions of the outputs of the tool. The research framework that was selected to carry out this research was phenomenology. Phenomenology examines how individuals perceive and talk about objects and events and a phenomenological study is a dynamic process in which the researcher is seen to have an active role.

This process allowed for the collection of participant feedback through two interviews. A baseline interview was carried out during the first visit and a final interview was 
conducted during the last visit. This provided data that was analysed using the tool NVivo 11 to find any similarities and contradictions within the interview transcripts.

\section{Objective 3: To evaluate the participant's understanding, interpretation and any changing perceptions of the LUCI tool through analysis of the interview transcripts.}

There are many elements that contribute to the participants understanding and interpretation of the LUCl outputs, one of these elements is their perceived credibility. All participants eventually found the outputs of LUCI to be credible, although this required a process of ground truthing for half of the participants. This process of ground truthing was beneficial as it led to a deeper understanding and connection with the LUCl outputs as the participants felt involved in the process. This is reflected in the literature which states that social learning that occurs through joint problem solving and reflection is more efficient and more likely to be accepted (Berkes, 2009).

Additionally, the process of frequent personal contact through telephone calls, emails and face to face meetings was beneficial as there was a level of trust able to be built between the researcher and participants (Addison et al., 2013). Any issues of credibility highlighted by the participant were simple to resolve as they resulted from either misunderstandings or data input errors. This means any issues of credibility were not directly linked to model structure and resultant outputs, it can therefore be concluded LUCI was perceived as credible for this research project.

Analysis of the participant interview transcripts also found that 4 out of the 5 participants thought that the $\mathrm{LUCl}$ outputs portrayed on farm information well and with adequate detail. There was an appreciation for the visual nature of the maps as well as the numerical values associated with nutrient loads and concentrations. An issue that was raised by one participant in terms of understanding the $\mathrm{LUCl}$ outputs was the challenge of interpreting the large volume of information. This was an important finding of this research. Although the other participants did not find that the volume of information inhibited how well LUCI portrayed their on-farm information, they did find that it reduced their ability to interpret the information. Reducing or summarizing the information presented would be beneficial for future projects, additional information could still be provided if the farmers were interested. It is recommended that the maps presented show nutrient load, nutrient accumulation, stream entry and exit points and their values. This would reduce the maps shown for 
nitrogen and phosphorus from 11 maps to 4 .

Any changing perceptions of $\mathrm{LUCl}$ were determined by assessing if the participants perceived knowledge and usefulness of the LUCI model changed from interview 1 to 2 . It was found that all participants, aside from participant 1, believed their knowledge of LUCl increased between the first and second interview. This is encouraging both in terms of LUCI being fit for purpose and suggesting the communication employed was appropriate. If the information had not been portrayed or explained appropriately participant knowledge would not have been expected to increase. The explanation for participant 1 believing there was no change in his knowledge of LUCI from interview 1 to interview 2 is unknown. In terms of usefulness of the model, it was found that all participants believed that models such as LUCI have the potential to be very useful tools apart from participant 6 who thought it needed more work and that there were already enough models available in a similar space. This participant did however still think LUCI was still reasonably useful.

Objective 4: To evaluate the effectiveness of using the land use decision support tool $\mathrm{LUCl}$ as a potential approach of displaying and communicating information around complex environmental issues to stakeholders.

The main way this research evaluated the effectiveness of $\mathrm{LUCl}$ was to determine the perceived value of LUCI for the research participants. If the participants saw the model to be of large value, this was thought to indicate an effective tool and vice versa. For 3 of the participants they could see immediate value in the model and changes they could make to their farm system as a result of the information LUCI portrayed. This was seen as a measure of effectiveness as the purpose of the model is to highlight potential mitigation measures that would improve on farm nutrient management.

For the 2 participants who could not see immediate value in the model, 1 of these participants could not see the value for the farm modelled as there were no waterways on his farm, he could however see immediate value of LUCI for his other 2 farms that did have waterways. The other participant did not feel the model added value to his farm as he felt he was already doing everything possible to be running their farm sustainably. This highlighted an important point that $\mathrm{LUCl}$ is likely to be of the most value, and the most effective, for end users who are not performing 
environmentally sustainably and therefore need appropriate mitigation measures. All participants thought LUCI would be a valuable tool for the wider farming community, especially as a method to identify hotspots that could be targeted first to make the biggest difference.

A further way to evaluate the effectiveness of $\mathrm{LUCl}$ would have been to determine if this research project resulted in any behaviour change for any of the research participants. Unfortunately, this was outside the scope of this research due to time constraints but is something that could be considered in any future work of this nature.

\section{Key findings from results:}

- A key theme that arose from transcript analysis was the rural/urban divide and a need for better representation in the media as a rural sector. These farmers felt that much of the hard work and progress they have made environmentally was not being illustrated to the wider public.

- Participants demonstrated an underlying fear that farming will lose its social licence as a result of the perceived negative public perception of farming.

- Finance is a significant driver and barrier in terms of decision making for these participants.

- There is a degree of uncertainty of the impact impending regulations will have on the future of farming. There is also a range of opinions on the impact these regulations will have, either not very little or farming will become a highly regulated space where everything will be measured.

- Knowledge of the regulatory tool OVERSEER was lower than expected due to the nature of the implementation of the NPS-FM, the Greater Wellington region has not yet implemented compulsory regulations that use OVERSEER like other New Zealand regions have.

- Innovative tools such as LUCl are well placed to support farmers and the agricultural sector.

\section{Future development of $\mathrm{LUCl}$ and potential further research}

The findings of this thesis highlighted a number of important points that should be 
considered for both any future projects using LUCI as well as future development of the tool.

- When presenting information from LUCI to stakeholders, end users and decision makers it is important that the communication manner is considered in great depth. The main recommendation is to condense the amount of information presented to the audience and ensure the important points are highlighted clearly. In terms of LUCl outputs, it is recommended that the maps shown portray load, accumulated load, the stream entry and exit points and their values.

- Once information on potential mitigation measures is presented and discussed with stakeholders, an action plan that has clear achievable steps to implement these solutions is also necessary. This would need to be a part of the process if LUCI were to be used as a tool to raise awareness and facilitate behavioural change. The financial values involved in these steps would also need to be provided. Without this additional information, it is unlikely the suggested mitigation measures would be implemented as it was found that finance was a large consideration in decision making for these farmers.

- As it was determined that this research targeted early adopters, people who are open to new information and change, it would be interesting to determine if they are also early adopters in terms of the GWRC Farm Environment Plans (FEP), a voluntary regulatory scheme. It was found that all farmers in this study had carried out an FEP, so it would be interesting to discover if this was representative of the whole catchment. The use of voluntary regulatory incentives was discussed as a possible method of implementing behavioural change in the literature review so determining the prevalence of FEP's in the whole catchment would be a good example to examine the success of this type of method.

- Carry out a similar project and have a FOCUS group that involved all the farmers. Due to the individual and confidential nature of this project the farmers were not told who else in the catchment was involved in the study. A catchment group environment may have been beneficial as was discussed in the literature review, social networks can be very influential in farming 
communities. A FOCUS group would have allowed the farmers to discuss their opinions together and if the outlook was positive this would have been beneficial for their own understanding of the model. It would also likely increase the chances of endorsement of the LUCI model to the wider farming community. As these farmers were early adopters this would encourage those who are typically later adopters to also use or be open to the use of $\mathrm{LUCl}$.

- Another interesting future study would be trying to use farmers who are not classed as early adopters and had not completed many environmental mitigations. It would be of interest to firstly see if they are as open to this method of information communication as the participants of this study and secondly how the available LUCI mitigation measures would vary. It would be expected that there would be more mitigations options that would be able to make a bigger impact available.

- To fully determine the influence of the study an additional step that could have been undertaken would have been to provide specific guidelines and the financial costs of implementing the suggested mitigations along with an additional future visit to see if any changes were made as a result of these suggestions.

- Another potential avenue of research would be to carry out a similar study in a region that was more advanced in terms of regional implementation of the NPS-FM. For example, farmer knowledge of OVERSEER may be different in regions such as Canterbury where farmers are required to carry out a baseline and year end nutrient budget using OVERSEER. This would be an interesting comparison to make to the Mangatarere Catchment where it was found the 6 farmers had a low knowledge of OVERSEER.

- Future development of $\mathrm{LUCl}$ should include a function that is able to consider the influence of deeper rooted plant tap roots. An interest in in deeper rooted plants is logical for the Mangatarere catchment due to the susceptibility of the area to flood and drought. The additional soil storage provides a buffer in flood or drought for plant available water. There is also an increased level of research in progress by organisations such as DairyNZ to determine the effectiveness of using deeper rooted plants such as plantain in pasture to reduce nitrogen leaching while maintaining or increasing milk solids production (DairyNZ). 
- Future developments of $L U C l$ should also include regional data of relative high and low nutrient loads that are subject to the same conditions as the farm being modelled. This would give the farmers a point of comparison to benchmark their progress in terms of nutrient management.

\section{Concluding remarks:}

A change in behaviour is needed to reduce the human impact on degrading water quality. Changing human behaviour is a complex task and from reviewing the literature it was found that information is often an essential component needed to implement change. Understanding how information is delivered to stakeholders through tools such as LUCI will allow for the management of information presentation so that it facilitates optimum uptake. This project carried out a case study using the LUCI model as a communicative tool to evaluate stakeholder uptake of the information $\mathrm{LUCl}$ provided. The interviews results proved LUCI to be a valuable tool for both the case study farmers and the wider farming community. Farmer feedback highlighted the importance of ensuring that information provided by such tools is communicated in a consolidated manner. In conclusion, innovative tools such as LUCI have the potential to be a beneficial method of engaging stakeholders in prominent issues such as degrading water quality. 


\section{References:}

Addison, P. F., Rumpff, L., Bau, S. S., Carey, J. M., Chee, Y. E., Jarrad, F. C., McBride, M.F., \& Burgman, M. A. (2013). Practical solutions for making models indispensable in conservation decision-making. Diversity and Distributions, 19(5-6), 490-502.

Agarwal, C., Green, G. M., Grove, J. M., Evans, T. P., \& Schweik, C. M. (2002). A review and assessment of land-use change models: dynamics of space, time, and human choice (Vol. 297). Newton Square, PA: US Department of Agriculture, Forest Service, Northeastern Research Station.

AgriOne. Udder. Retrieved from: http://www.onefarm.ac.nz/resources/toolbox/udder. Accessed 20 April 2018.

Ajzen, I., \& Fishbein, M. (1980). Understanding attitudes and predicting social behaviour.

Bagstad, K.J., Semmens, D.J., Wagge, S., Winthrop, R. (2013). A comparative assessment of decision-support tools for ecosystem service quantification and valuation. Ecosystem Services, 5, 27-29.

Ballantine, D. J., \& Davies-Colley, R. J. (2014). Water quality trends in New Zealand rivers: 1989-2009. Environmental Monitoring and Assessment, 186(3), 1939-1950.

Batte, M. T., \& Arnholt, M. W. (2003). Precision farming adoption and use in Ohio: case studies of six leading-edge adopters. Computers and Electronics in Agriculture, 38(2), 125-139.

Bouraoui, F., \& Grizzetti, B. (2014). Modelling mitigation options to reduce diffuse nitrogen water pollution from agriculture. Science of the Total Environment, 468, 1267-1277. 
Brewer, K. Farm Environment Plans. Available from:

https://www.planning.org.nz/Attachment?Action=Download\&Attachment id=4134. Accessed on 20 July 2017.

Cartwright, S. J., Bowgen, K. M., Collop, C., Hyder, K., Nabe-Nielsen, J., Stafford, R., ... \& Sibly, R. M. (2016). Communicating complex ecological models to non-scientist end users. Ecological Modelling, 338, 51-59.

Collins R, McLeod M, Hedley M, Donnison A, Close M, Hanly J, Horne D, Ross C, DaviesColley R, Bagshaw C et al. 2007. Best management practices to mitigate faecal contamination by livestock of New Zealand waters. New Zealand Journal of Agricultural Research 50: 267-278.

Creswell, J. (2007). Qualitative inquiry and research design: Choosing among five traditions (2nd ed). Thousand Oaks, CA: Sage.

Crowe, S., Cresswell, K., Robertson, A., Huby, G., Avery, A., \& Sheikh, A. (2011). The case study approach. BMC medical research methodology, 11(1), 100.

Cullen, R., Hughey, K., \& Kerr, G. (2006). New Zealand freshwater management and agricultural impacts. Australian Journal of Agricultural and Resource Economics, 50(3), 327-346.

Davies-Colley, R. J., Smith, D. G., Ward, R. C., Bryers, G. G., McBride, G. B., Quinn, J. M., \& Scarsbrook, M. R. (2011). Twenty years of New Zealand's national rivers water quality network: benefits of careful design and consistent operation.

Chao, Y. L. (2012). Predicting people's environmental behaviour: Theory of planned behaviour and model of responsible environmental behaviour. Environmental Education Research, 18(4), 437-461

Hargreaves, T. (2011). Practicing behaviour change: Applying social practice theory to pro-environmental behaviour change. Journal of consumer culture, 11(1), 79-99. 
De Snoo, G. R., Herzon, I., Staats, H., Burton, R. J.F., Schindler, S., van Dijk, J., Lokhorst, A. M., Bullock, J. M., Lobley, M., Wrbka, T., Schwarz, G. and Musters, C.J.M. (2013), Toward effective nature conservation on farmland: making farmers matter. Conservation Letters, 6: 66-72.

Duncan, R. (2017). The challenges of regulating diffuse agricultural pollution to improve water quality: a science policy perspective on approaches to setting enforceable catchment load limits in New Zealand. Case Studies in the Environment.

Duncan, R. (2014). Regulating agricultural land use to manage water quality: The challenges for science and policy in enforcing limits on nonpoint source pollution in New Zealand. Land Use Policy, 41, 378-387.

Eppink, F.V., Greenhalgh, S., Hart, G. (2015). An exploration of the impacts and dependencies of New Zealand's key export commodities on the ecosystem services provided by New Zealand's native ecosystems. Landcare Research New Zealand Ltd.

Fraser, C., Fenemor, A., Turner, J., Allen, W. (2014) The Wheel of Water Research Programme: Designing collaborative catchment decision-making processes using a WaterWheel- reflections from two case studies, MBIE, C1205601. Aqualinc Research Limited. 96 pp.

Gee, J. P. (2014). An introduction to discourse analysis: Theory and method. Routledge.

Goodland, R. (1995). The concept of environmental sustainability. Annual Review of Ecology and Systematics, 26, 1-24. 
Guggenmos, M. R., Jackson, B. M., \& Daughney, C. J. (2011). Investigation of groundwater-surface water interaction using hydrochemical sampling with high temporal resolution, Mangatarere catchment, New Zealand. Hydrology and Earth System Sciences Discussions, 8(6), 10225-10273.

Greater Wellington Regional Council. (2017). Ruamāhanga Whaitua. Available from: http://www.gw.govt.nz/ruamahanga-whaitua/. Accessed on 19 July 2017.

Greater Wellington Regional Council. 10 Year Plan 2015-25. Available from: http://www.gw.govt.nz/assets/Plans--Publications/LTP-2015-25/Accessible-versions/2Long-Term-Plan-2015-18-Section-10ct15.pdf. Accessed on 17 July 2017.

Jackson, B.M., Metherell, A.K., Roberts, A.H.C., Trodahl, M.I. \& White, M., 2016. Adaption of the LUCI framework to account for detailed farm management: a case study exploring potential for nutrient mitigation using data from the Southland Demonstration Farm. In: Integrated nutrient and water management for sustainable farming. (Eds L.D. Currie and R. Singh). http://flrc.massey.ac.nz/publication.html. Occasional Report No. 29. Fertilizer and Lime Research Centre, Massey University, Palmerston North, New Zealand. 10 pages.

Jensen, B. B. (2002). Knowledge, action and pro-environmental behaviour. Environmental education research, 8(3), 325-334.

Kennedy, A. L. (2010). Using community-based social marketing techniques to enhance environmental regulation. Sustainability, 2(4), 1138-1160.

Kollmuss, A. \& Agyeman, J. (2002) Mind the Gap: Why do people act environmentally and what are the barriers to pro-environmental behaviour?. Environmental Education Research, 8:3, 239-260

Lokhorst, A.M., Staats, H., van Dijk, J., van Dijk, E., de Snoo, G. (2011).

What's in it for me? Motivational differences between farmers' 
subsidised and non-subsidised conservation practices. Applied

Psychology: An international review, 60(3), 337-353.

Lucas, K., Brooks, M., Darnton, A., \& Jones, J. E. (2008). Promoting proenvironmental behaviour: existing evidence and policy implications. Environmental Science \& Policy, 11(5), 456-466.

Maxwell, J. A. (2005). Qualitative research design: An interactive approach. Thousand Oaks, CA: Sage.

Mackenzie -Mohr, D. (2000) Promoting Sustainable Behaviour: An Introduction to Community-Based Social Marketing. Journal of Social Issues, 56(3), 543-554.

Mackenzie -Mohr, D. (2011). Fostering sustainable behaviour. An introduction to Community-Based Social Marketing. $3^{\text {rd }}$ Edition., Gabriola Island, Canada: New Society Publishers.

McDowell, R.W., R.M. Monaghan, W.J. Dougherty, C.J.P. Gourley, R. Vibart,and M. Shepherd. (2017). Balancing water quality threats from nutrients and production in Australian and New Zealand dairy farms under low profit margins. Anim. Prod. Sci. 57:1419-1430

McDowell, R. W., Dils, R. M., Collins, A. L., Flahive, K. A., Sharpley, A. N., \& Quinn, J. (2016). A review of the policies and implementation of practices to decrease water quality impairment by phosphorus in New Zealand, the UK, and the US. Nutrient cycling in agroecosystems, 104(3), 289-305.

McKergow, L., Elliott, S., Mackay, A., Freeman, M., \& Faulkner, T. (2007). MAXMIMISING THE EFFECTIVENESS OF FARM PLANS.

Ministry for the Environment \& Statistics New Zealand (2015). New Zealand's Environmental Reporting Series: Environment Aotearoa 2015. Available from www.mfe.govt.nz and www.stats.govt.nz. Accessed on 12 March 2017. 
document. Wellington: Ministry for the Environment

Ministry for the Environment (2016). Reforming how we manage fresh water - an overview. Retrieved from: http://www.mfe.govt.nz/fresh-water/reformprogramme/reforming-how-we-manage-fresh-water. Accessed on 23 March 2017.

Milne, J. R., Tidswell, S., Perrie, A., Sorensen, P. (2010). Mangatarere Stream catchment water quality investigation. Greater Wellington Regional Council

NIWA (2015). FOCUS: Maximising the effectiveness of farm plans

NZ Herald. (2017). Election policy series: The battle over our rivers. Retrieved from: https://www.nzherald.co.nz/nz/news/article.cfm?c id=1\&objectid=11907801. Accessed on 10 June 2018.

Olsson, J. A., \& Andersson, L. (2006). Possibilities and problems with the use of models as a communication tool in water resource management. In Integrated Assessment of Water Resources and Global Change (pp. 97-110). Springer, Dordrecht.

O’Rourke, S. E. (2011). An Interpretative Phenomenological Exploration of Successful Students with Learning Disabilities Enrolled in Post-Secondary Education: A thesis submitted to the faculty of graduate studies in partial fulfilment of the requirements for the degree of Doctor of Philosophy. University of Calgary, Calgary, Alberta.

Pietkiewicz, I., \& Smith, J. A. (2014). A practical guide to using interpretative phenomenological analysis in qualitative research psychology. Psychological Journal, 20(1), 7-14.

Rajecki, D. W. (1982). Attitudes-Themes and Advances, Sinauer Assoc. Inc., Sunderland, MA.

Richards, L., \& Morse, J. M. (2007). Readme first for a user's guide to qualitative methods. Second Edition. Sage. 
Richards, L., (2015). Handling Qualitative Data: A Practical Guide. 3rd Edition. United States of America: SAGE Publications Inc.

Rouse, H. L., \& Norton, N. (2017). Challenges for freshwater science in policy development: reflections from the science-policy interface in New Zealand. New Zealand Journal of Marine and Freshwater Research, 51(1), 7-20.

Scarsbrook, M.R. and G.B. McBride, 2003. The Evolving Roles of Long-Term Monitoring Programmes in Water Resource Management: A New Zealand Case Study. In: Proceedings of a Conference "Monitoring Tailor-Made IV." St. Michielsgestel, 1518September, 2003. The Netherlands Institute for Inland Water Management and Waste Water Treatment (RIZA) and National Institute for Coastal and Marine Management (RIKZ)

Sohier, C., \& Degre, A. (2010). Modelling the effects of the current policy measures in agriculture: an unique model from field to regional scale in Walloon region of Belgium. environmental science \& policy, 13(8), 754-765.

Siegel, J., (2016). What Happened When New Zealand Got Rid of Government Subsidies for Farmers. Retrieved from: http://dailysignal.com/2016/09/22/whathappened-when-new-zealand-got-rid-of-government-subsidies-for-farmers/

Sharps, K., Masante, D., Thomas, A., Jackson, B., Redhead, J., May, L., ... \& Jones, L. (2017). Comparing strengths and weaknesses of three ecosystem services modelling tools in a diverse UK river catchment. Science of the Total Environment, 584, 118-130.

Smith, J. A. (2004). Reflecting on the development of interpretative phenomenological analysis and its contribution to qualitative research in psychology. Qualitative Research in Psychology, 1, 39-54. doi: 10.1348/014466699164248

Smith, J. A., Flowers, P. \& Larkin, M. (2009). Interpretative phenomenological analysis -theory, method and research. London, UK: Sage. 
Stern, P. C. (2000). New environmental theories: toward a coherent theory of environmentally significant behaviour. Journal of social issues, 56(3), 407-424.

Steg, L., Bolderdijk, J. W., Keizer, K., \& Perlaviciute, G. (2014). An integrated framework for encouraging pro-environmental behaviour: The role of values, situational factors and goals. Journal of Environmental Psychology, 38, 104-115.

Steg, L., \& Vlek, C. (2009). Encouraging pro-environmental behaviour: An integrative review and research agenda. Journal of environmental psychology, 29(3), 309-317.

Trodahl, M., Deslippe, J., Jackson, B. (2016). Improving Predictions of N \& P export to waterways from rural landscapes in New Zealand using LUCI.

Wheeler, D. M., Ledgard, S. F., De Klein, C. A. M., Monaghan, R. M., Carey, P. L., McDowell, R. W., \& Johns, K. L. (2003). OVERSEER ${ }^{\circledR}$ nutrient budgets-moving towards on-farm resource accounting. In Proceedings of the New Zealand Grassland Association (Vol. 65, pp. 191-194).

Williams, R., Brown, H., Dunbier, M., Edmeades, D., Hill, R., Metherell, A., Rahn, C. \& Thorburn, P. (2013). A critical examination of the role of OVERSEER ${ }^{\circledR}$ in modelling nitrate losses from arable crops. Occasional Report, (26), 8.

Vigerstol, K. L., \& Aukema, J. E. (2011). A comparison of tools for modelling freshwater ecosystem services. Journal of environmental management, 92(10), 2403-2409.

The Wheel of Water Programme. Collaborative catchment planning using the Waterwheel processes and tools

Van Bochove, E., Vanrolleghem, P. A., Chambers, P. A., Thériault, G., Novotná, B., \& Burkart, M. R. (2010). ISSUES AND SOLUTIONS TO DIFFUSE POLLUTION. 


\section{Appendix A: Interview Questions}

Interview One:

Before we start how much do you know about OVERSEER on a scale of 1-5?

How much do you know about LUCl on a scale of 1-5?

On a scale of 1-5 how useful do you think these kinds of models might be?

(Will ask these questions again after the exercise to gauge the difference and find out why)

1. How long have you been farming? At this property?

2. What on-farm decisions do you have to make? What do you see as issue areas?

3. How do you make decisions around these issues? What do you base these decisions on?

4. What (if any) tools do you use to make these decisions (OVERSEER etc.) or are there areas you are lacking the information needed to make informed decisions? Why? What is your opinion of using/or not using tools?

5. What is important to you as a farmer beyond your own farm?

6. What does environmental sustainability mean to you? Is it a factor in your land use decision making? If so, how?

7. What on-farm mitigation measures for nutrient management and other factors do you currently have?

8. How do the changing regulations around water quality affect you and the decisions you make?

9. Do you think the incoming policy will change farming in the future?

10. What do you know about LUCI?

11. What do you expect the model to do/achieve out of this practical exercise?

12. Do you think $\mathrm{LUCl}$ will change the way you make the decisions discussed earlier?

\section{Interview 2}

1. How has your understanding of $\mathrm{LUCl}$ changed (on the 1-5 scale)?

2. What is your opinion on the usefulness of models such as $\mathrm{LUCl}$ changed on the 1-5 
scale?

3. What was your experience of the modelling process?

4. What do you think of the maps and scenarios and how they portrayed on farm information?

5. Did the maps and scenarios $\mathrm{LUCl}$ created appear to be accurate and credible? If so/not, in what way?

6. What new mitigation opportunities (if any) did the maps and scenarios provide you with?

7. Are these mitigation measures realistic? (financially/physically etc)

8. What value (if any) will this modelling exercise add to your farm in the future?

9. In what way will information such as LUCI has provided will be useful to others in your catchment / the farming community?

10. How does the information given change your viewpoint on environmental land use? In what way do the red areas motivate you to explore possible land use behaviour changes?

11. How do you think the information LUCI provides will compare to the information gained from other decision-making tools you use?

12. Do you have any feedback on how to improve the modelling process?

13. Is there anything you would like the LUCI model to do or anything you would like to add or modify for the future?

\section{Appendix B: Ethics documentation}

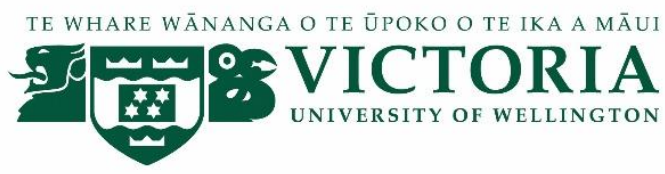

\section{Assessment of on farm nutrient losses and mitigation options in the Mangatarere Catchment}




\section{CONSENT TO USE MAPS IN FUTURE PUBLICATIONS AND PRESENTATIONS}

Researcher: Maggie Rogers, School of Geography Environment and Earth Sciences, Victoria University of Wellington.

- This document gives my consent for the maps and the interview analysis results that are related to myself and my property from Maggie Rogers' thesis to be used in any additional publications and presentations.

- I agree that while some quotations from the interview transcripts may be used in any publications and presentations associated with the thesis, they will not be attributed to me individually, and that my name will be replaced with a pseudonym.

Signature of participant:

Name of participant:

Date:

Contact details:

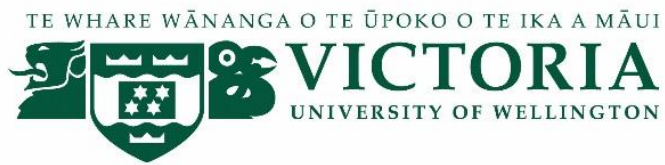

\section{Assessment of on farm nutrient losses and mitigation options in the Mangatarere Catchment}

CONSENT TO INTERVIEW

Researcher: Maggie Rogers, School of Geography Environment and Earth Sciences, Victoria University of Wellington.

- I have read the Information Sheet and the project has been explained to me. My questions have been answered to my satisfaction. I understand that I can ask further questions at any time.

- I agree to take part in an audio recorded interview. 
I understand that:

- I may withdraw from this study at any point before $1 / 12 / 2017$, and any information that I have provided will be returned to me or destroyed.

- I note that prior to completion of the research, the researcher will seek my approval to use any further maps developed by the researcher to help illustrate the data analysis, where it relates to the modelling outputs from my property and is identifiable to me.

- I understand that any information I provide through the interviews will be kept confidential to the researcher, the research supervisors, and the Ravensdown Consultant (who will sign a confidentiality form) but that the interview analysis results will be used in the thesis and could be used in future publications and presentations.

- I agree that while some quotations from the interview transcripts may be used in the thesis and future publications, they will not be attributed to me individually, and that my name will be replaced with a pseudonym in the thesis or any associated publications or presentations. However, I understand that there is a possibility that my involvement in the research may become evident to some parties due to the inclusion of maps generated as a resulting of the modelling process in Stage 1 of the research. I will have the opportunity to review these maps before inclusion in the thesis.

- I understand that the data I provide in my interviews will only be used in the context of this research, noting that I will be given the opportunity to review/comment on the content of my transcripts before 14/11/2017

- Any information I provide will be kept confidential to the researcher and the research supervisors, but that the interview analysis results will be used in the thesis and could be used in future publications and presentations.

- I note that the recordings of my interviews and my interview transcripts will destroyed 2-3 years after the completion of the research, and that they will be kept securely until that time.

- I would like to receive a copy of the final thesis and have added my email address below.

Signature of participant:

Name of participant:

Date:

Contact details: 


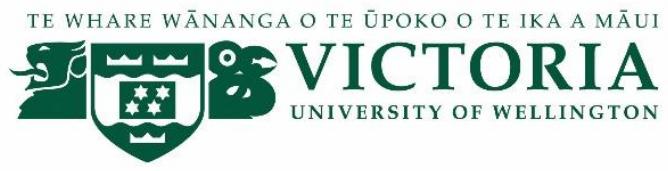

\section{Assessment of on farm nutrient losses and mitigation options in the Mangatarere Catchment \\ INFORMATION SHEET FOR PARTICIPANTS}

Thank you for your interest in this project. Please read this information before deciding whether or not to take part. If you decide to participate, thank you. If you decide not to take part, thank you for considering my request.

\section{Who am I?}

My name is Maggie Rogers and I am a Masters student in the Physical Geography programme at Victoria University of Wellington. This research interview will contribute to my thesis.

\section{What is the aim of the project?}

Through a collaboration between Victoria University of Wellington, Ravensdown and the Greater Wellington Regional Council, this project plans to apply the LUCI model on farms in the Mangatarere catchment with a group of 6 farmers. $\mathrm{LUCl}$ is a map-based computer model with the ability to assist farmers and land managers explore solutions to nutrient management and degraded water quality due to its fine spatial scale and focus on the rural environment. $\mathrm{LUCl}$ conveys this information through spatial maps and other outputs. The project will evaluate LUCl with each of the 6 participants and explore a range of mitigation scenarios that could be implemented to improve on-farm nutrient management.

The results will allow the project to determine if the information displayed through $\mathrm{LUCl}$ makes it a credible and an accurate tool that provides appropriate mitigation scenarios at the on-farm level. If $\mathrm{LUCl}$ is found to be useful, the model will be able to be refined with the results of this project for future use. Therefore, the aim of this project is to better understand the potential use of this tool for New Zealand based farm owners and managers.

\section{The Interview Process}

In collaboration with an experienced Ravensdown Environmental Consultant, I will conduct recorded and transcribed interviews through three field visits to your farm or chosen place at a time of your convenience. All field visits will take between 1-2 hours and will be audio recorded through a digital voice recorder. As a participant you can chose to not answer any question at any time and no explanation will be required.

\section{Stage One: Initial Interview}

A Ravensdown consultant and I will visit participants individually and the initial meeting will involve a short interview (30 mins) with open ended questions to establish current farming practices and knowledge of the LUCI model. Pre-mapped baseline LUCI maps for your farm will be shown to you at this stage. The information for these maps will be primarily generated from national data sets. 
During the next farm visit, I will work with the you to check model output after feedback and direct observations from the previous visit have been incorporated. Any issues will be identified and corrected, as appropriate, to establish an agreed upon baseline. Once a baseline model for each farm is agreed upon a range of potential on-farm mitigation scenarios such as riparian planting, fertiliser application time management, changes to crop management or stocking practices, etc. will be presented

\section{Stage Three: Final interview}

Within 6 weeks of the completion of Stage One and Two, I will meet with you to undertake a final interview about the results of the project and to gain any feedback on the model including any requirements for better mitigations measures and modelling needed for future model development. This visit is intended to take the form of a semi-structured interview with open-ended questions to form broad ranging discussions.

You will be shown the results of $\mathrm{LUCl}$ and their interview transcripts before the results are published. A variety of techniques will be used to make any critical findings confidential and you will have the ability to withdraw if they have concerns this confidentiality has not been adequately preserved. In respecting the importance of respecting such confidentiality, we do not anticipate this project will generate any significantly controversial results. Additionally, you will have the option to withdraw at anytime for any reason up until the $1^{\text {st }}$ of December 2018.

During the research, interview transcripts and recordings will be kept locked and secured. Note that 2-3 years after the completion of the research project, the interview recordings and transcripts will be destroyed. No other person besides the participant, Dr. Bethanna Jackson (my supervisor), Dr. Marcela Palomino-Schalscha (co-supervisor), Dr. Mairead de Roiste (cosupervisor), Colin Tyler (Ravensdown Consultant) and I will see the transcripts or hear the interview recordings.

The modelling outcomes (maps and associated data) and the interview transcripts will form the basis of my research project and will be analysed and included in a written report/thesis. While some statements and opinions made in the interviews may be used in the thesis and associated publications and presentations, all participants' names will be replaced with pseudonyms. Additionally, permission to use any maps in any additional publications or presentations will be sought at a later date as required.

It is important to note that even with the precautions outlined above, I cannot guarantee that participation in this research can be kept confidential because of the use of maps to illustrate the modelling outputs (Stage 1 of the research refers). Confidentiality is covered in the research consent form.

A $\$ 75$ koha will be offered to all participants who complete the three stages of the project as a token of appreciation for their time and knowledge - this may be in the form of a hamper/supermarket voucher.

The thesis will be submitted for marking to the School of Geography Environment and Earth Sciences, and deposited in the Victoria University Library. One or more articles will be submitted for publication in scholarly journals. A copy of the final thesis will also be made available to all participants

This research has been approved by the Victoria University of Wellington Human Ethics 
Committee (Application ID: 0000025202).

If you accept this invitation, what are your rights as a research participant?

You do not have to accept this invitation if you don't want to. If you do decide to participate, you have the right to:

- $\quad$ choose not to answer any question;

- $\quad$ ask for the recorder to be turned off at any time during the interview;

- $\quad$ withdraw from the study before $1 / 12 / 2017$;

- $\quad$ ask any questions about the study at any time;

- $\quad$ receive a copy of your interview transcript;

- be able to read the finished thesis by emailing the researcher to request a copy.

If you have any questions or problems, who can you contact?

If you have any further questions or would like to receive further information about the project, please contact me (Maggie Rogers) at my university e-mail address rogersmagg@myvuw.ac.nz or my supervisor Dr. Bethanna Jackson (04 4636116 or bethanna.jackson@vuw.ac.nz), at the School of Geography, Environment and Earth Sciences at Victoria University.

\section{Human Ethics Committee information}

If you have any concerns about the ethical conduct of the research you may contact the Victoria University HEC Convenor: Associate Professor Susan Corbett. Email susan.corbett@vuw.ac.nz or telephone +64-4-463 5480. 
